\title{
THREE ESSAYS ON ACCESS PRICING
}

$$
\text { by }
$$

\section{Ahmed Nasim Sydee}

\author{
A thesis submitted to the Faculty of Graduate Studies and Research \\ in partial fulfillment of \\ the requirements for the degree of
}

\author{
Doctor of Philosophy \\ (Economics) \\ Department of Economics \\ Carleton University \\ Ottawa, Ontario, Canada
}


Library and Archives

Canada

Published Heritage

Branch

395 Wellington Street Ottawa ON K1A ON4 Canada
Bibliothèque et

Archives Canada

Direction du

Patrimoine de l'édition

395, rue Wellington

Ottawa ON K1A ON4

Canada
Your file Votre neference

ISBN: 978-0-494-67884-8

Our file Notre référence

ISBN: 978-0-494-67884-8
NOTICE:

The author has granted a nonexclusive license allowing Library and Archives Canada to reproduce, publish, archive, preserve, conserve, communicate to the public by telecommunication or on the Internet, loan, distribute and sell theses worldwide, for commercial or noncommercial purposes, in microform, paper, electronic and/or any other formats.

The author retains copyright ownership and moral rights in this thesis. Neither the thesis nor substantial extracts from it may be printed or otherwise reproduced without the author's permission.
AVIS:

L'auteur a accordé une licence non exclusive permettant à la Bibliothèque et Archives Canada de reproduire, publier, archiver, sauvegarder, conserver, transmettre au public par télécommunication ou par l'Internet, prêter, distribuer et vendre des thèses partout dans le monde, à des fins commerciales ou autres, sur support microforme, papier, électronique et/ou autres formats.

L'auteur conserve la propriété du droit d'auteur et des droits moraux qui protège cette thèse. $\mathrm{Ni}$ la thèse ni des extraits substantiels de celle-ci ne doivent être imprimés ou autrement reproduits sans son autorisation.
In compliance with the Canadian Privacy Act some supporting forms may have been removed from this thesis.

While these forms may be included in the document page count, their removal does not represent any loss of content from the thesis.
Conformément à la loi canadienne sur la protection de la vie privée, quelques formulaires secondaires ont été enlevés de cette thèse.

Bien que ces formulaires aient inclus dans la pagination, il n'y aura aucun contenu manquant.

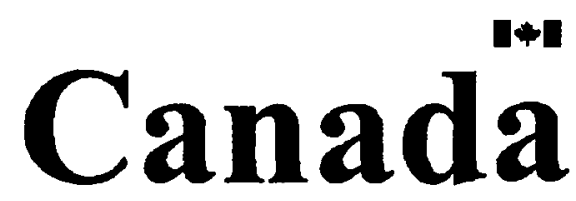




\begin{abstract}
The thesis consists of three essays on access pricing. In the first essay, a theoretical model is developed to determine the time path of optimal access price in the telecommunications industry. Determining the optimal access price is an important issue in the economics of telecommunications. Setting a high access price discourages potential entrants; a low access price, on the other hand, amounts to confiscation of private property because the infrastructure already built by the incumbent is sunk. Furthermore, a low access price does not give the incumbent incentives to maintain the current network and to invest in new infrastructures. Much of the existing literature on access pricing suffers either from the limitations of a static framework or from the assumption that all costs are avoidable. The telecommunications industry is subject to high stranded costs and, therefore, to address this issue a dynamic model is imperative. This essay presents a dynamic model of one-way access pricing in which the compensation involved in deregulatory taking is formalized and then analyzed. The short run adjustment after deregulatory taking has occurred is carried out and discussed. The long run equilibrium is also analyzed. A time path for the Ramsey price is shown as the correct dynamic price of access. The paper explicitly shows the impact of technological progress and economic growth - the two major forces that drive the dynamics of the telecommunications industry - on the equilibrium access price. With the help of a numerical example, we show that in the long run both economic growth and technological progress lower the access price.
\end{abstract}


In the second essay, a theoretical model is developed to determine the time path of optimal access price for an infrastructure that is characterized by congestion and lumpy investment. Much of the theoretical literature on access pricing of infrastructure prescribes that the access price be set at the marginal cost of the infrastructure. In proposing this rule of access pricing, the conventional analysis assumes that infrastructure investments are infinitely divisible so that it makes sense to talk about the marginal cost of investment. Often it is the case that investments in infrastructure are lumpy and can only be made in large chunks, and this renders the marginal cost concept meaningless. In this essay, we formalize a model of access pricing with congestion and in which investments in infrastructure are lumpy. To fix ideas, the model is formulated in the context of airport infrastructure investments, which captures both the element of congestion and the lumpiness involved in infrastructure investments. The optimal investment program suggests how many units of capacity should be installed and at which times. Because time is continuous in the model, the discounted cost - despite the lumpiness of capacity additions - can be made to vary continuously by varying the time a capacity addition is made. The main results that emerge from the analysis can be described as follows: First, the global demand for air travel rises with time and experiences an upward jump whenever a capacity addition is made. Second, the access price is constant and stays at the basic level when the system is not congested. When the system is congested, a congestion surcharge is imposed on top of the basic level, and the congestion surcharge rises with the level of congestion until the next capacity addition is made at which time the access price takes a downward jump. Third, the individual demand for air travel is constant before congestion sets in and after the last capacity 
addition takes place. During a time interval in which congestion rises, the individual demand for travel is below the level that prevails when there is no congestion and declines as congestion worsens. The analysis demonstrates that the optimal infrastructure investments depend on both the lumpiness of capacity additions and the unit capacity cost. The trade-off between congestion cost and capacity costs might lead to an optimal infrastructure investments program that alleviates, but not eliminate congestion.

The third essay contains a model of access pricing for natural gas transmission pipelines, both when pipeline operators are regulated and when they behave strategically. The high sunk costs involved in building a pipeline network constitute a serious barrier of entry, and competitive behaviour in the transmission pipeline sector cannot be expected. Most of the economic analyses of access pricing for natural gas transmission pipelines are carried out from the regulatory perspective, and the access price paid by shippers are cost-based. The model formalized is intended to capture some essential characteristics of networks in which components interact with one another when combined into an integrated system. The model shows how the topology of the network determines the access prices in different components of the network. The general results that emerge from the analysis can be summarized as follows. First, the monopoly power of a pipeline operator is reduced by the entry of a new pipeline supply connected in parallel to the same demand node. When the pipelines are connected in series, the one upstream enjoys a first-move advantage over the one downstream, and the toll set by the upstream pipeline operator after entry by the downstream pipeline operator will rise above the original monopoly level. The equilibrium prices of natural gas at the various nodes of the network 
are also discussed. In general, the entry of a new source of demand downstream raises the prices of natural gas paid by upstream end-users. When the pipelines are regulated, the same toll applies on the two pipelines are connected in parallel. Also, under the assumption that the regulator collects and then redistributes the toll revenues to the pipeline operators to enable them to recover their investments, it is possible that the regulated toll does not satisfy the individual revenue constraint of a pipeline operator. In such case, the regulator collects the toll revenue and redistribute among the pipeline operators according to their individual revenue constraints. 


\section{Dedication}

\section{To}

My Parents

Siraj Uddin Ahmed \& Ruquia Begum

My Daughter

Sarvenaaz, Sydee 


\section{Acknowledgements}

I would like to express my deepest thanks to my supervisor Professor Nguyen Van Quyen for his continuous support, guidance and advice. I am eternally grateful to him for showing the confidence in me by starting this research from scratch, on a completely new topic. It would have been impossible for me to continue my $\mathrm{PhD}$ thesis without his supervision. Sir, not only did you teach me about Economics research but also you provided me with valuable and inspiration life lessons. Every time I left your office I felt more self-assured and looking forward to finishing my thesis and starting my professional life with zeal and commitment.

I would also like to express my sincere gratitude to Professor Zhiqi Chen and Professor Gamal Atallah, who provided me with valuable comments which have enriched my thesis substantially. Professor Worswick listened to me with patience whenever I went to him, he did everything possible to make the transition from being a Ph.D. student to becoming a Doctor as smooth as possible. Your full cooperation is indeed appreciated. I would also like extend my appreciation to Professor Donald McFetridge for providing me with his helpful comments on my initial outline for the first essay. Thank you Professors.

I sincerely thank Marge Brooks for all her support; she was always there when I needed her. Marge you are a great administrator and a counsellor. I am grateful to the Department of Economics at Carleton University for the financial support and all the 
opportunities that were extended to me as a sessional lecturer teaching Economics over the years.

I cannot thank my elder brother, Moon, enough. It is because of him that I had the luxury of being a student for this long, he took on all the responsibilities without any complaint. He has always been there by my side. Bhaia, this dream of becoming a Ph.D. would not have come true without your support. I will always be indebted to you.

I whole heartedly thank my wonderful parents who provided me with the best of everything throughout my entire life. My father, Sirajuddin Ahmed, is the best human being I have ever encountered. He taught us to be fair and giving towards others. My mother, Ruquia Begum, was my first teacher and tutor till high school. She devoted hours on us so that we can attain proper education. She taught us to always dream big and aim high; without her guidance and aspirations I would not have been where I am now.

My lovely sister Liza deserves a special thanks for her unconditional love and affection throughout this journey. She never lost her confidence in me. Thank you Sis! I have done it.

After long library hours when I returned home my little princess Sarvenaaz worked wonders on me. Seeing her gorgeous smile made my day and took off all the stress right away. She provided me with great inspiration and reason to finish my thesis for a better 
life for her and us. Thank you my precious and beautiful daughter for providing Baba with your tension relieving magic!

I am not an expert with computer matters but I am extremely fortunate to have Zahir Alam as a friend, who is simply a genius! I never had to worry about losing any data or any other technical failure because I knew he was always there to rescue me. Zahir, I cannot repay your debt but please accept my sincere thanks for all your support with technical expertise. I must also thank my friend Monir Zaman (Rana) for his constant support during the bad and the good times. Rana, I am lucky to have a friend like you indeed.

Last but not least, my wife Sylvia has been a continuous source of inspiration to me in my work and her love, affection and sacrifices to help me achieve my goals are deeply appreciated. I dared to take off from work and completely focus on my thesis because you were there to take care of the rest. Your support is much more appreciated than you will ever know. Thank you so much for always believing in me and for telling me that I am capable of reaching where I am now.

I am indebted to all of you for everything that I have achieved and I hope that this work repays a small part of my debt. 


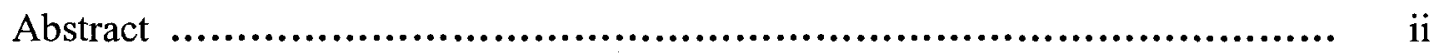

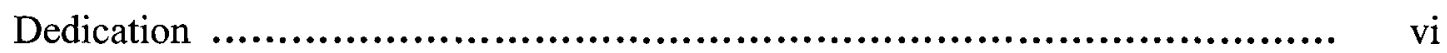

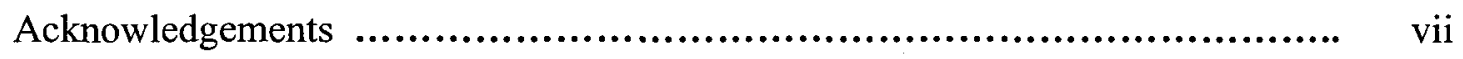

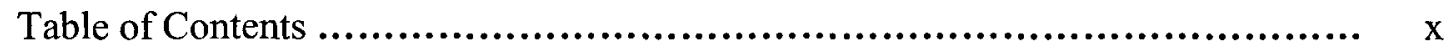

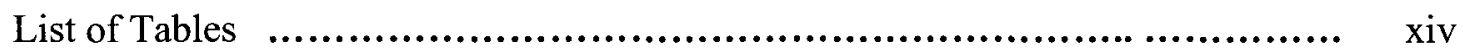

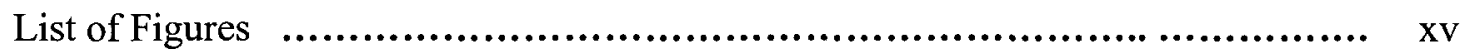

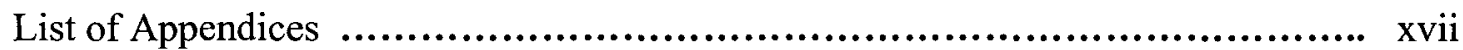

\section{Chapter One}

\section{STRANDED COSTS AND ONE-WAY ACCESS PRICING - A DYNAMIC}

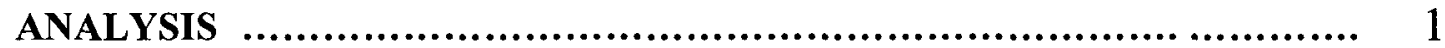

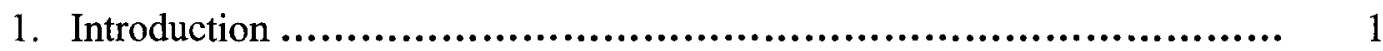

2. The Regulatory Contract .......................................................................................

2.1 Demand for Telecommunications Services ................................ 7

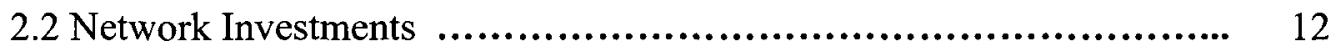

2.2.1 The Local Loops ................................................ 14

2.2.2 The Local Switches (The Bottlenecks) .......................... 15

2.2.3The Long-Distance Transmissions Investments ................... 16

2.3 The Costs of Operating a Telecommunications Network .................. 16

2.4 The Profit of the Regulated Firm under the Regulatory Contract ......... 17

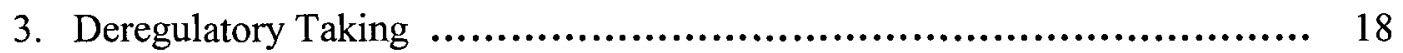


3.1 The Just Compensation .................................................. 18

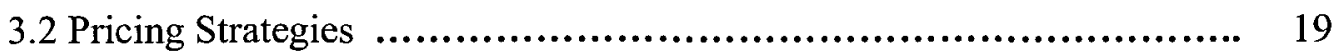

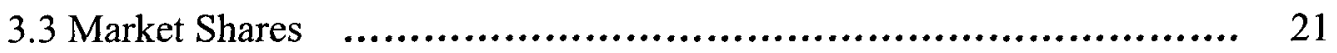

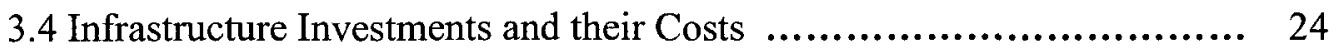

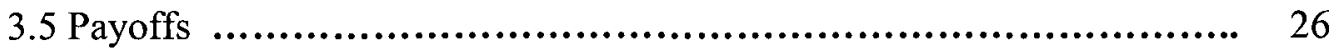

3.6. Admissible Deviations and their Payoffs for the Incumbent .............. 30

3.7 Admissible Deviations and their Payoffs for the Entrant .................. 33

3.8 Definition of the Sub-Game Perfect Nash Equilibrium ................... 36

4. The Optimal Price of Access ….............................................. 37

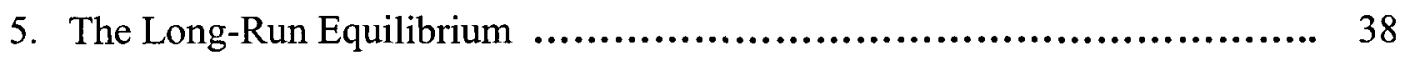

5.1 The Solution of the Ramsey Problem in the Long Run ..................... 38

5.1.1 The Entrant's Profit Maximization Problem in the Long Run ....... 40

5.1.2 The Incumbent's Profit Maximization Problem in the Long Run ... 41

5.1.3 The Optimal Price of Access in the Long Run ..................... 43

5.2 A Numerical Example ................................................. 44

6. The Transition to the Long-Run Equilibrium ............................... 48

7. Concluding Remarks ..................................................... 50

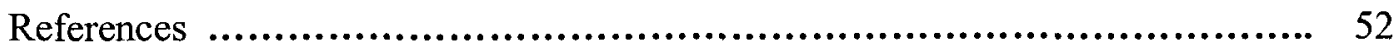

\section{Chapter Two}

ACCESS PRICING WITH CONGESTION AND LUMPY INFRASTRUCTURE

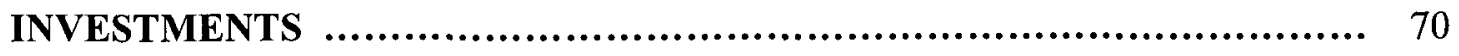

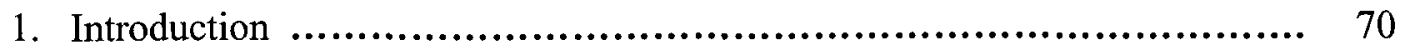

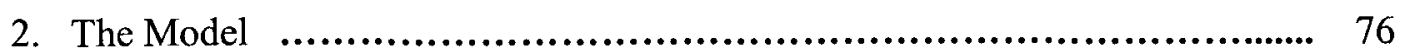




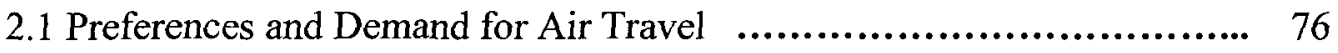

2.2 The Instantaneous Equilibrium Market Volume of Air Travel .............. 79

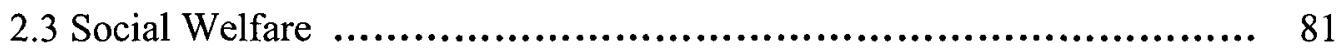

2.4 Lumpy Infrastructure Investments .......................................................... 81

3. Access Pricing when it is not Optimal to Install more than one unit of Capacity. 82

4. Access Pricing when it is not Optimal to Install more than two units of Capacity ............................................................. 91

4.1 Access Pricing when Only One Unit of Capacity is Installed ............... 91 4.2 Access Pricing when Two Units of Capacity are Installed and Given the Time the Second Unit of Capacity is Installed .................................. 99

4.3 Lumpy Investments when it is not Optimal to Install more than two units of

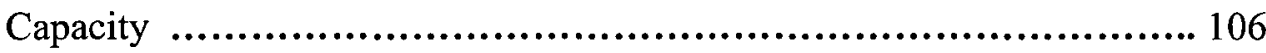

5. Access Pricing and Lumpy Investments when it is not Optimal to Install more

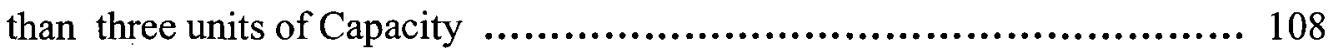

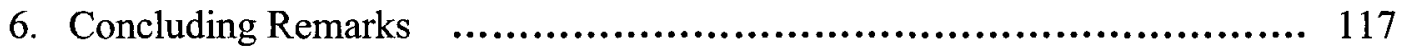

References $\quad$....................................................................... 119

\section{Chapter Three}

ACCESS PRICING FOR NATURAL GAS PIPELINES _................... 130

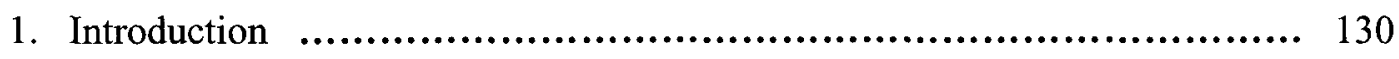

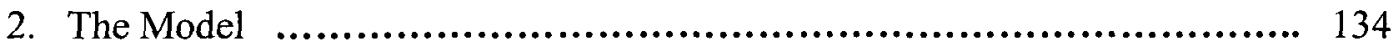

3. The Access Price for a Two-Node Network: One Source of Supply and One Source of Demand 
4. The Access Prices for a Three-Node Network: Two Supply Sources and One Demand Source Linked By Two Pipelines Connected in Parallel

5. The Access Price for a Three-Node Network with One Source of Supply and Two Sources of Demand Connected in Series

6. The Access Prices in Different Parts of the Global Network ............... 149

7. The Access Prices for the Global Network under Regulation ............... 154

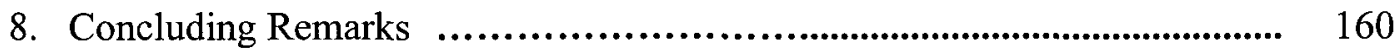

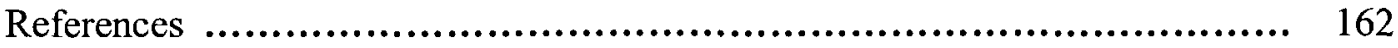




\section{List of Tables}

\section{Chapter One}

STRANDED COSTS AND ONE WAY ACCESS PRICING - A DYNAMIC

\section{ANALYSIS}

Table I : The Long-run Equilibrium Prices for various values of the

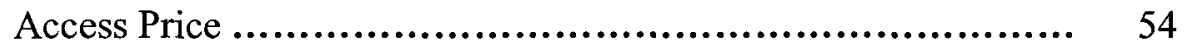

Table II: Equilibrium Outputs and Market Shares ........................ 55

Table III: Firms' Profits and Industry Profits ............................... 56

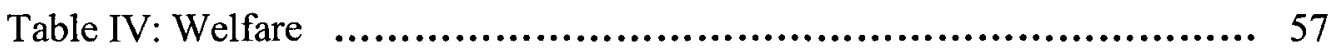

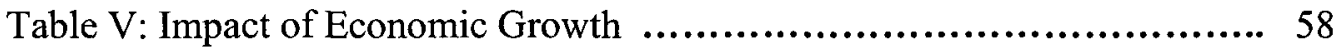




\section{List of Figures}

\section{Chapter One}

STRANDED COSTS AND ONE-WAY ACCESS PRICING - A DYNAMIC

\section{ANALYSIS}

Figure-1: The Demand For Long-Distance Calls by a Consumer

\section{Chapter Two}

\section{ACCESS PRICING WITH CONGESTION AND LUMPY INFRASTRUCTURE}

\section{INVESTMENTS}

Figure -1: The Congestion Cost Per Trip

Figure -2: The Instantaneous Equilibrium Market Volume of Air Travel ......

Figure-3: The Optimal Market Volume of Air Travel at each Instant when only one unit of Capacity is Installed: The case $\bar{K}=2$

Figure-4: The Optimal Market Volume of Air Travel at each Instant when two units of Capacity are Installed: The case $\bar{K}=2$

\section{Chapter Three}

\section{ACCESS PRICING FOR NATURAL GAS PIPELINES}

Figure-1: The Topology of the Network

Figure -2: A Two-node Network: One Source of Supply and One Source of

Demand 164

Figure-3: Two Sources of Supply Connected by Two Pipelines in Parallel to One 
Figure-4: A Three-node Network: One Source of Supply and Two Sources of Demand 166 
List of Appendices

Chapter One

STRANDED COSTS AND ONE-WAY ACCESS PRICING - A DYNAMIC ANALYSIS

Appendix: Long- run Equilibrium

Chapter Two

ACCESS PRICING WITH CONGESTION AND LUMPY INFRASTRUCTURE

INVESTMENTS

Appendix A : The Proof of Proposition 4

Appendix B: The Downward Jump of the Access Price

Chapter Three

ACCESS PRICING FOR NATURAL GAS PIPELINES

Appendix: Mathematica Coding for the Determination of the Access Price for the

Global Network under Regulation 167 


\section{Chapter One}

\section{STRANDED COSTS AND ONE-WAY ACCESS PRICING}

A DYNAMIC ANALYSIS

\section{INTRODUCTION}

For more than a century - since the invention of the telephone by Alexander Graham Bell in the 1870's until several decades ago - the plain old telephone networks in countries around the world were either owned by the State or operated by a regulated monopoly. The rationale for this form of market structure was that telecommunications were a natural monopoly, and it was not efficient to have more than one firm providing the service. In the US, a single vertically integrated telecommunications carrier - AT\&T provided both local and long-distance telephone services throughout the country until the 1960 's, when a small company called MCI (Microwave Communications Incorporated) began constructing a microwave ${ }^{1}$ network between Chicago and St. Louis. The original intent of MCI was to provide private-line services to businesses in the high-volume corridor. Later on, MCI wished to expand its long-distance service, and requested for permission from AT\&T to allow it to interconnect with the latter's local networks so that MCI could connect its subscribers to AT\&T's subscribers, and vice versa. It was no surprise that AT\&T - in order to protect its long-distance service - refused the request. MCI then brought the case to court, and obtained a favorable decision in 1978 . The court's decision to allow MCI to interconnect with AT\&T's local networks effectively created a second long-distance carrier in direct competition with AT\&T, and the erosion

\footnotetext{
1 The availability of microwave transmission equipments after the Second World War lowered the economic and technological barriers into the long-distance telecommunications markets substantially.
} 
of the market power of AT\&T began. The success of $\mathrm{MCI}$ undermines the natural monopoly argument, and convinces regulators that competition in the telecommunications industry is viable. Because the construction of the local loops is extremely costly, allowing MCI to interconnect with AT\&T's local networks is seen both as a means of lowering the barriers of entry and avoiding the wasteful duplication of networks. There is thus a justification for interconnection. Furthermore, to prevent AT\&T from monopoly leveraging - charging a high price for access to its local networks - in the local loops to disadvantage the competition in the long-distance segment of the market, there is also a need for regulating the price of interconnection.

Finding the right price of access is a difficult task. Setting a high access price discourages potential entrants. A low access price, on the other hand, amounts to confiscation of private property because the infrastructure already built by the incumbent is sunk. Furthermore, a low access price does not give the incumbent incentive to maintain the existing network and to invest in new infrastructures. Regulators in the US have decided that the price of interconnection should be cost-based and that efficiency suggests that it be set equal to the TELRIC (Total Element Long-Run Incremental Cost). To compute the access price according to the TELRIC concept, the cost of a network built according to the latest technology to serve the incumbent's current needs and to provide the access service demanded by the entrant must be first determined. The incremental cost of the infrastructure built to provide access to the entrant then represents the cost of access that the latter must pay as interconnection fee. For a computation of the price of 
interconnection using the forward-looking cost concept of TELRIC, the reader can consult Zolnierek (2006).

The TELRIC methodology is based upon a static concept of network deployment: If the network that is required to serve the incumbent and provide access to the entrant could be instantaneously constructed today, what technology would be adopted? The question of what an efficient network looks like in a dynamic environment - with growing demand and technological progress - has received little attention. This lack of attention stands in marked contrast with the excessive efforts spent in the design of an efficient static forward-looking network. ${ }^{2}$ Severe criticisins have been leveled at the concept of TELRIC. According to Hausman (2000), it puts the incumbent in a no-win situation. If future economic conditions turn out to be favorable and the entrant uses the access service provided by the incumbent, then the latter just breaks even. In the case future economic conditions turn out to be unfavorable and the extra capacity built to provide the access that is no longer needed, the incumbent is saddled with the stranded investment. Furthermore, because a telecommunications network produces several products which share a common cost, there is no cost function for each product in its own right, and a scheme - which is necessarily arbitrary - must be adopted to allocate the common cost among the various products in order to compute the access price according to the costbased approach.

There exists also a theoretical literature on access pricing and interconnection. Armstrong (2002) provided a comprehensive survey of the subject from a static framework. In the

\footnotetext{
${ }^{2}$ See Sharkey(2002) for a model of this type.
} 
models treated by this author, all costs are avoidable, and the principle of marginal cost pricing can be applied to set access charges. Laffont and Tirole (2000) derived the access price, not from the principle of marginal cost pricing, but by solving an inter-temporal Ramsey problem. These researchers, like Armstrong (2002), also assumed that all costs are avoidable. The important issue of stranded costs - past sunk investments in infrastructure - and the just compensation for deregulatory taking are not considered, although it has received an extensive discussion - without a formal model - by Sidak and Spullber (1997). At the end of the survey, Armstrong (2002) stated that

"... the strong focus on static analysis is perhaps the leading limitation of the analysis... An important next step for theoretical research in this area is, I believe, to provide a proper analysis of the dynamic of access pricing, focusing on the need to provide longrun stable incentives for the incumbent (and other firms) to invest efficiently in infrastructure and innovation. "

Our objective in this chapter is to fill part of this lacuna in the literature. The model we formulate applies to telecommunications, railroads, and electric utilities.

Now a model that is intended for analyzing the problem of access pricing with stranded cost must necessarily be dynamic. Such a model must encompass three phases: (i) one dealing with the sunk investments in infrastructure made by the incumbent under the regulatory contract, (ii) one dealing with the short-run adjustments after deregulatory taking has occurred, and (iii) one dealing with the long-run equilibrium. Furthermore, the 
forces that drive the dynamics of the model, namely technological progress and income growth, must also been incorporated. In the model we formalize, technological progress manifests itself through the declining $\operatorname{costs}^{3}$ of transmission and switching equipments, while income growth generates growth in demand for telecommunications services.

Because firms in the telecommunications industry must incur enormous set-up costs - the costs of constructing a network - the number of firms that the market can sustain is necessarily small. Hence the market structure that is appropriate for analyzing the competition in the telecommunications industry is oligopoly. We choose to formulate the problem of stranded costs in access pricing under the market structure of a duopoly - an incumbent and an entrant. A generalization to the case of more than two firms is straightforward.

Finally, the most defining feature of the telecommunications industry involves large expenditures on infrastructures, but a negligible marginal cost ${ }^{4}$ in service provision. Our model has been formulated to capture this special feature of the telecommunications industry by concentrating on the capacity investments of the incumbent and the entrant.

The chapter is organized as follows. In Section 2, the regulatory contract is formalized. Section 3 presents the model of deregulatory taking. The definition of the sub-game perfect Nash equilibrium for the game associated with deregulatory taking is given in

3 In telecommunications, innovations can be classified as incremental innovations, architectural innovations, platform innovations, and radical innovations. We have chosen to model technological progress as incremental innovations that revolve around the dominant design to reduce cost and improve performance. For a discussion and examples of these concepts of innovations, see Sherif (2006).

${ }^{4}$ The marginal cost of providing a service is the cost of the electricity needed to produce this unit. 
Section 4. In Section 5, the optimal time path of the access price is determined by solving an inter-temporal Ramsey problem that incorporates the constraint of just compensation for the incumbent due to deregulatory taking. The analysis of the equilibrium path is conducted in Section 6. Some concluding remarks are given in Section 7.

\section{THE REGULATORY CONTRACT}

In the stylized model, there are two identical cities, and a regulated carrier provides telecommunications services for the residents of these cities. There are two types of telecommunications services: local (intra-city) calls and long-distance (inter-city) calls. The regulatory contract is represented by the list $(\bar{m}, \bar{p}, T)$, where $\bar{m}$ is the flat-rate monthly fee for access to the carrier's network; $\bar{p}$ is the price per minute of longdistance calls; and $T$ is the length of the regulatory contract. The regulatory contract also specifies that a subscriber can receive any call - local or long-distance - and make an unlimited number of local calls without additional charge once the monthly access fee has been paid. To achieve the goal of universal service, the regulator fixes the flat monthly fee at a very low level so that all consumers subscribes to the network. ${ }^{5}$ Such an action makes it impossible for the regulated firm to pay for the operating costs and recover its investment in the local network only from the monthly fees collected. To allow the regulated firm to earn an acceptable rate of return, the regulator then sets the price of long-distance calls at a level close to the monopoly price. The profits generated in the long-distance segment of the market are then used to subsidize the losses in the local calls segment.

\footnotetext{
${ }^{s}$ In the US, more than $90 \%$ of homes are connected.
} 


\subsection{Demand for Telecommunications Services}

In what follows, time is continuous and denoted by $t, t \geq 0$. In each city and at each instant $t$, there is a continuum of consumers of measure 1 , who are differentiated by incomes. A consumer consumes two groups of commodities: telecommunications services and a numéraire that represents all the other goods in the economy. To study the impact of income growth on the demand for telecommunications services, we shall eschew quasi-linear preferences ${ }^{6}-$ the conventional preferences used in the economics of telecommunications - and assume that the preferences of a consumer are represented by a Dixit-Stiglitz utility function ${ }^{7}$ of the following form:

$$
u\left[x_{0}, x_{1}, x_{2}\right]=x_{0}^{\alpha}\left(u_{1}\left[x_{1}\right]+u_{2}\left[x_{2}\right]\right)^{1-\alpha},
$$

where $x_{0}, x_{1}$, and $x_{2}$ represent, respectively, the consumption of the numéraire, local calls, and long-distance calls. Also, $\alpha, 0<\alpha<1$, is a parameter. As for $u_{1}\left[x_{1}\right]$ and $u_{2}\left[x_{2}\right]$, they represent, respectively, the sub-utility functions of local and long-distance calls, and are assumed to have the following functional forms:

$$
u_{i}\left[x_{i}\right]=a_{i}+b_{i} x_{i}-\frac{1}{2} c_{i} x_{i}^{2},
$$

where $a_{i}, b_{i}$, and $c_{i}$ are positive constants.

With quasi-linear preferences, social welfare can be obtained by summing consumers' surplus and producers' surplus. This approach for measuring welfare is no longer

\footnotetext{
${ }^{6}$ Quasi-linear preferences have no income effect: for a consumer with quasi-linear preferences, the demand for telecommunications services depends only on prices, not on income. Thus income growth alone will not generate growth in demand for telecommunications services.

${ }^{7}$ This is a functional form proposed by Dixit and Stiglitz (1977) to study the optimum number of product varieties. It has been used extensively in international trade.
} 
appropriate with the Dixit-Stiglitz utility function. The correct methodology is to consider the profits made by the telecommunications carriers as part of the income of the consumers, and then summing their utilities to arrive at a measure of social welfare. Thus the income of a consumer comes from two sources: income from ownership of telecommunications carriers and income from all the other sources. The former source represents the dividends distributed by telecommunications firms, and is thus endogenous. The latter source will be taken as exogenous to the model.

In what follows, we shall assume that the income of a consumer at any instant depends on his type, say $\theta, 0<\underline{\theta} \leq \theta$, with a known distribution function $F[\theta], \theta \geq \underline{\theta}$. To generate the growth in demand for telecommunication services, we shall suppose that the income at time $t$ of a consumer of type $\theta$ is $y[t \mid \theta]=\theta e^{\gamma[t]}+\pi_{t}, t \geq 0$. Here $\pi_{t}$, which, for simplicity, is assumed to be the same ${ }^{8}$ for all consumers, represents the dividends she receives from partial ownership of the telecommunications carriers, and $\theta e^{\gamma[t]}$ represents the income from sources other than ownership of telecommunication carriers, with $\gamma[t]$ being a non-negative, increasing, and continuously differentiable function of time., and $\gamma[0]=0$. The type of a consumer is thus her initial income from sources other than telecommunications, and these sources of income rise through time at the same rate for all consumers. Note that $\underline{\theta}$ is the lowest initial income - among the population - from sources other than telecommunications.

\footnotetext{
${ }^{8}$ This amounts to assuming that all the consumers own the same number of shares in the telecommunications carriers. A more general specification will make the shares owned by a consumer depend on her type.
} 
Now let $m$ and $p$ denote, respectively, the fixed monthly fee and the price of longdistance calls faced by the consumers at an instant $t \geq 0$. Consider a consumer with income $y$. If $m \geq y$, then the consumer will not consume any telecommunications service: all her income will be spent on the numéraire. If $m<y$, then she might or might not choose to get connected by paying the fixed monthly fee. In case she decides to get connected to the regulated firm, then the income she has left to spend the numéraire and long-distance calls is $y-m$. Because the price of local calls is 0 , the consumer will consume the saturation number of local calls after paying the fixed monthly fee to get connected to the regulated firm's network. The number of long-distance calls she will make is obtained by solving the following maximization problem:

$$
\max _{\left(x_{0}, x_{2}\right)}\left(x_{0}\right)^{\alpha}\left(u_{1}^{\max }+a_{2}+b_{2} x_{2}-\frac{1}{2} c_{2} x_{2}^{2}\right)^{1-\alpha}
$$

subject to

$$
x_{0}+p x_{2}=y-m
$$

In (3), we have let

$$
u_{1}^{\max }=u_{1}\left[x_{1}^{\max }\right]
$$

represent the saturation sub-utility of local calls, and

$$
x_{1}^{\max }=b_{1} / c_{1},
$$

represents the saturation number of local calls.

Using the budget constraint (4) in (3), and then taking the logarithm of the resulting expression, we obtain 


$$
\max _{x_{2} \geq 0}\left(\alpha \log \left[y-m-p x_{2}\right]+(1-\alpha) \log \left[u_{1}^{\max }+a_{2}+b_{2} x_{2}-\frac{1}{2} c_{2} x_{2}^{2}\right]\right)
$$

The first-order condition that characterizes the solution of (7) is

$$
-\frac{\alpha p}{y-m-p x_{2}}+\frac{(1-\alpha)\left(b_{2}-c_{2} x_{2}\right)}{u_{1}^{\max }+a_{2}+b_{2} x_{2}-\frac{1}{2} c_{2} x_{2}^{2}} \leq 0
$$

with equality holding if $x_{2}>0$.

Note that the curve $x_{2} \rightarrow \alpha p /\left(y-m-p x_{2}\right)$ is strictly rising from $\alpha p /(y[t \mid \theta]-\bar{m})$ to infinity as $x_{2}$ rises from 0 to $(y-m) / p$. As for the curve

$$
x_{2} \rightarrow(1-\alpha)\left(b_{2}-c_{2} x_{2}\right) /\left(u_{1}^{\max }+a_{2}+b_{2} x_{2}-c_{2} x_{2}^{2} / 2\right)
$$

it is strictly declining from $(1-\alpha) b_{2} /\left(u_{1}^{\max }+a_{2}\right)$ to 0 as $x_{2}$ rises from 0 to $b_{2} / c_{2}$. Hence, if

$$
\frac{1-\alpha}{u_{1}^{\max }+a_{2}} b_{2} \leq \frac{\alpha}{y-m} p
$$

then the demand for long-distance calls will be equal 0 . Otherwise, the demand for longdistance calls is the unique value of $x_{2}$ that solves the following equation:

$$
-\frac{\alpha p}{y-m-p x_{2}}+\frac{(1-\alpha)\left(b_{2}-c_{2} x_{2}\right)}{u_{1}^{\max }+a_{2}+b_{2} x_{2}-\frac{1}{2} c_{2} x_{2}^{2}}=0
$$

We shall let $x_{2}[m, p, y]$ denote the instantaneous demand for long-distance calls by an individual with income $y$, given that she has paid the fixed monthly fee. We have

$$
x_{2}[m, p, y]=0 \text { if } \frac{1-\alpha}{u_{1}^{\max }+a_{2}} b_{2} \leq \frac{\alpha p}{y-m}
$$




$$
=\frac{-\xi_{1}-\sqrt{\xi_{1}^{2}-4 \xi_{0} \xi_{2}}}{2 \xi_{2}} \text {, otherwise, }
$$

where

$$
\begin{aligned}
& \xi_{0}=\alpha\left(a_{2}+u_{1}^{\max }\right) p-b_{2}(1-\alpha)(y-m), \\
& \xi_{1}=b_{2} p-c_{2}(1-\alpha)(y-m), \\
& \xi_{2}=c_{2}\left(1-\frac{\alpha}{2}\right) p
\end{aligned}
$$

The determination of $x_{2}[m, p, y]$ is depicted in Figure- 1 . Note that $x_{2}[m, p, y]$ is increasing in income, but decreasing in $m$ and $p$. The consumer will choose to be connected to the regulated firm's network if the utility obtained by getting connected is greater than or equal to the utility obtained by spending all the income on the numéraire, i.e., if

$$
\left(y-m-p x_{2}[m, p, y]\right)^{\alpha}\left(u_{1}^{\max }+u_{2}\left[x_{2}[m, p, y]\right]\right)^{1-\alpha} \geq y^{\alpha}\left(a_{1}+a_{2}\right)^{1-\alpha} .
$$

Now if $y$ is large relative to $m$, then because $u_{1}^{\max }>a_{1}$, we must have

$$
(y-m)^{\alpha}\left(u_{1}^{\max }+a_{2}\right)^{1-\alpha} \geq y^{\alpha}\left(a_{1}+a_{2}\right)^{1-\alpha},
$$

and this means the consumer will choose to get connected. Thus, for any given $(m, p)$ there is a critical income level, say $\underline{y}[m, p]$, such that a consumer will get connected if and only if her income is at least equal to $\underline{y}[m, p]$. The indirect utility function of a consumer whose income is $y$ and who faces the prices $(m, p)$ is then given by

$$
\begin{aligned}
& v[m, p, y]=\left(y-m-p x_{2}[m, p, y]\right)^{\alpha}\left(u_{1}^{\max }+u_{2}\left[x_{2}[m, p, y]\right]\right)^{1-\alpha}, \text { if } y \geq \underline{y}[m, p] \\
&=y^{\alpha}\left(a_{1}+a_{2}\right)^{1-\alpha}, \text { otherwise. }
\end{aligned}
$$

If $(m, p)$ is the prices set by the regulated firm at time $t$, then the number of local calls made in each city is 


$$
\begin{aligned}
X_{1}[m, p, t]= & \int_{\left(\underline{y}[m, p]-\pi_{y}\right) / e^{\gamma(t]}}^{\infty} x^{\max } d F[\theta] \\
& =\left(1-F\left[\left(\underline{y}[m, p]-\pi_{t}\right) / e^{\gamma[t]}\right]\right) x_{1}^{\max },
\end{aligned}
$$

while the number of long-distance calls made by the residents in each city is given by

$$
X_{2}[m, p, t]=\int_{\left(\underline{y}[m, p]-\pi_{t}\right) / e^{\gamma \mid t]}}^{\infty} x_{2}\left[m, p, \theta e^{\gamma[t]}+\pi_{t}\right] d F[\theta] .
$$

Note that (16) is an increasing function of $t$ due to the growth in income.

To attain the objective of universal service, regulatory authorities have set the fixed monthly fee low enough, so that (13) is satisfied for $y=\underline{\theta}$ and $m=\bar{m}$. In this case, (15) and (16), respectively, become

$$
X_{1}[\bar{m}, \bar{p}, t]=x_{1}^{\max },
$$

and

$$
X_{2}[\bar{m}, \bar{p}, t]=\int_{\underline{\theta}}^{\infty} x_{2}\left[\bar{m}, \bar{p}, \theta e^{\gamma[t]}+\pi_{t}\right] d F[\theta] .
$$

\subsection{Network Investments}

To keep the exposition from becoming too burdensome, we shall make the simplifying assumption that a network can be built instantaneously although in reality it takes time to construct an infrastructure. At the present time, the volume of traffic carried by a local loop is well below its capacity. Hence local loops are not traffic-sensitive. As for switching equipments, the capacity of a switch - which is a powerful computer - depends on the number of electronic circuits it contains. A switch with more circuits can route more calls. The capacity of a switch also depends on the computer programs installed for 
traffic signaling and for routing calls. A large switch can handle the highest number of calls at times of emergency. However, it will be idle most of the time. Hence a switch is only built to accommodate the number of calls during peak hours and for a given pattern of demand. As time goes on and demand grows, larger switches are needed. Hence the bottlenecks in the system reside at the local switches, and the regulated firm must have enough switching capacity to satisfy the demand for local and long-distance calls in order to fulfill its obligations under the regulatory contract.

Now in building a network, a carrier can make the trade-off between switches and transmission lines. If only a switch is used for the entire city, then all the local loops must be connected to the switch, and the cost of laying the needed twisted pairs of copper wires (or optical fibers) can be substantial. On the other hand, if several switches are used, then a local loop can be connected to one of these switches, and the switches connected to each other. This action reduces the costs of the local loops, but increases the costs of switches. The optimal network architecture then depends on the spatial distribution of subscribers, the cost of switches, and the costs of laying the cables. For our purposes, we shall assume that there is only one local exchange in each city, and that all the local loops in a city are connected to the switch housed in the local exchange.

For a long-distance carrier, it has to invest in transmissions equipments and switches to route calls. In a model of multiple cities, a long-distance carrier might have a network consisting of both transmissions lines and switches to concentrate and route traffic. For our stylized model of two cities, logically there is no need for more switches other than 
the two local switches located in the two cities. The two local switches can be linked by trunks to carry long-distance traffic.

\subsubsection{The Local Loops}

For any $t \geq 0$, let $\ell[t]$ denote the cost - at time $t$ - of building a local loop. Thus $\ell[0]$ is the cost - at time 0 - of building the local loop ${ }^{9}$ needed by a subscriber. Technological progress in the construction of local loops can be modeled by assuming that a future local loop carries more traffic than a current local loop. Technological progress can also be modeled - as in the case of optical fibers - by assuming that the cost of constructing a local loop might be rising through time, but the cost of its repair and maintenance declines sufficiently to make the total cost of constructing a loop plus the cost of its repair and maintenance fall through time.

At time 0 , the total cost of building the local loops to connect all subscribers to the local exchange in each city is then given by $\int_{\underline{\theta}}^{\infty} \ell[0] d F[\theta]=\ell[0]$. As these local loops age, the costs of repair and maintenance will rise, and there comes a time when these costs are sufficiently high that it is more economical to replace them. We shall make the assumption that $T$ - the length of the regulatory contract - is equal to the age of the local loops at which they must be replaced. ${ }^{10}$

\footnotetext{
${ }^{9}$ A twisted pair of copper wires.

${ }^{10}$ To keep the problem from becoming too burdensome, we have chosen not to model the optimal date of replacement - from the perspective of the regulated carrier - of equipments. Thus, the economic life of a local loop, a transmission line, and a switch is taken to be exogenous, and these pieces of equipments must be replaced at regular intervals. Also, to model technological progress in different parts of a network, we allow different economic lives for local loops, transmission lines, and switches.
} 


\subsubsection{The Local Switches (The Bottlenecks)}

As for switches, they depreciate faster and become obsolete sooner due to the rapid pace of innovation that takes place in the telecommunications industry. We shall let $\sigma$ denote the age at which a switch is replaced, and to make the computations more bearable, we shall make the simplifying assumption that $T$ is a multiple of $\sigma$. Thus the local switch in a city must be replaced at instants $\sigma, 2 \sigma, \ldots, n \sigma, \ldots, T-\sigma$.

Now for each time $t$, the number of calls - local and long-distance - handled by the local switch in a city is given by ${ }^{11}$

$$
X[m, p, t]=X_{1}[m, p, t]+2 X_{2}[m, p, t]
$$

We shall assume that the cost - at time $t$ - of a new local switch that can handle $Q$ calls - local and long-distance - is given by

$$
S[t]+s[t] Q
$$

where $S[t]$ and $s[t]$ are both functions of time. In conforming with our assumption that innovations are incremental, we can expect the fixed cost $S[t]$ to rise with $t$, but the variable cost $s[t]$ to decline through time, so that the average cost of switching equipments needed to handle one call, namely $(S[t] / Q)+s[t]$, for a large value of $Q$ is declining both in $Q$ and in $t$ : there are scale economies in manufacturing switching equipments, and scale economies improve with time. The cost of the switch installed at time 0 in the local exchange of each city is then given by $S[0]+s[0] X[m, p, \sigma]$.

\footnotetext{
"Note that long-distance calls served by the local switch of a city include both outgoing long-distance calls and in-coming long-distance calls.
} 
Similarly, for each $n=1, \ldots, T-\sigma$, the cost of the new local switch installed at time $n \sigma$ is $S[n \sigma]+s[n \sigma] X[m, p,(n+1) \sigma]$.

\subsubsection{The Long-Distance Transmissions Investments}

To model the investments needed for transporting long-distance traffic, we shall assume that for each time $t \geq 0$, the cost - at time $t$ - of constructing a long-distance network (the trunks) between the two cities that can accommodate $Q_{2}$ long-distance calls is given by

$$
K[t]+k[t] Q_{2}
$$

The cost that the regulated carrier must incur at time 0 to serve the long-distance segment of the market is then given by

$$
K[0]+2 k[0] X_{2}[m, p, T]
$$

Note that in (22) we have assumed that the transmissions equipments have a lifetime of $T$. As in the case of switches, we can also expect that $\left(K[t] / Q_{2}\right)+k[t]$ declines through time due to technological progress.

\subsection{The Costs of Operating a Telecommunications Network}

Once a telecommunications network has been constructed, the costs of running the network consist of (i) wages, (ii) the costs of repair and maintenance, and (iii) the cost of electricity used to transport calls. The cost of electricity is negligible, and will be ignored. Although wages constitute an important part of the operating costs at any instant, they do not vary with the number of calls made, and can thus be considered as fixed cost. The cost component that plays an important role in our analysis is the cost associated with 
maintenance and repair. As a piece of equipment ages, it breakdowns more often, and more and more resources must be expended for is repair and maintenance to provide the service needed at a desired quality level. The cost of repair and maintenance thus reflects the physical depreciation of a piece of equipment, not the depreciation allowance - a purely accounting concept - that a firm is allowed to use in computing the costs it incurs at each time for taxation purposes. ${ }^{12}$

In what follows, let $C_{\text {Labor }}[t], 0 \leq t \leq T$, denote the current labor costs of running the network at time $t$. Also, let $C_{\text {LocalLoop }}[h \mid t]$ denote the current cost of repair and maintenance of the local loops in a city, given that the loops were constructed at time $t$ and that their current age is $h$. For a local switch that is $h$ years old and that was constructed at time $t$ to route $Q$ calls, the current cost of repair and maintenance is represented by $C_{S w i t h}[h \mid t, Q]$. Also, for the trunks that are $h$ years old, and that were constructed at time $t$ to transport $Q_{2}$ long-distance calls, the current cost of repair and maintenance is represented by $C_{T r u n k}\left[h \mid t, Q_{2}\right]$.

\subsection{The Profit of the Regulated Firm under the Regulatory Contract}

The present value of the stream of profits made by the regulated firm over the lifetime of the regulatory contract is given by

\footnotetext{
${ }^{12}$ See the discussion on the two - often very confusing in the literature of telecommunications deregulation - concepts of depreciation in a report entitled "Access Pricing in Telecommunications," by OECD(2004). Here we adopt the concept of physical depreciation - reflected by increasing costs of maintenance and repair - in contrast with the concept of accounting depreciation adopted by the OECD (2004). Regulators in the OECD compute the accounting depreciation by solving a Ramsey pricing problem.
} 


$$
\begin{aligned}
& \Pi[\bar{m}, \bar{p}, T]=2 \int_{0}^{T} \bar{m} e^{-r t} d t+2 \int_{0}^{T} \bar{p} X_{2}[\bar{m}, \bar{p}, t] e^{-r t} d t \\
& -\int_{0}^{T} C_{\text {Labor }}[t] e^{-r t} d t \\
& \left.-2\left(\ell[0]+\int_{0}^{T} C_{\text {LocalLoop }}[t \mid 0]\right] e^{-r t} d t\right) \\
& -2 \sum_{n=0}^{(T / \sigma)-1}\left(\begin{array}{l}
(S[n \sigma]+s[n \sigma] X[\bar{m}, \bar{p},(n+1) \sigma]) e^{-r n \sigma} \\
+\int_{n \sigma}^{(n+1) \sigma} C_{S w i t c h}[t-n \sigma \mid n \sigma, X[\bar{m}, \bar{p},(n+1) \sigma]] e^{-r t} d t
\end{array}\right) \\
& -\left(K[0]+2 k[0] X_{2}[\bar{m}, \bar{p}, T]+\int_{0}^{T} C_{T r u n k}\left[t \mid 2 X_{2}[\bar{m}, \bar{p}, T]\right] e^{-r t} d t\right)
\end{aligned}
$$

In (23), $r$ denotes the rate of interest. In order for the carrier to accept the regulatory contract, we must have $\Pi[\bar{m}, \bar{p}, T] \geq 0$.

\section{DEREGULATORY TAKING}

\subsection{The Just Compensation}

Suppose that at some time $\tau, 0 \leq \tau<T$, the regulator breaches the regulatory contract by allowing another telecommunications carrier to enter the long-distance segment of the market. The regulator also mandates the incumbent to provide the entrant with access to its local loops, and sets the price of the interconnection. For simplicity, suppose that $\tau$ is a multiple of $\sigma$, and this means the incumbent will replace the local switch in each city at time $\tau$. Next, let 


$$
\begin{aligned}
& H[\tau \mid(\bar{m}, \bar{p}, T)]= 2 \int_{\tau}^{T} \bar{m} e^{-r t} d t+2 \int_{\tau}^{T} \bar{p} X_{2}[\bar{m}, \bar{p}, t] e^{-r t} d t \\
&-\int_{\tau}^{T} C_{\text {Labor }}[t] e^{-r t} d t \\
&\left.-2 \int_{\tau}^{T} C_{\text {LocalLoop }}[t \mid 0]\right] e^{-r t} d t \\
&-2 \sum_{n=\tau / \sigma}^{(T / \sigma)-1}\left(\begin{array}{c}
(S[n \sigma]+s[n \sigma] X[\bar{m}, \bar{p},(n+1) \sigma]) e^{-r n \sigma} \\
(n+1) \sigma \\
\int_{n \sigma} C_{S w i t c h}[t-n \sigma \mid n \sigma, X[\bar{m}, \bar{p},(n+1) \sigma]] e^{-r t} d t
\end{array}\right) \\
& \quad-\int_{\tau}^{T} C_{T r u n k}\left[t \mid 2 X_{2}[\bar{m}, \bar{p}, T]\right] e^{-r t} d t .
\end{aligned}
$$

As defined, $H[\tau \mid(\bar{m}, \bar{p}, T)]$ represents the present value of the stream of profits made by the regulated firm for the remaining part of the regulatory contract if it is not breached. According to Sidak and Spullber (1997), $H[\tau \mid(\bar{m}, \bar{p}, T)]$ is the compensation that the regulated carrier should receive for breach of the regulatory contract, and this constraint, should be considered by the regulator in setting the access price.

\subsection{Pricing Strategies}

To avoid the possibility that a consumer might switch long-distance carriers for an infinite number of times in a given interval of time, we shall assume that for each $n=0,1, \ldots$, the long-distance contract that she signs with one of the carriers starts at the beginning of the time interval $I_{n}=[n \sigma,(n+1) \sigma)$ and terminates at the end of this time interval. Thus for each time interval $I_{n}, n=0,1, \ldots$, a consumer will subscribe to the longdistance carrier that yields a higher present value for the stream of utilities she obtains during this time interval. 
Let $\phi[t], t \geq \tau$, denote the price paid by the entrant at time $t$ for access to a local loop to originate or terminate a long-distance call made by a subscriber to its network. To keep the exposition more tractable, we shall assume that the map $t \rightarrow \phi[t], t \geq \tau$, is a rightcontinuous step function defined in the following manner: First, let $(\phi[\tau+n \sigma])_{n=0}^{\infty}$ be a sequence of positive numbers that we interpret as the price of access set by the regulator during the time interval $I_{n}$. Next, let ${ }^{13}$

$$
\phi[t]=\phi[\tau+n \sigma]
$$

As defined, $\phi[t], t \geq \tau$, represents the regulated access price at each instant after entry has occurred. The access price, thus defined, is a right-continuous step function of time, which is constant inside each of the time intervals $I_{n}$.

To continue, let $\left(m[t], p_{I}[t]\right)$ be the price strategy of the incumbent after entry has occurred. Here $m[t]$ represents the fixed monthly fee and $p_{I}[t]$ represents the price it charges for a long-distance call. As in the case of the time path of the access price, we also assume that the time path of the prices set by the incumbent is a right-continuous step function, and have the following forms:

$$
m[t]=m[\tau+n \sigma]
$$

and

$$
p_{I}[t]=p_{I}[\tau+n \sigma], \quad\left(t \in I_{n}\right) .
$$

\footnotetext{
${ }^{13}$ Note that the points in time $\tau+n \sigma, n=0,1,2, \ldots$, coincide with the instants at which the local switches are replaced. Although the choice of the end points of the time intervals $I_{n}=[\tau+n \sigma, \tau+(n+1) \sigma), n=0,1, \ldots$, is somewhat arbitrary, it simplifies the computations considerably.
} 
where $(m[\tau+n \sigma])_{n=0}^{\infty}$ and $\left(p_{I}[\tau+n \sigma]\right)_{n=0}^{\infty}$ are two sequences of positive numbers.

To concentrate in the competition between the incumbent and the entrant in the longdistance of the market, we shall presume that it is never optimal for the incumbent to set the fixed monthly fee during any time interval $I_{n}$ that will induce consumers at the low end of the income scale not to get connected.

As for a price strategy of the entrant, it has the following form:

$$
p_{E}[t]=p_{E}[\tau+n \sigma]
$$

where $\left(p_{E}[\tau+n \sigma]\right)_{n=0}^{\infty}$ is a sequence of positive numbers.

\subsection{Market Shares}

At the time the entrant enters the long-distance segment of the market, the incumbent has $100 \%$ of the market in this segment. To induce consumers to switch to its long-distance network, the entrant must offer a price that is lower than that of the incumbent. Charging the same price for long-distance calls as the incumbent will not induce any consumer to switch to its long-distance service. One reason - the cost incurred by a consumer when switching to another carrier - is often advanced to explain the reluctance of consumers to switch to a new carrier. Another reason is the preferences of consumers for one-stop shopping. Joseph Nacchio, former Executive Vice President of AT\&T, cited surveys that indicate that two-thirds of consumers want local and long distance services from a single 
carrier. $^{14}$ Ware (1998) suggested that the preferences of consumers for one-stop shopping - the ability to buy all the telecommunications services from a single carrier and pay for the services with a single bill - has been a driving force behind the mergers and the vertical integration of telecommunications providers after the 1996 Telecommunications Act in the United States. For our purpose, we adopt the preference for one-stop shopping as the reason why consumers are reluctant to abandon the incumbent and switch to the entrant for their long-distance telephone services, and model this preference as a disutility associated with switching.

To find the market share of each carrier during a time interval $I_{n}$, consider a consumer with type $\theta$. Also, assume that the stream of dividends distributed to each consumer, namely $\left(\pi_{t}\right)_{t \geq \tau}$, is given. The income at time $t$ of this consumer is thus $y[t \mid \theta]=\theta e^{\gamma[t]}+\pi_{t}$, which we assume for simplicity to be spent completely on goods and services at that instant. ${ }^{15}$ If she signs a contract for long-distance service with the incumbent, then her demand for long-distance calls at each time $t \in I_{n}$, is given by $x_{2}\left[m[t], p_{I}[t], y[t \mid \theta]\right]$. The present value of the stream of utilities she obtains during the time interval $I_{n}$ is then given by

$$
\int_{t \in I_{n}} e^{-\rho t} v\left[m[t], p_{I}[t], y[t \mid \theta]\right] d t=\int_{t \in I_{n}} e^{-\rho t} v\left[m[\tau+n \sigma], p_{I}[\tau+n \sigma], y[t \mid \theta]\right] d t
$$

where $\rho$ is her rate of time preference.

\footnotetext{
14 Communications Week, February 26, 1996.

${ }^{15}$ A more general treatment of the problem of utility maximization under infinite time horizon makes the problem more complicated without adding much to the model.
} 
On the other hand, if she subscribes to the long-distance service provided by the entrant, then her demand for long-distance calls is given by $x_{2}\left[m[t], p_{E}[t], y[t \mid \theta]\right]$. The indirect utility function associated with this action is then given by

$$
v\left[m[t], p_{E}[t], y[t \mid \theta]\right]-\varepsilon(y[t \mid \theta]-y[t \mid \underline{\theta}])^{2},
$$

where $\varepsilon>0$ is a parameter. The expression $\varepsilon(y[t \mid \theta]-y[t \mid \underline{\theta}])^{2}$ is intended to capture the disutility of subscribing to the entrant's long-distance network instead of the one-stop shopping of having one firm - the incumbent - providing both local and long-distance services. As specified, the disutility of switching is an increasing and convex function of income, with the consumers having the lowest income experiencing no disutility of switching.

The present value of the stream of utilities the consumer obtains during the time interval $I_{n}$ if her long-distance calls are handled by the entrant is then given by

$$
\begin{aligned}
\int_{t \in I_{t}} e^{-\rho t}\left(v\left[m[t], p_{E}[t], y[t \mid \theta]\right]-\varepsilon(y[t \mid \theta]-y[t \mid \underline{\theta}])^{2}\right) d t \\
\quad=\int_{t \in I_{t}} e^{-\rho t}\left(v\left[m[\tau+n \sigma], p_{E}[\tau+n \sigma], y[t \mid \theta]\right]-\varepsilon(y[t \mid \theta]-y[t \mid \underline{\theta}])^{2}\right) d t
\end{aligned}
$$

The choice of long-distance carrier can be represented by the following binary decision variable, which takes on the value 1 if the incumbent is chosen and the value 0 if the entrant is chosen:

$$
\delta_{n}\left[\left(m[t], p_{I}[t]\right)_{t \geq \tau},\left(p_{E}[t]\right)_{t \geq \tau}, \theta \mid\left(\pi_{t}\right)_{t \geq \tau}\right]=\left\{\begin{array}{l}
1 \text { if }(29) \text { is greater than }(30), \\
0, \text { otherwise. }
\end{array}\right.
$$


At each instant $t^{\prime} \in I_{n}$, the demand for the incumbent's long-distance service in each city then given by

$$
\begin{aligned}
X_{2, I}\left[\left(m[t], p_{I}[t]\right)_{t \geq \tau},\left(p_{E}[t]\right)_{t \geq \tau}, t^{\prime} \mid\left(\pi_{t}\right)_{t \geq \tau}\right]= \\
\quad \int_{\underline{\theta}}^{\infty} \delta_{n}\left[\left(m[t], p_{I}[t]\right)_{t \geq \tau},\left(p_{E}[t]\right)_{t \geq \tau}, \theta \mid\left(\pi_{t}\right)_{t \geq \tau}\right] x_{2}\left[m\left[t^{\prime}\right], p_{I}\left[t^{\prime}\right], y\left[t^{\prime} \mid \theta\right]\right] d F[\theta],
\end{aligned}
$$

and the demand for the entrant's long-distance service in each city is given by

$$
\begin{aligned}
X_{2, E} & {\left[\left(m[t], p_{I}[t]\right)_{t \geq \tau},\left(p_{E}[t]\right)_{t \geq \tau}, t^{\prime} \mid\left(\pi_{t}\right)_{t \geq \tau}\right]=} \\
& \int_{\underline{Q}}^{\infty}\left(1-\delta_{n}\left[\left(m[t], p_{I}[t]\right)_{t \geq \tau},\left(p_{E}[t]\right)_{t \geq \tau}, \theta \mid\left(\pi_{t}\right)_{t \geq \tau}\right]\right) x_{2}\left[m\left[t^{\prime}\right], p_{E}\left[t^{\prime}\right], y\left[t^{\prime} \mid \theta\right]\right] d F[\theta] .
\end{aligned}
$$

\subsection{Infrastructure Investments and their Costs}

Now at time $\tau$, when the regulatory contract is breached, the incumbent has a legacy network that consists of the local loops in each city and the transmission lines connecting the two cities, and the legacy network will not be replaced until time $T$, when the regulatory contract were expected to expire. As already mentioned in the section on the regulatory contract, the local loops are not traffic sensitive. Hence the only capacity constraint that the incumbent must respect is the capacity - already installed - of the transmission lines during the time interval $[\tau, T]$. Furthermore, recall that the capacity of the transmission lines that the incumbent installed to provide long-distance service under the regulatory contract is $X_{2}[\bar{m}, \bar{p}, T]$. Hence a combination of price strategies $\left(\left(m[t], p_{I}[t]\right)_{t \geq \tau},\left(p_{E}[t]\right)_{t \geq \tau}\right)$ is admissible only if the following legacy capacity constraint is satisfied:

$$
X_{2, I}\left[\left(m[t], p_{I}[t]\right)_{t \geq \tau},\left(p_{E}[t]\right)_{t \geq \tau}, t^{\prime} \mid\left(\pi_{t}\right)_{t \geq \tau}\right] \leq X_{2}[\bar{m}, \bar{p}, T], \quad\left(\tau \leq t^{\prime}<T\right)
$$


The new infrastructure investments that are required to sustain the combination of price strategies $\left(\left(m[t], p_{I}[t]\right)_{t \geq \tau},\left(p_{E}[t]\right)_{t \geq \tau}\right)$ can be determined as follows. First, recall that the local loops and the long-distance transmission lines of the incumbent are replaced at instants $T, 2 T, 3 T, \ldots$ Given the combination of price strategies $\left(\left(m[t], p_{I}[t]\right)_{t \geq \tau},\left(p_{E}[t]\right)_{t \geq \tau}\right)$ , the capacity of the transmission lines that the incumbent must install at time $n T, n=1,2, \ldots$, to handle the volume of long-distance calls made by its subscribers during the time interval $[n T,(n+1) T), n=1,2, \ldots$, is given by

$$
\begin{aligned}
Q_{2, I}\left[n T \mid\left(\left(m[t], p_{I}[t]\right)_{t \geq \tau},\left(p_{E}[t]\right)_{t \geq t}\right),\left(\pi_{t}\right)_{t \geq \tau}\right] \\
\quad=2 \sup _{n T \leq t^{\prime}<(n+1) T} X_{2, I}\left[\left(\left(m[t], p_{I}[t]\right)_{t \geq \tau},\left(p_{E}[t]\right)_{t \geq \tau}\right), t^{\prime} \mid\left(\pi_{t}\right)_{t \geq \tau}\right]
\end{aligned}
$$

$$
(n=1,2, \ldots)
$$

The cost of this investment is

$$
K[n T]+k[n T] Q_{2, I}\left[n T \mid\left(\left(m[t], p_{I}[t]\right)_{t \geq \tau},\left(p_{E}[t]\right)_{t \geq \tau}\right),\left(\pi_{t}\right)_{t \geq \tau}\right], \quad(n=1,2, \ldots) .
$$

Next, for each $n=0,1, \ldots$, let

$$
\begin{aligned}
Q_{2, E}[\tau & \left.+n T \mid\left(\left(m[t], p_{I}[t]\right)_{t \geq \tau},\left(p_{E}[t]\right)_{t \geq \tau}\right),\left(\pi_{t}\right)_{t \geq \tau}\right] \\
& =2 \sup _{\tau+n T \leq t^{\prime}<\tau+(n+1) T} X_{2, E}\left[\left(\left(m[t], p_{I}[t]\right)_{t \geq \tau},\left(p_{E}[t]\right)_{t \geq \tau}\right), t^{\prime} \mid\left(\pi_{t}\right)_{t \geq \tau}\right],
\end{aligned}
$$

$$
(n=0,1, \ldots)
$$

denote the investment in transmission capacity that the entrant makes at time $\tau+n T$ to provide long-distance service during the time interval $[\tau+n T, \tau+(n+1) T)$. The total cost of constructing the transmission lines (37) is given by

$$
K[\tau+n T]+k[\tau+n T] Q_{2, I}\left[\tau+n T \mid\left(\left(m[t], p_{I}[t]\right)_{t \geq \tau},\left(p_{E}[t]\right)_{t \geq \tau}\right),\left(\pi_{t}\right)_{t \geq \tau}\right]
$$

$$
(n=0,1, \ldots)
$$

Finally, for each $n=0,1, \ldots$, let 


$$
\begin{aligned}
& Q\left[\tau+n \sigma \mid\left(\left(m[t], p_{I}[t]\right)_{t \geq \tau},\left(p_{E}[t]\right)_{t \geq \tau}\right),\left(\pi_{t}\right)_{t \geq \tau}\right]=x_{1}^{\max } \\
& +2 \sup _{\tau+n \sigma \leq t^{\prime}<\tau+(n+1) \sigma}\left(\begin{array}{l}
X_{2, I}\left[\left(\left(m[t], p_{I}[t]\right)_{t \geq \tau},\left(p_{E}[t]\right)_{t \geq \tau}\right), t^{\prime} \mid\left(\pi_{t}\right)_{t \geq \tau}\right] \\
+X_{2, E}\left[\left(\left(m[t], p_{I}[t]\right)_{t \geq \tau},\left(p_{E}[t]\right)_{t \geq \tau}\right), t^{\prime} \mid\left(\pi_{t}\right)_{t \geq \tau}\right]
\end{array}\right)
\end{aligned}
$$

be the investment in the capacity of the local switch in each city that the incumbent makes at time $\tau+n \sigma$, The total cost of such a switch is given by

$$
S[\tau+n \sigma]+s[\tau+n \sigma] Q\left[\tau+n \sigma \mid\left(\left(m[t], p_{I}[t]\right)_{t \geq \tau},\left(p_{E}[t]\right)_{t \geq \tau}\right),\left(\pi_{t}\right)_{t \geq \tau}\right], \quad(n=0,1, \ldots)
$$

\subsection{Payoffs}

Let $\phi[t], t \geq \tau$, be the time path for the access price set by the regulator, $\left(\pi_{t}\right)_{t \geq \tau}$ be a stream of dividends distributed by the telecommunications carriers to each consumer, and $\mathcal{P}=\left(\left(m[t], p_{I}[t]\right)_{t \geq \tau},\left(p_{E}[t]\right)_{t \geq \tau}\right)$ be an admissible combination of price strategies chosen by the incumbent and the entrant after entry has occurred. To define the equilibrium of the post-entry game between the incumbent and the entrant, we first compute the present value of the stream of profits - under the combination of price strategies $\mathcal{P}$ - for the subgame that begin at each of the instants $\tau+n \sigma, n=0,1, \ldots$. To this end, for any nonnegative integer $n$, let $j_{l}[n]$ and $j_{E}[n]$ denote, respectively, the integers that satisfy the following conditions:

$$
j_{I}[n] T \leq \tau+n \sigma<\left(1+j_{I}[n]\right) T
$$

and

$$
\tau+j_{E}[n] T \leq \tau+n \sigma<\tau+\left(1+j_{E}[n]\right) T
$$

As defined, $j_{I}[n] T$ and $\tau+j_{E}[n] T$ represent, respectively, the instants at which the incumbent and the entrant replace their long-distance transmission lines. For the sub- 
game that begins at time $\tau+n \sigma$, if $j_{I}[n] T<\tau+n \sigma$, then there is an infrastructure legacy constraint on the part of the incumbent. More specifically, the volume of long-distance calls that the incumbent can handle during the time interval $j_{I}[n] T \leq t<\left(1+j_{I}[n]\right) T$ cannot exceed $Q_{2, I}\left[j_{l}[n] T \mid \mathcal{P},\left(\pi_{t}\right)_{t \geq \tau}\right]$. On the other hand, if $j_{l}[n] T=\tau+n \sigma$, then at the exact time the sub-game begins, the incumbent makes a new investment by replacing the old long-distance transmission lines. Similarly, if $\tau+j_{E}[n] T<\tau+n \sigma$, then when the sub-game begins, there is an infrastructure legacy constraint on the part of the entrant. On the other hand, if $\tau+j_{E}[n] T=\tau+n \sigma$, then the entrant will replace its long-distance transmission lines when the sub-game begins. Note that exactly one of these infrastructure legacy constraints holds for the sub-game that begins at time $\tau+n \sigma$.

If $j_{I}[n] T<\tau+n \sigma$, then given the time path of the access price $\phi[t], t \geq \tau$, the time path of dividends $\left(\pi_{t}\right)_{t \geq \tau}$, and the combination of strategies $\mathcal{P}$, the present value of the stream of profits earned by the incumbent in the sub-game that begins at time $\tau+n \sigma$ is

$$
\begin{aligned}
\Pi_{I}^{\tau+n \sigma}\left[\mathcal{P} \mid(\phi[t])_{t \geq \tau},\left(\pi_{t}\right)_{t \geq \tau}\right] & = \\
2 \int_{\tau+n \sigma}^{\infty} e^{-r t}(m[t] & \left.+p_{I}[t] X_{2, I}\left[\mathcal{P}, t \mid\left(\pi_{t}\right)_{t \geq \tau}\right]+\phi[t] X_{2, E}\left[\mathcal{P}, t \mid\left(\pi_{t}\right)_{t \geq \tau}\right]\right) d t \\
& -\int_{\tau+n \sigma}^{\infty} e^{-r t} C_{\text {Labor }}[t] d t \\
& -2 \int_{\tau+n \sigma}^{\left(j_{l}[n]+1\right) T} e^{-r t} C_{\text {LocalLoop }}\left[t-j_{I}[n] T \mid j_{l}[n] T\right] d t \\
& -\int_{\tau+n \sigma}^{\left(j_{I}[n]+1\right) T} e^{-r t} C_{\text {Trunk }}\left[t-j_{I}[n] T \mid j_{I}[n] T, Q_{2, I}\left[j_{l}[n] T \mid \mathcal{P},\left(\pi_{t}\right)_{t \geq \tau}\right]\right] d t
\end{aligned}
$$




$$
\begin{aligned}
& -2 \sum_{i=1}^{\infty}\left(\int_{\left(j_{I}[n]+i\right) T}^{e^{-r\left(j_{I}[n]+i\right) T} \ell\left[\left(j_{I}[n]+i\right) T\right]+}\left(C_{\text {LocalLoop }}\left[t-\left(j_{I}[n]+i\right) T \mid\left(j_{I}[n]+i\right) T\right] e^{-r t} d t\right)\right. \\
& -\sum_{i=1}^{\infty}\left(\begin{array}{l}
e^{-r\left(j_{I}[n]+i\right) T}\left(K\left[\left(j_{I}[n]+i\right) T\right]+k\left[\left(j_{I}[n]+i\right) T\right] Q_{2, I}\left[\left(j_{I}[n]+i\right) T \mid \mathcal{P},\left(\pi_{t}\right)_{t \geq \tau}\right]+\right) \\
\left.\int_{\left(j_{I}[n]+i+1\right) T} C_{T r t n k}\left[t-\left(j_{I}[n]+i\right) T \mid\left(j_{I}[n]+i\right) T\right], Q_{2, I},\left[\left(j_{I}[n]+i\right) T \mid \mathcal{P},\left(\pi_{t}\right)_{t \geq \tau}\right]\right] e^{-r t} d t
\end{array}\right) \\
& -2 \sum_{i=0}^{\infty}\left(\begin{array}{l}
e^{-r(\tau+(n+i) \sigma)}\left(\begin{array}{l}
S[\tau+(n+i) \sigma] \\
+s[\tau+(n+i) \sigma] Q\left[\tau+(n+i) \sigma \mid \mathcal{P},\left(\pi_{t}\right)_{t \geq \tau}\right]
\end{array}\right) \\
+\int_{\tau+n \sigma}^{\tau+(n+1) \sigma} C_{S w i t c h}\left[t-(\tau+n \sigma) \mid(\tau+n \sigma), Q\left[(\tau+n \sigma) \mid \mathcal{P},\left(\pi_{t}\right)_{t \geq \tau}\right]\right] e^{-r t} d t
\end{array}\right) .
\end{aligned}
$$

On the other hand, if $j_{I}[n] T=\tau+n \sigma$, then the present value of the stream of profits earned by the incumbent is given by

$$
\begin{aligned}
& \Pi_{I}^{\tau+n \sigma}\left[\mathcal{P} \mid(\phi[t])_{t \geq \tau},\left(\pi_{t}\right)_{t \geq \tau}\right]= \\
& 2 \int_{\tau+n \sigma}^{\infty} e^{-r t}\left(m[t]+p_{I}[t] X_{2, I}\left[\mathcal{P}, t \mid\left(\pi_{t}\right)_{t \geq \tau}\right]+\phi[t] X_{2, E}\left[\mathcal{P}, t \mid\left(\pi_{t}\right)_{t \geq \tau}\right]\right) d t \\
& -\int_{\tau+n \sigma}^{\infty} e^{-r t} C_{\text {Labor }}[t] d t \\
& -2 \sum_{i=0}^{\infty}\left(\begin{array}{l}
e^{-r\left(j_{l}[n]+i\right) T} \ell\left[\left(j_{I}[n]+i\right) T\right]+ \\
\left.\int_{\left(j_{I}[n]+i\right) T} C_{\text {LocalLoop }}\left[t-\left(j_{I}[n]+i\right) T \mid\left(j_{l}[n]+i\right) T\right]\right] e^{-r t} d t
\end{array}\right) \\
& -\sum_{i=0}^{\infty}\left(\begin{array}{l}
e^{-r\left(j_{I}[n]+i\right) T}\left(K\left[\left(j_{I}[n]+i\right) T\right]+k\left[\left(j_{I}[n]+i\right) T\right] Q_{2, I}\left[\left(j_{I}[n]+i\right) T \mid \mathcal{P},\left(\pi_{t}\right)_{t \geq \tau}\right]\right)+ \\
\left.\left.\int_{\left(j_{I}[n]+i\right) T}^{(n]+i+1) T} C_{T_{r u n k}}\left[t-\left(j_{I}[n]+i\right) T \mid\left(j_{I}[n]+i\right) T\right], Q_{2, I}\left[\left(j_{I}[n]+i\right) T \mid \mathcal{P},\left(\pi_{t}\right)_{t \geq \tau}\right]\right] e^{-r t} d t\right)
\end{array}\right. \\
& -2 \sum_{i=0}^{\infty}\left(\begin{array}{l}
e^{-r(\tau+(n+i) \sigma)}\left(S[\tau+(n+i) \sigma]+s[\tau+(n+i) \sigma] Q\left[\tau+(n+i) \sigma \mid \mathcal{P},\left(\pi_{t}\right)_{t \geq \tau}\right]\right)+ \\
\int_{\tau+n \sigma}^{\tau+(n+1) \sigma} C_{S w i t c h}\left[t-(\tau+n \sigma)\left|(\tau+n \sigma), Q\left[\tau+n \sigma \mid \mathcal{P},\left(\pi_{t}\right)_{t \geq \tau}\right]\right|\right] e^{-r t} d t
\end{array}\right)
\end{aligned}
$$


As for the present value of the stream of profits earned by the entrant in the sub-game, if $\tau+j_{E}[n] T<\tau+n \sigma$, then it is given by

$$
\begin{aligned}
& \Pi_{E}^{\tau+n \sigma}\left[\mathcal{P} \mid(\phi[t])_{t \geq \tau},\left(\pi_{t}\right)_{t \geq \tau}\right]= \\
& 2 \int_{\tau+n \sigma}^{\infty} e^{-r t}\left(p_{E}[t]-\phi[t]\right) X_{2, E}\left[\mathcal{P}, t \mid\left(\pi_{t}\right)_{t \geq \tau}\right] d t-\int_{\tau+n \sigma}^{\infty} e^{-r t} C_{\text {Labor }}[t] d t \\
& -\int_{\tau+n \sigma}^{\tau+\left(j_{E}[n]+1\right) T} e^{-r t} C_{\text {Trunk }}\left[t-\left(\tau+j_{E}[n] T\right) \mid \tau+j_{E}[n] T, Q_{2, E}\left[\tau+j_{E}[n] T \mid \mathcal{P},\left(\pi_{t}\right)_{t \geq \tau}\right]\right] d t \\
& -\sum_{i=1}^{\infty}\left(\begin{array}{l}
e^{-r\left(j_{E}[n]+i\right) T}\left(\begin{array}{l}
K\left[\tau+\left(j_{E}[n]+i\right) T\right]+ \\
\left.k\left[\tau+\left(j_{E}[n]+i\right) T\right] Q_{2, E}\left[\left(\tau+j_{E}[n]+i\right) T \mid \mathcal{P},\left(\pi_{t}\right)_{t \geq \tau}\right]\right]
\end{array}\right)+ \\
\int_{\tau+\left(j_{E}[n]+i\right) T} e^{-r t} C_{T r u n k}\left[\begin{array}{l}
t-\left(\tau+\left(j_{E}[n]+i\right) T\right) \mid \\
\tau+\left(j_{E}[n]+i\right) T, Q_{2, E}\left[\tau+\left(j_{E}[n]+i\right) T \mid \mathcal{P},\left(\pi_{t}\right)_{t \geq \tau}\right]
\end{array}\right]
\end{array}\right)
\end{aligned}
$$

Note that for simplicity, we have assumed that the labor cost of the entrant, who runs only a long-distance network, is the same as the labor cost of the incumbent, who runs a long-distance network and the local network in each city. Hence on the first line of (45) the integral involving the labor costs of the entrant at each instant is the same as that of the incumbent.

Next, if $\tau+j_{E}[n] T=\tau+n \sigma$, then the present value of the stream of profits earned by the entrant is given by 


$$
\begin{aligned}
& \Pi_{E}^{\tau+n \sigma}\left[\mathcal{P} \mid(\phi[t])_{t \geq \tau},\left(\pi_{t}\right)_{t \geq \tau}\right]= \\
& \quad 2 \int_{\tau+n \sigma}^{\infty} e^{-r t}\left(p_{E}[t]-\phi[t]\right) X_{2, E}\left[\mathcal{P}, t \mid\left(\pi_{t}\right)_{t \geq \tau}\right] d t-\int_{\tau+n \sigma}^{\infty} e^{-r t} C_{\text {Labor }}[t] d t \\
& -\sum_{i=0}^{\infty}\left(\begin{array}{l}
e^{-r\left(j_{E}[n]+i\right) T}\left(\begin{array}{l}
K\left[\tau+\left(j_{E}[n]+i\right) T\right]+ \\
k\left[\tau+\left(j_{E}[n]+i\right) T\right] Q_{2, E}\left[\left(\tau+j_{E}[n]+i\right) T \mid \mathcal{P},\left(\pi_{t}\right)_{t \geq \tau}\right]
\end{array}\right)+ \\
\left.\int_{\tau+\left(j_{E}[n]+i+1\right) T} e^{-r t} C_{\text {Trunk }}\left[\begin{array}{l}
t-\left(\tau+\left(j_{E}[n]+i\right) T\right) \\
\tau+\left(j_{E}[n]+i\right) T, Q_{2, E}\left[\tau+\left(j_{E}[n]+i\right) T \mid \mathcal{P},\left(\pi_{t}\right)_{t \geq \tau}\right]
\end{array}\right] d t\right)
\end{array}\right.
\end{aligned}
$$

\subsection{Admissible Deviations and their Payoffs for the Incumbent}

Let $\phi[t], t \geq \tau$, be the time path for the access price set by the regulator, $\left(\pi_{t}\right)_{t \geq \tau}$ be a stream of dividends distributed by the telecommunications carriers to each consumer, and $\mathcal{P}=\left(\left(m[t], p_{I}[t]\right)_{t \geq \tau},\left(p_{E}[t]\right)_{t \geq \tau}\right)$ be a combination of price strategies chosen by the incumbent and the entrant after entry has occurred. Suppose that this combination of price strategies has been carried out until a time immediately before time $\tau+n \sigma, n \geq 0$, when the incumbent decides to deviate from $\left(m[t], p_{I}[t]\right)_{t \geq \tau+n \sigma}$. Let $\left(\hat{m}[t], \hat{p}_{I}[t]\right)_{t \geq \tau+n \sigma}$ be the incumbent's new price strategies in the sub-game that begins at time $\tau+n \sigma$, and

$$
\hat{\mathcal{P}}_{I}=\left(\begin{array}{l}
\left(\left(m[t], p_{I}[t]\right)_{t<\tau+n \sigma},\left(p_{E}[t]\right)_{t<\tau+n \sigma}\right) \\
\left(\left(\hat{m}[t], \hat{p}_{I}[t]\right)_{t \geq \tau+n \sigma},\left(p_{E}[t]\right)_{t \geq \tau+n \sigma}\right)
\end{array}\right) .
$$

We shall denote by $\Gamma^{n}$ the sub-game that begins at time $\tau+n \sigma$. The incumbent's deviation is only admissible if the infrastructure legacy constraints that exist at time 
$\tau+n \sigma$ are respected under the combination of price strategies $\left(\left(\hat{m}[t], \hat{p}_{I}[t]\right)_{t \geq \tau+n \sigma},\left(p_{E}[t]\right)_{t \geq \tau+n \sigma}\right)$. There are three possibilities to consider.

First, if $\tau+n \sigma=j_{I}[n] T$, then the incumbent has no legacy constraint of its own to respect. However, there is a legacy constraint on the part of the entrant. In this case, the deviation by the incumbent is only admissible if

$$
\begin{aligned}
2 X_{2, E}\left[\left(\left(\hat{m}[t], \hat{p}_{I}[t]\right)_{t \geq \tau+n \sigma},\left(p_{E}[t]\right)_{t \geq \tau+n \sigma}\right), t^{\prime} \mid\left(\pi_{t}\right)_{t \geq \tau}\right] \\
\leq Q_{2, E}\left[\tau+j_{E}[n] T \mid \mathcal{P},\left(\pi_{t}\right)_{t \geq \tau}\right]
\end{aligned}
$$

$\left.\tau+n \sigma \leq t^{\prime}<\tau+\left(j_{E}[n]+1\right) T\right)$ Furthermore, the present value of the stream of profits that the incumbent obtains in the sub-game $\Gamma^{n}$ is given by

$$
\begin{gathered}
\hat{\Pi}_{I}^{\tau+n \sigma}\left[\hat{\mathcal{P}}_{I} \mid(\phi[t])_{t \geq \tau},\left(\pi_{t}\right)_{t \geq \tau}\right]= \\
\int_{\tau+n \sigma}^{\infty} e^{-r t}\left(\hat{m}[t]+\hat{p}_{I}[t] X_{2, I}\left[\hat{\mathcal{P}}_{I}, t \mid\left(\pi_{t}\right)_{t \geq \tau}\right]+\phi[t] X_{2, E}\left[\hat{\mathcal{P}}_{I}, t \mid\left(\pi_{t}\right)_{t \geq \tau}\right]\right) d t \\
-\int_{\tau+n \sigma}^{\infty} e^{-r t} C_{\text {Labor }}[t] d t \\
-2 \sum_{i=0}^{\infty}\left(\int_{\left(j_{I}[n]+i\right) T}^{-r\left(j_{I}[n]+i\right) T} \ell\left[\left(j_{I}[n]+i\right) T\right]+\right. \\
\left(j_{I}[n]+i+1\right) T \\
\left.C_{\text {LocalLoop }}\left[t-\left(j_{I}[n]+i\right) T \mid\left(j_{I}[n]+i\right) T\right] e^{-r t} d t\right)
\end{gathered}
$$

$-\sum_{i=0}^{\infty}\left(\begin{array}{l}e^{-r\left(j_{I}[n]+i\right) T}\left(K\left[\left(j_{I}[n]+i\right) T\right]+k\left[\left(j_{I}[n]+i\right) T\right] Q_{2, I}\left[\left(j_{I}[n]+i\right) T \mid \hat{\mathcal{P}}_{I},\left(\pi_{t}\right)_{t \geq \tau}\right]\right)+ \\ \left.\left.\int_{\left(j_{I}[n]+i\right) T}^{\left(j_{I}[n]+i+1\right) T} C_{T n n k}\left[t-\left(j_{I}[n]+i\right) T \mid\left(j_{I}[n]+i\right) T\right], Q_{2, I}\left[\left(j_{I}[n]+i\right) T \mid \hat{\mathcal{P}}_{I},\left(\pi_{t}\right)_{t \geq \tau}\right]\right] e^{-r t} d t\right)\end{array}\right)$

$$
-2 \sum_{i=0}^{\infty}\left(\begin{array}{l}
e^{-r(\tau+(n+i) \sigma)}\left(S[\tau+(n+i) \sigma]+s[\tau+(n+i) \sigma] Q\left[\tau+(n+i) \sigma \mid \hat{\mathcal{P}}_{I},\left(\pi_{t}\right)_{t \geq \tau}\right]\right) \\
+\int_{\tau+n \sigma}^{\tau+(n+1) \sigma} C_{S w i t c h}\left[t-(\tau+n \sigma) \mid(\tau+n \sigma), Q\left[\tau+n \sigma \mid \hat{\mathcal{P}}_{I},\left(\pi_{t}\right)_{t \geq \tau}\right]\right] e^{-r t} d t
\end{array}\right)
$$


If $\tau+n \sigma=\tau+j_{E}[n] T$, then the entrant has no legacy constraint on its own to respect. However, there is a legacy constraint on the part of the incumbent. In this case, the deviation by the incumbent is only admissible if

$$
\begin{array}{r}
2 X_{2, I}\left[\left(\left(\hat{m}[t], \hat{p}_{I}[t]\right)_{t \geq \tau+n \sigma},\left(p_{E}[t]\right)_{t \geq \tau+n \sigma}\right), t^{\prime} \mid\left(\pi_{t}\right)_{t \geq \tau}\right] \leq Q_{2, I}\left[\tau+j_{I}[n] T \mid \mathcal{P},\left(\pi_{t}\right)_{t \geq \tau}\right], \\
\left(\tau+n \sigma \leq t^{\prime}<\left(j_{I}[n]+1\right) T\right) .
\end{array}
$$

Furthermore, the present value of the stream of profits that the incumbent obtains in the sub-game $\Gamma^{n}$ is given by

$$
\begin{aligned}
& \hat{\Pi}_{I}^{\tau+n \sigma}\left[\hat{\mathcal{P}}_{I} \mid(\phi[t])_{t \geq \tau},\left(\pi_{t}\right)_{t \geq \tau}\right]= \\
& \int_{\tau+n \sigma}^{\infty} e^{-r t}\left(\hat{m}[t]+\hat{p}_{I}[t] X_{2, I}\left[\hat{\mathcal{P}}_{I}, t \mid\left(\pi_{t}\right)_{t \geq \tau}\right]+\phi[t] X_{2, E}\left[\hat{\mathcal{P}}_{I}, t \mid\left(\pi_{t}\right)_{t \geq \tau}\right]\right) d t \\
& -\int_{\tau+n \sigma}^{\infty} e^{-r t} C_{\text {Labor }}[t] d t \\
& -\int_{\tau+n \sigma}^{\left(j_{I}[n]+1\right) T} e^{-r t} C_{\text {Localloop }}\left[t-j_{I}[n] T \mid j_{I}[n] T\right] d t \\
& -2 \sum_{i=1}^{\infty}\left(\begin{array}{l}
e^{-r\left(j_{I}[n]+i\right) T} \ell\left[\left(j_{I}[n]+i\right) T\right]+ \\
\left.\left.\int_{\left(j_{I}[n]+i\right) T}^{\left(j_{I}[n]+i+1\right) T} C_{\text {LcalLoop }}\left[t-\left(j_{I}[n]+i\right) T \mid\left(j_{I}[n]+i\right) T\right]\right] e^{-r t} d t\right)
\end{array}\right) \\
& -\int_{\tau+n \sigma}^{\left(j_{I}[n]+1\right) T} e^{-r t} C_{T r u n k}\left[t-j_{I}[n] T \mid j_{I}[n] T, Q_{2, I}\left[j_{I}[n] T \mid \mathcal{P},\left(\pi_{t}\right)_{t \geq \tau}\right]\right] d t
\end{aligned}
$$$$
-\sum_{i=1}^{\infty}\left(\begin{array}{l}
e^{-r\left(j_{I}[n]+i\right) T}\left(K\left[\left(j_{I}[n]+i\right) T\right]+k\left[\left(j_{I}[n]+i\right) T\right] Q_{2, I}\left[\left(j_{I}[n]+i\right) T \mid \hat{\mathcal{P}}_{I},\left(\pi_{t}\right)_{t \geq \tau}\right]\right)+ \\
\left.\left.\int_{\left(j_{I}[n]+i\right) T}^{\left(j_{I}[n]+i+1\right) T} C_{T r u n k}\left[t-\left(j_{I}[n]+i\right) T \mid\left(j_{I}[n]+i\right) T\right], Q_{2, I}\left[\left(j_{I}[n]+i\right) T \mid \hat{\mathcal{P}}_{I},\left(\pi_{t}\right)_{t \geq \tau}\right]\right] e^{-r t} d t\right)
\end{array}\right)
$$ 


$$
-2 \sum_{i=1}^{\infty}\left(\begin{array}{l}
e^{-r(\tau+(n+i) \sigma)}\left(S[\tau+(n+i) \sigma]+s[\tau+(n+i) \sigma] Q\left[\tau+(n+i) \sigma \mid \hat{\mathcal{P}}_{I},\left(\pi_{t}\right)_{t \geq \tau}\right]\right) \\
+\int_{\tau+n \sigma}^{\tau+(n+1) \sigma} C_{S w i t c h}\left[t-(\tau+n \sigma) \mid(\tau+n \sigma), Q\left[\tau+n \sigma \mid \hat{\mathcal{P}}_{I},\left(\pi_{t}\right)_{t \geq \tau}\right]\right] e^{-r t} d t
\end{array}\right)
$$

If $\tau+n \sigma$ is greater than both $j_{I}[n] T$ and $\tau+j_{E}[n] T$, then there are two legacy constraints - one for the incumbent and one for the entrant - that must be taken into account when the sub-game begins. In this case, the deviation by the incumbent is only admissible if the following two constraints are satisfied:

$$
2 X_{2, I}\left[\hat{\mathcal{P}}_{I}, t \mid\left(\pi_{t}\right)_{t \geq \tau}\right] \leq Q_{2, I}\left[\tau+j_{I}[n] T \mid \mathcal{P},\left(\pi_{t}\right)_{t \geq \tau}\right], \quad\left(\tau+n \sigma \leq t<\left(j_{I}[n]+1\right) T\right),
$$

and

$$
2 X_{2, E}\left[\hat{\mathcal{P}}_{I}, t \mid\left(\pi_{t}\right)_{t \geq \tau}\right] \leq Q_{2, E}\left[\tau+j_{E}[n] T \mid \mathcal{P},\left(\pi_{t}\right)_{t \geq \tau}\right], \quad\left(\tau+n \sigma \leq t<\tau+\left(j_{E}[n]+1\right) T\right)
$$

The present value of the stream of profits that the incumbent obtains in the sub-game $\Gamma^{n}$ under the new price strategy is then given by (51).

\subsection{Admissible Deviations and their Payoffs for the Entrant}

Let $\phi[t], t \geq \tau$, be the time path for the access price set by the regulator, $\left(\pi_{t}\right)_{t \geq \tau}$ be a stream of dividends distributed by the telecommunications carriers to each consumer, and $\mathcal{P}=\left(\left(m[t], p_{l}[t]\right)_{t \geq t},\left(p_{E}[t]\right)_{t \geq t}\right)$ be a combination of price strategies chosen by the incumbent and the entrant after entry has occurred. Suppose that this combination of price strategies has been carried out until a time immediately before $\tau+(n-1) \sigma, n \geq 1$, when the entrant decides to deviate from $\left(p_{E}[t]\right)_{t \geq \tau+n \sigma}$ to $\left(\hat{p}_{E}[t]\right)_{t \geq \tau+n \sigma}$. Let 


$$
\hat{\mathcal{P}}_{E}=\left(\begin{array}{l}
\left(\left(m[t], p_{I}[t]\right)_{t<\tau+n \sigma},\left(p_{E}[t]\right)_{t<\tau+n \sigma}\right) \\
\left(\left(m[t], p_{I}[t]\right)_{t \geq \tau+n \sigma},\left(\hat{p}_{E}[t]\right)_{t \geq \tau+n \sigma}\right)
\end{array}\right)
$$

We shall denote by $\Gamma^{n}$ the sub-game that begins at time $\tau+n \sigma$. The entrant's deviation is only admissible if the infrastructure legacy constraints that exist at time $\tau+n \sigma$ are respected under the combination of price strategies $\left((m[t], p[t])_{t \geq \tau+n \sigma},\left(\hat{p}_{E}[t]\right)_{t \geq \tau+n \sigma}\right)$. There are three possibilities to consider.

If $\tau+n \sigma=j_{I}[n] T$, then the incumbent has no legacy constraint on its own to respect. However, there is a legacy constraint on the part of the entrant. In this case, the deviation by the entrant is only admissible if

$$
2 X_{2, E}\left[\hat{\mathcal{P}}_{E}, t \mid\left(\pi_{t}\right)_{t \geq \tau}\right] \leq Q_{2, E}\left[\tau+j_{E}[n] T \mid \mathcal{P},\left(\pi_{t}\right)_{t \geq \tau}\right], \quad\left(\tau+n \sigma \leq t<\tau+\left(j_{E}[n]+1\right) T\right) .
$$

Furthermore, the present value of the stream of profits that the entrant obtains in the subgame $\Gamma^{n}$ under the new price strategy is then given by

$$
\begin{aligned}
& \hat{\Pi}_{E}^{\tau+n \sigma}\left[\hat{\mathcal{P}}_{E} \mid(\phi[t])_{t \geq \tau},\left(\pi_{t}\right)_{t \geq \tau}\right]= \\
& 2 \int_{\tau+n \sigma}^{\infty} e^{-r t}\left(\left(\hat{p}_{E}[t]-\phi[t]\right) X_{2, E}\left[\hat{\mathcal{P}}_{E}, t \mid\left(\pi_{t}\right)_{t \geq \tau}\right]\right) d t-\int_{\tau+n \sigma}^{\infty} e^{-r t} C_{L a b o r}[t] d t \\
& -\int_{\tau+n \sigma}^{\left(j_{E}[n]+1\right) T} e^{-r t} C_{T r u n k}\left[t-j_{E}[n] T \mid j_{E}[n] T, Q_{2, E}\left[j_{E}[n] T \mid \mathcal{P},\left(\pi_{t}\right)_{t \geq \tau}\right]\right] d t \\
& -\sum_{i=1}^{\infty}\left(\begin{array}{c}
e^{-r\left(j_{E}[n]+i\right) T}\left(K\left[\left(j_{E}[n]+i\right) T\right]+k\left[\left(j_{E}[n]+i\right) T\right] Q_{2, E}\left[\left(j_{E}[n]+i\right) T \mid \hat{\mathcal{P}}_{E},\left(\pi_{t}\right)_{t \geq \tau}\right]\right) \\
+\int_{\left(j_{l}(n]+i\right) T}^{\left(j_{I}[n]+i+1\right) T} C_{\text {runk }}\left[\begin{array}{l}
t-\left(j_{E}[n]+i\right) T \\
\left.\mid\left(j_{E}[n]+i\right) T\right], Q_{2, E}\left[\left(j_{E}[n]+i\right) T \mid \hat{\mathcal{P}}_{E},\left(\pi_{t}\right)_{t \geq \tau}\right]
\end{array}\right] e^{-r t} d t
\end{array}\right) .
\end{aligned}
$$


If $\tau+n \sigma=\tau+j_{E}[n] T$, then the entrant has no legacy constraint on its own to respect. However, there is a legacy constraint on the part of the incumbent. In this case, the deviation by the entrant is only admissible if

$$
2 X_{2, I}\left[\hat{\mathcal{P}}_{E}, t \mid\left(\pi_{t}\right)_{t \geq \tau}\right] \leq Q_{2, I}\left[j_{I}[n] T \mid \mathcal{P},\left(\pi_{t}\right)_{t \geq \tau}\right], \quad\left(\tau+n \sigma \leq t<\left(j_{I}[n]+1\right) T\right) .
$$

Furthermore, the present value of the stream of profits that the incumbent obtains in the sub-game $\Gamma^{n}$ under the new price strategy is given by

$$
\begin{aligned}
& \hat{\Pi}_{E}^{\tau+n \sigma}\left[\hat{\mathcal{P}}_{E} \mid(\phi[t])_{t \geq \tau},\left(\pi_{t}\right)_{t \geq \tau}\right]= \\
& 2 \int_{\tau+n \sigma}^{\infty} e^{-r t}\left(\left(\hat{p}_{E}[t]-\phi[t]\right) X_{2, E}\left[\hat{\mathcal{P}}_{E}, t \mid\left(\pi_{t}\right)_{t \geq \tau}\right]\right) d t-\int_{\tau+n \sigma}^{\infty} e^{-r t} C_{\text {Labor }}[t] d t \\
& -\sum_{i=0}^{\infty}\left(\begin{array}{l}
e^{-r\left(j_{E}[n]+i\right) T}\left(K\left[\left(j_{E}[n]+i\right) T\right]+k\left[\left(j_{E}[n]+i\right) T\right] Q_{2, E}\left[\left(j_{E}[n]+i\right) T \mid \hat{\mathcal{P}}_{E},\left(\pi_{t}\right)_{t \geq \tau}\right]\right) \\
+\int_{\left(j_{I}[n]+i\right) T}^{\left(j_{I}[n]+i+1\right) T} C_{T r u n k}\left[\begin{array}{l}
t-\left(j_{E}[n]+i\right) T \\
\left.\mid\left(j_{E}[n]+i\right) T\right], Q_{2, E}\left[\left(j_{E}[n]+i\right) T \hat{\mathcal{P}}_{E},\left(\pi_{t}\right)_{t \geq \tau}\right]
\end{array}\right] e^{-r t} d t
\end{array}\right)
\end{aligned}
$$

If $\tau+n \sigma$ is greater than both $j_{I}[n] T$ and $\tau+j_{E}[n] T$, then there are two legacy constraints - one for the incumbent and one for the entrant - that must be taken into account when the sub-game begins. In this case, the deviation by the entrant is only admissible if the following two constraints are satisfied:

$$
2 X_{2, E}\left[\hat{\mathcal{P}}_{E}, t \mid\left(\pi_{t}\right)_{t \geq \tau}\right] \leq Q_{2, E}\left[\tau+j_{E}[n] T \mid \mathcal{P},\left(\pi_{t}\right)_{t \geq \tau}\right], \quad\left(\tau+n \sigma \leq t<\tau+\left(j_{E}[n]+1\right) T\right),
$$

and

$$
2 X_{2, I}\left[\hat{\mathcal{P}}_{E}, t \mid\left(\pi_{t}\right)_{t \geq \tau}\right] \leq Q_{2, I}\left[j_{I}[n] T \mid \mathcal{P},\left(\pi_{t}\right)_{t \geq \tau}\right], \quad\left(\tau+n \sigma \leq t<\left(j_{l}[n]+1\right) T\right)
$$

The present value of the stream of profits that the entrant obtains in the sub-game $\Gamma^{n}$ under the new price strategy is then given by (56). 


\subsection{Definition of the Sub-Game Perfect Nash Equilibrium}

Let $\phi[t], t \geq \tau$, be the time path for the access price set by the regulator. Given $\phi[t], t \geq \tau$, a admissible combination of price strategies $\mathcal{P}=\left(\left(m[t], p_{l}[t]\right)_{t \geq \tau},\left(p_{E}[t]\right)_{t \geq \tau}\right)$ is said to constitute a sub-game perfect Nash equilibrium if there exists a stream of dividends $\left(\pi_{t}\right)_{t \geq \tau}$ distributed by the telecommunications carriers to each consumer, such that for each $n=0,1, \ldots$, the following two conditions are satisfied:

$$
\begin{aligned}
& \hat{\Pi}_{I}^{\tau+n \sigma}\left[\hat{\mathcal{P}}_{I} \mid(\phi[t])_{t \geq \tau},\left(\pi_{t}\right)_{t \geq \tau}\right] \leq \Pi_{I}^{\tau+n \sigma}\left[\mathcal{P} \mid(\phi[t])_{t \geq \tau},\left(\pi_{t}\right)_{t \geq \tau}\right] \\
& \hat{\Pi}_{E}^{\tau+n \sigma}\left[\hat{\mathcal{P}}_{E} \mid(\phi[t])_{t \geq \tau},\left(\pi_{t}\right)_{t \geq \tau}\right] \leq \Pi_{E}^{\tau+n \sigma}\left[\mathcal{P} \mid(\phi[t])_{t \geq \tau},\left(\pi_{t}\right)_{t \geq \tau}\right]
\end{aligned}
$$

and

$$
\int_{\tau}^{\infty} \pi_{t} e^{-r t} d t=\frac{1}{2}\left(\Pi_{I}^{0}\left[\mathcal{P} \mid(\phi[t])_{t \geq \tau},\left(\pi_{t}\right)_{t \geq \tau}\right]+\Pi_{E}^{0}\left[\mathcal{P} \mid(\phi[t])_{t \geq \tau},\left(\pi_{t}\right)_{t \geq \tau}\right]\right)
$$

In (61),

$$
\hat{\mathcal{P}}_{T}=\left(\begin{array}{c}
\left(\left(m[t], p_{I}[t]\right)_{t<\tau+n \sigma},\left(p_{E}[t]\right)_{t<\tau+n \sigma}\right) \\
\left(\left(\hat{m}[t], \hat{p}_{I}[t]\right)_{t \geq \tau+n \sigma},\left(p_{E}[t]\right)_{t \geq \tau+n \sigma}\right)
\end{array}\right),
$$

and ( $\left.\hat{m}[t], \hat{p}_{l}[t]\right)_{t \geq \tau+n \sigma}$ is an admissible deviation at time $\tau+n \sigma$ for the incumbent, given that the combination of price strategies $\mathcal{P}=\left(\left(m[t], p_{I}[t]\right)_{t \geq \tau},\left(p_{E}[t]\right)_{t \geq \tau}\right)$ has been played prior to that time. Similarly, In (62),

$$
\hat{\mathcal{P}}_{E}=\left(\begin{array}{l}
\left(\left(m[t], p_{I}[t]\right)_{t<\tau+n \sigma},\left(p_{E}[t]\right)_{t<\tau+n \sigma}\right) \\
\left(\left(m[t], p_{I}[t]\right)_{t \geq \tau+n \sigma},\left(\hat{p}_{E}[t]\right)_{t \geq \tau+n \sigma}\right)
\end{array}\right)
$$

and $\left(\hat{p}_{E}[t]\right)_{t \geq \tau+n \sigma}$ is an admissible deviation at time $\tau+n \sigma$ for the entrant, given that the combination of price strategies $\mathcal{P}=\left(\left(m[t], p_{I}[t]\right)_{t \geq t},\left(p_{E}[t]\right)_{t \geq \tau}\right)$ has been played prior to that time. Also, note that (63) represents the constraint that the sum of the present value of the stream of profits of the incumbent and the present value of the stream of profits of 
the entrant constitute the present value of the stream of dividends received by all the consumers in the two cities.

\section{THE OPTIMAL PRICE OF ACCESS}

Let $(\phi[t])_{t \geq \tau}$ be the time path for the access price set by the regulator, and

$$
\mathcal{P}\left[(\phi[t])_{t \geq \tau}\right]=\left(\left(m\left[t^{\prime} \mid(\phi[t])_{t \geq \tau}\right]\right)_{t^{\prime} \geq \tau},\left(p_{I}\left[t^{\prime} \mid(\phi[t])_{t \geq \tau}\right]\right)_{t^{\prime} \geq \tau},\left(p_{E}\left[t^{\prime} \mid(\phi[t])_{t \geq \tau}\right]\right)_{t^{\prime} \geq \tau}\right)
$$

be the sub-game perfect Nash equilibrium induced by $(\phi[t])_{t \geq \tau}$. Also, let $\left(\pi_{t}\right)_{t \geq \tau}$ denote the stream of dividends distributed to each consumer under the sub-game perfect Nash equilibrium. The present value of the social welfare obtained under the policy $(\phi[t])_{t \geq \tau}$ is given by

$$
\Omega\left[(\phi[t])_{t \geq \tau}\right]=\int_{\underline{\underline{\theta}}}^{\infty}\left(\sum_{n=0}^{\infty} \omega\left[\tau+n \sigma \mid \mathcal{P}\left[(\phi[t])_{t \geq \tau}\right], \theta\right]\right) d F[\theta]
$$

where we have let

$$
\begin{aligned}
& \omega[\tau+n\left.\mid \mathcal{P}\left[(\phi[t])_{t \geq \tau}\right], \theta\right]= \\
& \max \left\{\begin{array}{c}
\int_{\tau+n \sigma}^{\tau+(n+1) \sigma} e^{-\rho t^{\prime}} v\left[m\left[t^{\prime} \mid(\phi[t])_{t \geq \tau}\right], p_{I}\left[t^{\prime} \mid(\phi[t])_{t \geq \tau}\right], \theta e^{\gamma\left[t^{\prime}\right]}+\pi_{t}\right] d t^{\prime}, \\
\int_{\tau+n \sigma}^{\tau+(n+1) \sigma}\left(e^{-\rho t^{\prime}} v\left[m\left[t^{\prime} \mid(\phi[t])_{t \geq \tau}\right], p_{E}\left[t^{\prime} \mid(\phi[t])_{t \geq \tau}\right], \theta e^{\gamma\left[t^{\prime}\right]}+\pi_{t}\right]-\varepsilon(\theta-\underline{\theta})^{2} e^{2 \gamma\left[t^{\prime}\right]}\right) d t^{\prime}
\end{array}\right\} \\
&(n=0,1, \ldots) .
\end{aligned}
$$

denote the discounted welfare during the time interval $I_{n}$ of a consumer of type $\theta$ under the sub-game perfect Nash equilibrium induced by $(\phi[t])_{t \geq t}$. 
The optimal time path for the price of access is obtained by solving the following dynamic Ramsey problem:

$$
\max _{(\phi[t]]_{i 2 z}} \Omega\left[(\phi[t])_{t \geq \tau}\right]
$$

subject to the following constraints:

$$
\begin{aligned}
& \Pi_{I}^{\tau}\left[\mathcal{P}\left[(\phi[t])_{t \geq \tau}\right] \mid(\phi[t])_{t \geq \tau},\left(\pi_{t}\right)_{t \geq \tau}\right] \geq H[\tau \mid \bar{m}, \bar{p}, T], \\
& \Pi_{I}^{\tau+n \sigma}\left[\mathcal{P}\left[(\phi[t])_{t \geq \tau}\right] \mid(\phi[t])_{t \geq \tau},\left(\pi_{t}\right)_{t \geq \tau}\right] \geq 0, \quad(n=1,2, \ldots),
\end{aligned}
$$

and

$$
\Pi_{E}^{\tau+n \sigma}\left[\mathcal{P}\left[(\phi[t])_{t \geq \tau}\right] \mid(\phi[t])_{t \geq \tau},\left(\pi_{t}\right)_{t \geq \tau}\right] \geq 0
$$

$$
(n=0,1, \ldots)
$$

Note that (67) represents the constraint of just compensation for the incumbent due to deregulatory taking, and (68) represents the constraints that the new infrastructure investments that the incumbent makes under the sub-game perfect Nash equilibrium $\mathcal{P}\left[(\phi[t])_{t \geq \tau}\right]$ must earn at least a non-negative discounted profit for the sub-game that begins at time $\tau+n \sigma, n=0,1, \ldots$ As for (69), it represents the constraints that the infrastructure investments that the entrant makes under the sub-game perfect Nash equilibrium $\mathcal{P}\left[(\phi[t])_{t \geq \tau}\right]$ must earn at least a non-negative discounted profit for the subgame that begins at time $\tau+n \sigma, n=0,1 \ldots$

\section{THE LONG-RUN EQUILIBRIUM}

\subsection{The Solution of the Ramsey Problem in the Long Run}

In this section, we study the behavior of the system in the long run. To this end, suppose that incomes have ceased to grow, and technologies have matured. More specifically, let 


$$
\begin{aligned}
& \gamma=\lim _{t \rightarrow \infty} \gamma[t], \\
& \ell=\lim _{t \rightarrow \infty} \ell[t], \\
& K=\lim _{t \rightarrow \infty} K[t], \\
& k=\lim _{t \rightarrow \infty} k[t], \\
& S=\ell_{i \rightarrow \infty} S[t],
\end{aligned}
$$

and

$$
s=\lim _{t \rightarrow \infty} s[t] .
$$

Also, let

$$
C_{\text {Labor }}=\lim _{t \rightarrow \infty} C_{\text {Labor }}[t]
$$

denote the long-run labor costs of running a network at each instant,

$$
C_{\text {Localloop }}[h]=\lim _{t \rightarrow \infty} C_{\text {Localloop }}[h \mid t]
$$

denote the long-run costs of repair and maintenance of the local loops in a city that are incurred at each instant, given that the age of the loops is $h$. For a local switch that is $h$ years old and that was constructed to route $Q$ calls, the long-run costs of repair and maintenance that are incurred at each instant are

$$
C_{\text {Switch }}[h \mid Q]=\lim _{t \rightarrow \infty} C_{\text {Switch }}[h \mid t, Q]
$$

As for the trunks that are $h$ years old, and that were constructed to transport $Q_{2}$ longdistance calls, the long-run costs of repair and maintenance that are incurred at each instant are

$$
C_{\text {Trunk }}\left[h \mid Q_{2}\right]=\lim _{t \rightarrow \infty} C_{\text {Trunh }}\left[h \mid t, Q_{2}\right] .
$$

To find the long-run equilibrium, consider a point in time in the distant future. Without any loss in generality, we shall normalize this point in time as time 0 . To find the long- 
run equilibrium, let $p_{I}$ and $p_{E}$ be the prices that the incumbent and the entrant charge for their long-distance service in the long run, respectively. Also, let $\phi$ be the price of access in the long run that is set by the regulator.

Consider an arbitrary point in time in the distant future which is the starting point of a sub-game; that is, at that point in time the incumbent replaces the local switch in each city. Let $m, p_{1}$, and $p_{E}$ represent, respectively, the fixed monthly fee, the price of longdistance calls charged by the incumbent, and the price of long-distance calls charged by the entrant. Also, let $\pi$ be the dividend that a consumer receives from the two telecommunications carriers at each instant in the long run. As in the previous sections, we continue to presume that it is not optimal for the incumbent to set the fixed monthly fee at a level that induces some consumers not to get connected. This presumption means that in equilibrium all consumers subscribe to the local service offered by the incumbent, and the only impact of the magnitude of the fixed monthly fee on the behavior of a consumer is to determine the consumer's residual income - to be spent on the numéraire and long-distance calls - after paying for the local service. Given $\left(m, p_{I}, p_{E}\right)$ and $\pi$, the volume of long-distance calls provided by the incumbent and the volume of long-distance calls provided by the entrant in the long run are given, respectively, by $X_{2, I}\left[m, p_{I}, p_{E} \mid \pi\right]$ and $X_{2, E}\left[m, p_{1}, p_{E} \mid \pi\right]$.

\subsection{The Entrant's Profit Maximization Problem in the Long Run}

Because capacity is fully utilized in the long run, $2 X_{2, E}\left[m, p_{I}, p_{E} \mid \pi\right]$ must be equal to the capacity of the transmissions lines that the entrant replaces at regular time intervals of 
length $T$ in the long run. The discounted profit - discounted to the time the new capacity is installed - that the entrant earns during a cycle (the time interval that encompasses two successive dates of transmission capacity replacements) is given by

$$
\begin{array}{r}
S_{E}\left[m, p_{I}, p_{E} \mid \phi, \pi\right]=2 \int_{0}^{T} e^{-r t}\left(p_{E}-\phi\right) X_{2, E}\left[m, p_{I}, p_{E} \mid \pi\right] d t \\
-\int_{0}^{T} e^{-r t} C_{\text {Labor }} d t-\int_{0}^{T} e^{-r t} C_{\text {Trunk }}[t] d t \\
\quad-\left(K+2 k X_{2, E}\left[m, p_{l}, p_{E} \mid \pi\right]\right) .
\end{array}
$$

Given $\phi,\left(m, p_{I}\right)$, and $\pi$, the value of $p_{E}$ that maximizes (70) is the best response of the entrant to $\left(m, p_{I}\right)$. The following first-order condition characterizes this best response:

$$
\frac{\partial \varsigma_{E}}{\partial p_{E}}\left[m, p_{I}, p_{E} \mid \phi, \pi\right]=0
$$

\subsubsection{The Incumbent's Profit Maximization Problem in the Long Run}

Because in the long run capacities are fully utilized, the capacities of the transmission lines and the local switch in each city that the incumbent must replace at regular time intervals are given, respectively, by $2 X_{2, I}\left[m, p_{l}, p_{E} \mid \pi\right]$ and

$$
x_{1}^{\max }+2\left(X_{2, I}\left[m, p_{l}, p_{E} \mid \pi\right]+X_{2, E}\left[m, p_{l}, p_{E} \mid \pi\right]\right)
$$

The discounted profit - discounted to the time the new capacity is installed - that the incumbent earns during a cycle (the time interval that encompasses two successive dates of capacity replacements) is given by 


$$
\begin{array}{r}
\varsigma_{I}\left[m, p_{I}, p_{E} \mid \phi, \pi\right]=2 \int_{0}^{T} e^{-r t}\left(\begin{array}{l}
m+p_{I} X_{2, I}\left[m, p_{I}, p_{E} \mid \pi\right] \\
+\phi X_{2, E}\left[m, p_{I}, p_{E} \mid \pi\right]
\end{array}\right) d t-\int_{0}^{T} e^{-r t} C_{\text {Labor }} d t \\
-\left(K+2 k X_{2, I}\left[m, p_{I}, p_{E} \mid \pi\right]+\int_{0}^{T} e^{-r t} C_{T_{r u n k}}\left[t \mid 2 X_{2, I}\left[m, p_{I}, p_{E} \mid \pi\right]\right] d t\right) \\
-2 \sum_{n=0}^{(T / \sigma)-1} e^{-n \sigma}\left(\begin{array}{l}
S+s\left(x_{1}^{\max }+2\left(X_{2, I}\left[m, p_{I}, p_{E} \mid \pi\right]+X_{2, E}\left[m, p_{I}, p_{E} \mid \pi\right]\right)\right. \\
+\int_{0}^{\sigma} e^{-r t} C_{\text {Switch }}\left[t \mid x_{1}^{\max }+2\left(X_{2, I}\left[m, p_{I}, p_{E} \mid \pi\right]+X_{2, E}\left[m, p_{I}, p_{E} \mid \pi\right]\right] d t\right)
\end{array}\right.
\end{array}
$$

Given $\phi$ and $\pi$, the best response of the incumbent to $p_{E}$ satisfies the following firstorder condition:

$$
\begin{aligned}
& \frac{\partial \varsigma_{I}}{\partial m}\left[m, p_{I}, p_{E} \mid \phi, \pi\right]=0 \\
& \frac{\partial \varsigma_{I}}{\partial p_{I}}\left[m, p_{I}, p_{E} \mid \phi, \pi\right]=0
\end{aligned}
$$

Given $\phi$ and $\pi$, the first-order conditions (71), (73), and (74) constitute a system of three equations in the three unknowns $m, p_{l}$, and $p_{E}$. We shall assume that this system has a solution, say $\left(m[\phi, \pi], p_{I}[\phi, \pi], p_{E}[\phi, \pi]\right)$.

Now if we let $\psi_{l}[\phi, \pi]$ be the value obtained by spreading evenly over the cycle the costs of investments in infrastructures plus the costs of operating, repairing, and maintaining the network that the incumbent incurs over a cycle, then we have 


$$
\begin{aligned}
& \int_{0}^{T} e^{-r t} \psi_{I}[\phi, \pi] d=\int_{0}^{T} e^{-r t} C_{L a b o r} d t \\
& +\left(\begin{array}{l}
K+2 k X_{2, I}\left[m[\phi, \pi], p_{I}[\phi, \pi], p_{E}[\phi, \pi] \mid \pi\right]+ \\
\int_{0}^{T} e^{-r t} C_{T r u n k}\left[t \mid 2 X_{2, I}\left[m[\phi, \pi], p_{I}[\phi, \pi], p_{E}[\phi, \pi] \mid \pi\right]\right] d t
\end{array}\right)
\end{aligned}
$$

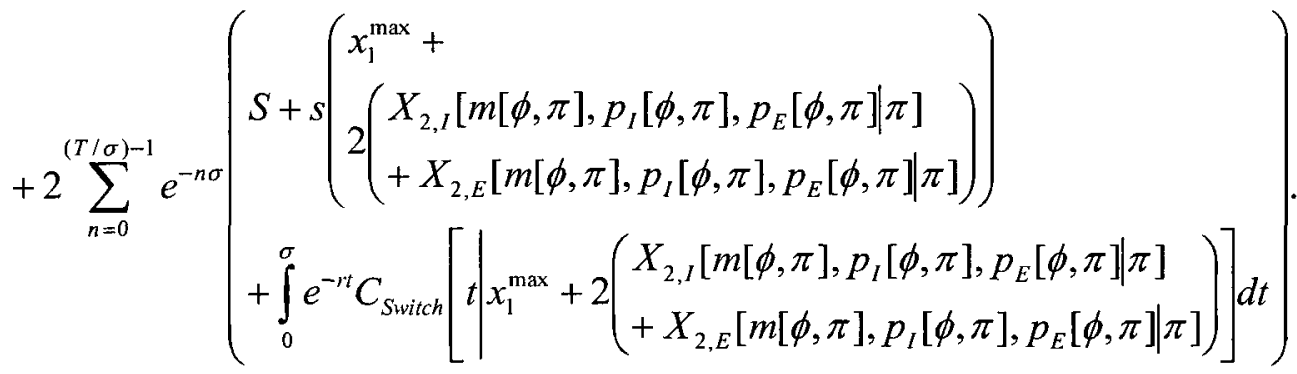

Similarly, if we let $\psi_{E}[\phi, \pi]$ be the value obtained by spreading evenly over the cycle the costs of investments in infrastructures plus the costs of operating, repairing, and maintaining the network that the entrant incurs over a cycle, then we have

$$
\begin{aligned}
\int_{0}^{T} e^{-r t} \psi_{E}[\phi, \pi] d= & \int_{0}^{T} e^{-r t} C_{\text {Labor }} d t \\
& +\left(\begin{array}{l}
K+2 k X_{2, E}\left[m[\phi, \pi], p_{I}[\phi, \pi], p_{E}[\phi, \pi] \pi\right] \\
\left.+\int_{0}^{T} e^{-r t} C_{T r u n k}\left[t \mid 2 X_{2, E}\left[m[\phi, \pi], p_{I}[\phi, \pi], p_{E}[\phi, \pi] \mid \pi\right]\right] d t\right)
\end{array}\right.
\end{aligned}
$$

\subsubsection{The Optimal Price of Access in the Long Run}

The optimal price of access in the long run can be found by finding the values of $\phi$ and $\pi$ that solve the following welfare maximization:

$$
\max _{(\phi, \pi)}\left(\begin{array}{l}
\int_{\underline{\underline{\theta}}}^{\infty} \max \left\{\begin{array}{l}
v\left[m[\phi, \pi], p_{I}[\phi, \pi], \theta e^{\gamma}+\pi\right], \\
v\left[m[\phi, \pi], p_{E}[\phi, \pi], \theta e^{\gamma}+\pi\right]-\varepsilon(\theta-\underline{\theta})^{2} e^{2 \gamma}
\end{array}\right\} d F[\theta]
\end{array}\right)
$$

subject to the constraint 


$$
\pi=\frac{1}{2}\left(\begin{array}{l}
2\left(m[\phi, \pi]+p_{I}[\phi, \pi] X_{2, I}\left[m[\phi, \pi], p_{I}[\phi, \pi], p_{E}[\phi, \pi] \mid \pi\right]\right)-\psi_{I}[\phi, \pi] \\
+2 p_{E}[\phi, \pi] X_{2, E}\left[m[\phi, \pi], p_{I}[\phi, \pi], p_{E}[\phi, \pi] \mid \pi\right]-\psi_{E}[\phi, \pi]
\end{array}\right)
$$

\subsection{A Numerical Example}

For the numerical example, the preference parameters assume the following values

$$
\left\{\alpha \rightarrow \frac{3}{4}, a_{1} \rightarrow 1, b_{1} \rightarrow 1, c_{1} \rightarrow 4, a_{2} \rightarrow 0, b_{2} \rightarrow 1, c_{2} \rightarrow 1, \epsilon \rightarrow 10^{-4},\right.
$$

while the cost parameters assume the following values

$$
\{T \rightarrow 1, \sigma \rightarrow 0.20, l \rightarrow 1, K \rightarrow 0.25, k \rightarrow 0.1, S \rightarrow 0.1, s \rightarrow 0.1, r \rightarrow 0.01\}
$$

For simplicity, the incomes coming from sources other than the ownership of the telecommunications carriers are assumed to be uniformly distributed on the interval $[100,200]$. Also, to concentrate on the pricing strategies of the two firms, we have ignored labor costs as well as repair and maintenance costs. These costs do affect the overall profit, but not their strategies, of the firms. Under these assumptions, the long-run equilibrium is computed for various values of the access price set by the regulator. The results of the calculations are presented in Tables I through IV.

Table I presents the equilibrium combinations of pricing strategies. In the first column of this table are found the various values of the access price $(\phi)$ used in the calculations. The access price ranges from a low value of 3.25 to a high value of 20.25 .In the second column of the table are found the fixed monthly fee $(m)$ the incumbent charges for its local service. The third and fourth columns present the prices of long-distance calls set by the incumbent and the entrant, respectively. 
As can be seen from the second column, the fixed monthly fee is an increasing function of the access price. To understand the intuition behind this result, first note that due to the multiplicative specification of the Dixit-Stiglitz utility function (1), the higher the total income - from partial ownership of the firms and from other sources - of a consumer, the more utility an individual will obtain from the local service, and a fortiori the more she will be willing to pay to get connected to the local service offered by the incumbent. This result can be seen from the discussion leading to (13). Second, as can be seen from the fourth column of Table III, the higher is the access price, the higher will be the flow of industry profits, and the flow of the industry profits constitute the dividends the consumer receives from partial ownership of the two firms. Together, these two results explain why a higher access price leads to a higher willingness to pay for the local service. We also would like to mention that the fixed monthly fee set by the incumbent is the highest level possible without inducing any consumer not to get connected, and the optimal fixed monthly fee is a constant fraction of the total income of the consumer at the lower end of the income scale. Furthermore, it is never optimal for the incumbent to set the fixed monthly fee below the level that induces all consumers to subscribe to the local service. A reduction in the fixed monthly fee implies an equal loss in revenues for the incumbent. However, the extra revenues thus obtained by the consumers will be spent partly on the numéraire and partly on long-distance calls, and thus it does not pay for the incumbent to cut its fixed monthly fee below the highest possible level that captures all the consumers.

The third and fourth columns of Table I list the prices of long-distance calls set by the incumbent and the entrant, respectively. Note that the higher the access price, the higher is the cost of the entrant, and this means the higher the price set by this firm. For the 
incumbent, a higher access price presents some conflicting effects. A higher access price, by raising the cost of the entrant, gives the incumbent a competitive edge in the longdistance segment of the market. A higher price set by the entrant for its long-distance service also allows the incumbent to raise its price of long-distance calls without losing market share. Observe the price differential that the incumbent enjoys from the advantage of one-stop shopping.

Table II presents the equilibrium outputs of the two firms and their market shares, as functions of the access price $(\phi)$. The outputs of the incumbent and the entrant are found, respectively, in the second and third columns of Table II. Observe that as long as the entrant is active in the long-distance segment, the output of the incumbent rises with the access price, but the output of the entrant declines when the access price goes up. Furthermore, industry output declines consistently as the access price rises. In particular when the access price is high enough, entry will not occur. The movement of the market shares reflects the movements of the outputs of the two firms: the incumbent gains market share as the access price rises.

Table III presents the equilibrium profits as the access price rises. In the second and third columns of the table are found the discounted profits - operating revenues minus capacity investments - with the discounting of revenues and costs of switches carried out to the beginning of the cycle. Here recall that a cycle represents the left-closed, right-open time interval between two successive replacements of the transmission lines. The last column represents the constant flow of profit, which constitutes the dividend received distributed to each consumer at each instant. As can be seen from the last column of Table III, the 
income coming from the telecommunications industry exhibits a rising trend when the access price goes up.

Table IV presents the impact of the variation in welfare when the access price rises. As can be seen from the second column of Table IV, welfare first rises, reaches a maximum at the access price of 11.00 , and then declines as the access price continues to rise. Recall from Table I that as the access price rises, a consumer pays more for access to the local networks and the long-distance services provided by both the incumbent and the entrant. The impact of rising prices is negative on consumer welfare. On the other hand, a rise in the access price raises the income obtained from the telecommunications sector. At the beginning, the rise in this source of income dominates the negative effect of higher prices, leading to a rise in consumer welfare. However, when the access price is high enough (around the level of 20.25), the entrant will not enter the market, and the incumbent becomes the de facto monopoly. Under this scenario, the monopoly price of long-distance calls dominates the positive effect of higher dividends. As can be seen from the third column of Table IV, the socially optimal (Ramsey) price of access is $\phi \phi=11.00$.

To study the impact of economic growth on the access price in the long run, we carry out a numerical comparative static analysis by raising the income from other sources by 5 for all consumers. The incomes from sources other than telecommunications are now assumed to be uniformly distributed over the interval [105,205]. Table $\mathrm{V}$ presents the results of the numerical exercise. Observe that the optimal access price is now 10.95, which is lower than that before the rise in income. On the other hand, the equilibrium prices charged by the two firms are now higher than those before the rise in income: the 
rise in incomes generates more demand for long-distance calls, and induces a rise in the prices set by both firms.

To study the impact of technological progress in the telecommunications industry, we now reduce the cost of capacity investments. The marginal cost of capacity investments for transmission lines and for switches - are reduced from 0.1 to 0.01 , while the fixed cost of investments in switches and transmission lines remain the same. As can be expected, the lower costs result in a rise in supply, and the rise in supply induces a fall in the price of long-distance calls to entice consumers into buying more of this service. The new optimal price of access is $\phi=10.90$, which is lower than that before the technological improvement. Also, the prices set by the two firms are now $p_{I}=13.10$ and $p_{E}=12.29$, which are both lower than their levels before the change. As for the fixed monthly fee, it is now $m=4.68$, which is higher than the level before the change: the technological improvement generates more income, and leads to the rise in the fixed monthly fee.

Both income growth and technological progress have similar effects on the access price in the long run: the higher income tends to lower the access price, and so does any technological progress.

\section{THE TRANSITION TO THE LONG-RUN EQUILIBRIUM}

Because of the complexity of the model, the many parameters involved, and the time path of income growth as well as the time paths of technological progress, it is difficult to 
analyze the transition to the long-run equilibrium, and a numerical solution of the model might be necessary. We have used this procedure in studying the behavior of the model in the long run, and will not repeat this exercise here. Instead, we shall try to discern some properties of the transition to the long-run equilibrium by contemplating the behavior of the agents in the model.

First, consider any time interval that encompasses two consecutive replacements of the local switch in each city. During such an interval, the price of access and the price strategies of the two telecommunications carriers do not vary, and the number of consumers who subscribe to each carrier remains the same. Ceteris paribus, the exogenous growth in income will induce each consumer to consume more of the numéraire as well as long-distance calls. This action raises the revenues earned by each carrier at each instant, and a fortiori the dividend received by each consumer. The total income from the two sources thus rises with time during such a time interval, and this means that the number of long-distance calls provided by each telecommunications rises during such a time interval. This last result implies that it is not optimal for the incumbent to have excess switching capacity when the switch is replaced. More specifically, when the local switch in a city is replaced, there is excess switching capacity, and the switch is only used up to capacity at the end of its economic life.

At the beginning, the access price is expected to be high to compensate the incumbent for the infrastructure investments it has already made under the regulatory contract. As time goes on, the compensation for stranded investments become less onerous and the burden 
borne by the access price lessens. Also, the improvements in switching technology will lower the average cost of servicing a call, and the regulator might be able to lower the access price, which helps the entrant to compete more forcefully with the incumbent, and raise social welfare. Thus, we can expect the access price to fall as time goes on.

The rise in income, ceteris paribus, raises the market demand for long-distance calls, and this tends to raise prices. On the other hand, the technological progress in switching and long-distance cables, which lowers investments costs, tends to lower prices. Depending on their relative growth, the price of long-distance calls charged by each telecommunications carrier might rise or fall through time. We might expect the prices of long-distance calls to fall rapidly at the beginning due to the rapid technological progress in switching and transmission. However, when the technologies become mature and productivity tapers off, we should expect a rise in the prices of long-distance calls as income growth drives the growth in demand. The continuous growth in demand for longdistance calls, as in the case of local switches, also implies that the capacity of the longdistance transmission lines are only reached at the end of their economic life when they are replaced.

\section{CONCLUDING REMARKS}

The price of interconnection is an important subject in the economics of telecommunications. There is a large literature on the subject dealing with both one-way and two-way access pricing. However, most of the contributions in this area are static. No formal attempt has been made to model the effects of technological progress and 
economic growth on the telecommunications industry. Furthermore, except for Sidak and Spullber (1997), the issue of deregulatory taking has not received any attention. This paper has presented a model of one-way access pricing in which the compensation involved in deregulatory taking is formalized and then analyzed in great detail. The paper has also modeled explicitly the impact of technological progress and economic growth, which are the most important factors that drive the dynamics of the telecommunications sector. The view taken in the model is that the correct price of access is the Ramsey price. A numerical solution of the model in the long run has been presented. In the numerical example, the optimal access price is computed, and two comparative static analysis exercises - one that deals with the impact of income growth, the other with technological progress - have been carried out. The results of the numerical analysis suggest that in the long run, both economic growth and technological progress help to lower the optimal access price. 


\section{REFERENCES}

“Access Pricing in Telecommunications," : OECD Reports on Access Pricing 2004 at http://www.oecd.org/dataoecd/26/6/27767944.pdf (obtained Feb 12, 2008)

"A Telecom Smorgasbord .- New Law Sets a Table of big Profits and Fights for Local, Long-distance markets", Communications Week. February 26, 1996.

Armstrong, Mark 2002: "The Theory of Access Pricing and Interconnection," Chapter 8 in Handbook of Telecommunications Economics, Volume 1, Ed. By Martin E. Cave, Sumit K. Majumdar, and Ingo Vogelsang, First Edition, 2002, North Holland.

Dixit, Avinash And J. E. Stiglitz 1977: "Monopolistic Competition and Optimum Product Variety," American Economic Review, Vol. 67, No. 3: 297-308. Hausman, Jerry A. 2000: "Regulated Costs and Prices in Telecommunications," Chapter 12, The International Handbook of Telecommunications Economics Volume II; Edited by Gary Madden Scott J Savage, MIT, Cambridge, USA Laffont, Jean-Jacques and Tirole, Jean 2000: "Competition in Telecommunications", MIT Press, 2000.

Sharkey, William W. 2002: "Representation of Technology and Production," Chapter 6 in Handbook of Telecommunications Economics, Volume 1, Ed. By Martin E. Cave, Sumit K. Majumdar, and Ingo Vogelsang, First Edition, 2002, North Holland.

Sherif, Mostafa Hashem 2006: "Managing Projects in Telecommunication Services", Hoboken, NJ : Wiley-Interscience, c2006. 
Sidak, J. Gregory and Spulber, Daniel F 1997: "Deregulatory Takings and the Regulatory Contract : the Competitive Transformation of Network Industries in the United States", Cambridge, [England] ; New York, N.Y. : Cambridge University Press, 1997

Ware, Harold 1998: "Competition and Diversification Trends in Telecommunications: Regulatory, Technological and Market Pressures", Journal of Regulatory Economics 13(1): 59-94.

Zolnierek, James 2006: “A Comparison of Embedded and Forward-looking Local Loop Cost estimates for Small Rural Telephone Companies in Illinois", Published online: 4 October 2006, (C) Springer Science \& Business Media, LLC 2006 
TABLE I

THE LONG-RUN EQUILIBRIUM PRICES FOR VARIOUS VALUES OF THE ACCESS PRICE

( $\phi$ :access price, $m:$ fixed monthly fee, $p_{I}$ : incumbent's price, $p_{E}:$ entrant's price)

$\begin{array}{lccc}\phi & m & p_{I} & p_{E} \\ 3.25 & 4.36 & 6.98 & 5.55 \\ 4.25 & 4.36 & 6.50 & 5.72 \\ 10.25 & 4.60 & 12.65 & 11.79 \\ 10.75 & 4.61 & 13.10 & 12.18 \\ 11.00 & 4.62 & 13.34 & 12.47 \\ 11.20 & 4.63 & 13.54 & 12.68 \\ 11.25 & 4.63 & 13.58 & 12.70 \\ 11.30 & 4.63 & 13.59 & 12.70 \\ 11.75 & 4.64 & 14.38 & 13.44 \\ 12.00 & 4.64 & 14.26 & 13.42 \\ 12.25 & 4.65 & 14.48 & 13.65 \\ 15.25 & 4.70 & 17.03 & 20.25 \\ 20.25 & 4.71 & 20.07 & 17.03\end{array}$


TABLE II

\section{EQUILIBRIUM OUTPUTS AND MARKET SHARES}

( $X_{2, I}$ : output of incumbent, $X_{2, E}$ : output of entrant, $X_{2, I}+X_{2, E}$ : industry output, $m s_{I}$ : market share of incumbent, $m s_{E}$ : market share of entrant)

$\begin{array}{llllll}\phi & X_{2, I} & X_{2, E} & X_{2, I}+X_{2, E} & m s_{I} & m s_{E} \\ 3.25 & 0.39 & 0.42 & 0.80 & 0.48 & 0.52 \\ 4.25 & 0.50 & 0.30 & 0.80 & 0.62 & 0.38 \\ 10.25 & 0.42 & 0.20 & 0.62 & 0.68 & 0.32 \\ 10.75 & 0.41 & 0.20 & 0.61 & 0.67 & 0.33 \\ 11.00 & 0.41 & 0.19 & 0.61 & 0.68 & 0.32 \\ 11.20 & 0.41 & 0.18 & 0.60 & 0.69 & 0.31 \\ 11.25 & 0.41 & 0.19 & 0.60 & 0.68 & 0.32 \\ 11.30 & 0.41 & 0.19 & 0.60 & 0.68 & 0.32 \\ 11.75 & 0.40 & 0.18 & 0.58 & 0.68 & 0.32 \\ 12.00 & 0.41 & 0.17 & 0.58 & 0.70 & 0.30 \\ 12.25 & 0.41 & 0.17 & 0.58 & 0.71 & 0.29 \\ 15.25 & 0.50 & 0 & 0.50 & 1.00 & 0 \\ 20.25 & 0.43 & 0 & 0.43 & 1.00 & 0\end{array}$


TABLE III

\section{FIRMS' PROFITS AND INDUSTRY PROFITS}

$\left(\Pi_{I}:\right.$ discounted profit of incumbent for a cycle, $\Pi_{E}$ : discounted profit of entrant during acycle,,$\frac{r\left(\Pi_{I}+\Pi_{E}\right)}{1-e^{-r}}$ : the sum $\Pi_{I}+\Pi_{E}$ conveted into a constant flow)

$\phi \quad \Pi_{I} \quad \Pi_{E} \quad \frac{r\left(\Pi_{I}+\Pi_{E}\right)}{1-e^{-r}}$

$\begin{array}{llll}3.25 & 11.59 & 1.61 & 13.27 \\ 4.25 & 12.54 & 0.60 & 13.21 \\ 10.25 & 19.14 & 0.35 & 19.58 \\ 10.75 & 19.47 & 0.32 & 19.87 \\ 11.00 & 19.65 & 0.29 & 20.04 \\ 11.20 & 19.79 & 0.28 & 20.17 \\ 11.25 & 19.81 & 0.28 & 20.19 \\ 11.30 & 19.83 & 0.26 & 20.19 \\ 11.75 & 20.18 & 0.35 & 20.63 \\ 12.00 & 20.26 & 0.22 & 20.59 \\ 12.25 & 20.40 & 0.20 & 20.70 \\ 15.25 & 21.88 & 0 & 21.99 \\ 20.25 & 22.26 & 0 & 22.37\end{array}$


TABLE IV

WELFARE

$\begin{array}{lr}\phi & \text { Welfare } \\ 3.25 & 48.9708 \\ 4.25 & 48.9921 \\ 10.25 & 49.4177 \\ 10.75 & 49.4211 \\ 11.00 & 49.4241 \\ 11.20 & 49.4224 \\ 11.25 & 49.4218 \\ 11.30 & 49.4225 \\ 11.75 & 49.4127 \\ 12.00 & 49.4177 \\ 12.25 & 49.4116 \\ 15.25 & 49.3632 \\ 20.25 & 49.1166\end{array}$


TABLE V

IMPACT OF ECONOMIC GROWTH

$\begin{array}{lcccc}\phi & \text { Welfare } & m & p_{I} & p_{E} \\ 10.75 & 50.7251 & 4.84 & 13.09 & 12.25 \\ 10.95 & 50.7273 & 4.85 & 13.63 & 12.60 \\ 11.00 & 50.7268 & 4.85 & 13.73 & 12.67 \\ 11.20 & 50.724 & 4.86 & 14.01 & 12.9\end{array}$


FIGURE-1: THE DEMAND FOR LONG-DISTANCE CALLS BY A CONSUMER

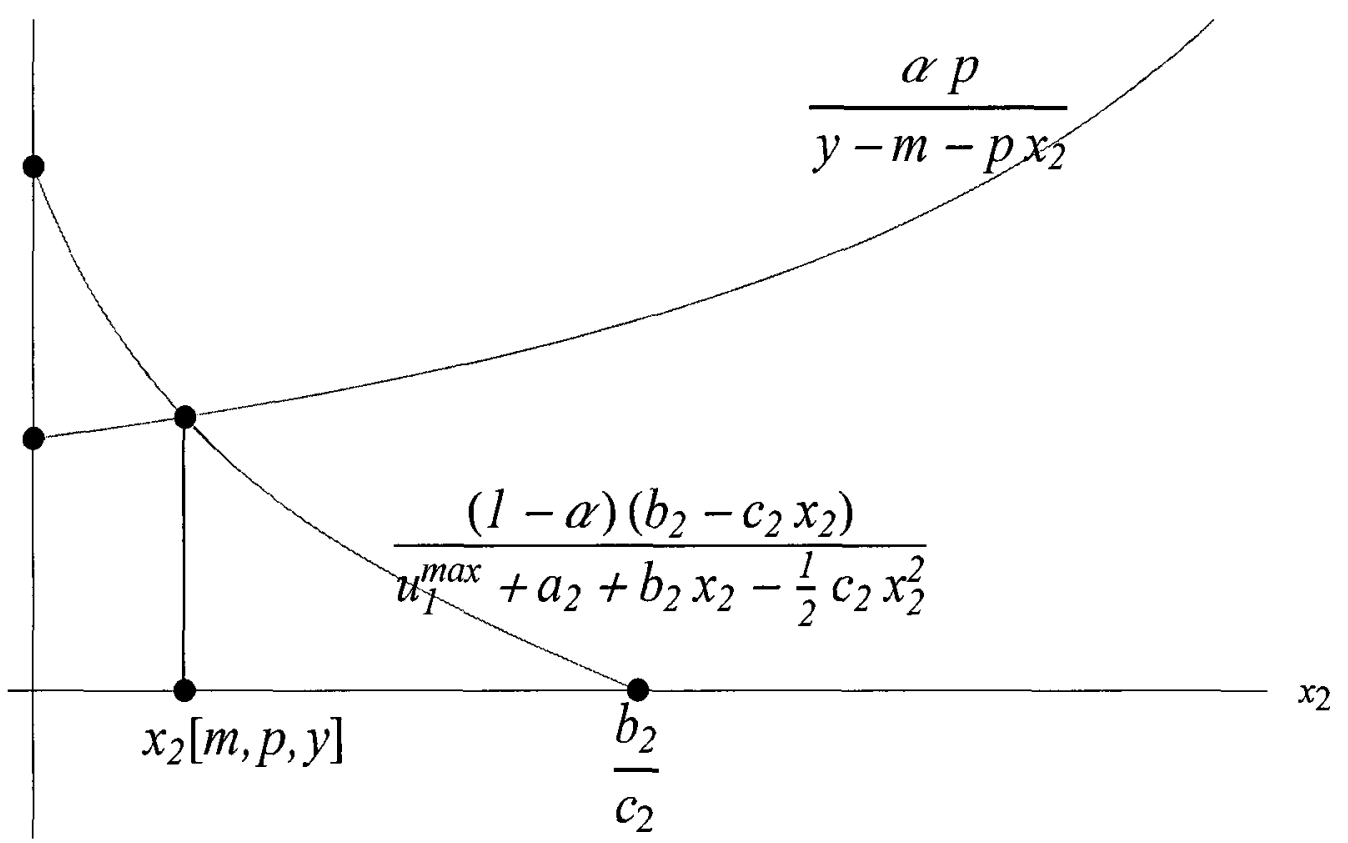




\section{APPENDIX}

\section{LONG RUN EQUILIBRIUM}

We carried out the computations of Long-run equilibrium with different values for $\phi$. However we have appended here the determination of the long-run equilibrium for $\phi=11.75$. For other values of $\phi$ the long run equilibrium can be derived in similar fashion.

\section{The Values of the Parameters}

Preference parameters

parameters $[0]=\left\{\alpha \rightarrow 3 / 4, \mathrm{a}[1] \rightarrow 1, \mathrm{~b}[1] \rightarrow 1, \mathrm{c}[1] \rightarrow 4, \mathrm{a}[2] \rightarrow 0, \mathrm{~b}[2] \rightarrow 1, \mathrm{c}[2] \rightarrow 1, \in \rightarrow 10^{-4}\right\} ;$

Technology parameters

parameters $[1]=\left\{\mathrm{T} \rightarrow 1, \sigma \rightarrow 0.20, \in \rightarrow 10^{-4}\right.$,LocalLoops $\rightarrow 1, \mathrm{~K} \rightarrow 1 / 4, \mathrm{k} \rightarrow 0.1, \mathrm{~S} \rightarrow 1 / 10, \mathrm{~s} \rightarrow 0.1, \mathrm{r} \rightarrow$ $0.01\}$

\section{Preferences}

The sub-utility function of local calls

$\mathrm{u}[1]=\mathrm{a}[1]+\mathrm{b}[1] \mathrm{x}-1 / 2 \mathrm{c}[1] \mathrm{x}^{2}$

The sub-utility function of long-distance calls

$u[2]=a[2]+b[2] x-1 / 2 c[2] x^{2} ;$

\section{The saturation number of local calls is $x \max [1]$}

$\mathrm{du}[1]=\mathrm{D}[\mathrm{u}[1], \mathrm{x}]$

$\mathrm{b}[1]-\mathrm{x} c[1]$

$\mathrm{s} 1=$ Solve $[\mathrm{du}[1]==0, \mathrm{x}] / /$ Flatten 
$\{\mathrm{x} \rightarrow \mathrm{b}[1] / \mathrm{c}[1]\}$

$\mathrm{x} \max [1]=\mathrm{x} / \mathrm{s} 1$

$\mathrm{b}[1] / \mathrm{c}[1]$

The saturation utility of local calls is umax[1].

$\mathrm{umax}[1]=\mathrm{u}[1] / \mathrm{x} \rightarrow \mathrm{xmax}[1]$

$\mathrm{a}[1]+\mathrm{b}[1]^{2} /(2 \mathrm{c}[1])$

$\mathrm{xmax}[1]=\mathrm{xmax}[1] /$.parameters $[0]$

$1 / 4$

$\operatorname{umax}[1]=\operatorname{umax}[1] /$ parameters $[0]$

$9 / 8$

The saturation number of long-distance calls is umax[2].

$\mathrm{du}[2]=\mathrm{D}[\mathrm{u}[2], \mathrm{x}]$

$\mathrm{b}[2]-\mathrm{x} \mathrm{c}[2]$

$\mathrm{s} 2=$ Solve $[\mathrm{du}[2]==0, \mathrm{x}] / /$ Flatten

$\{\mathrm{x} \rightarrow \mathrm{b}[2] / \mathrm{c}[2]\}$

$\mathrm{xmax}[2]=\mathrm{x} / \mathrm{s} 2$

$\mathrm{b}[2] / \mathrm{c}[2]$

$\mathrm{umax}[2]=\mathrm{u}[2] / \mathrm{x} \rightarrow \mathrm{x} \max [2]$

$a[2]+b[2]^{2} /(2 c[2])$

$\mathrm{xmax}[2]=\mathrm{xmax}[2] /$ parameters[0]

1

umax[2]/.parameters[0]

$1 / 2$ 


\section{Distribution of Income}

A consumer has two sources of income: (i) income from ownership of telecommunications firms, and (ii) income from other sources. It is assumed that each consumer has an equal share in each of the telecommunications firms, and thus receives the same dividend, say $\Delta y$, from the telecommunications firms. The value of $\Delta y$ is determined in the model.

As for the other source of income, it is exogenous, but varies across consumers. The exogenous income is assumed to be uniformly distributed over the interval $[100,200]$. The total income of the consumers in the model - denoted by $\mathrm{y}$ - is thus uniformly distributed over the interval $[100+\Delta y, 200+\Delta y]$, with $\Delta y$ to be determined in the model. For the calculations, the initial guess for the income coming from ownership of the telecommunications firms is

$\triangle y=20.42126695847423^{\circ}$

20.4213

\section{The Upper Bound for the Fixed Monthly Fee}

The critical value for the fixed monthly fee above which a consumer with income y will choose not to get connected.

$\left.(\mathrm{y}-\mathrm{m})^{\alpha}(\operatorname{umax}[1])^{1-\alpha}==\mathrm{y}^{\alpha}(\mathrm{a}[1]+\mathrm{a}[2])^{1-\alpha}\right)$

$\mathrm{m}=\mathrm{y}\left(1-((\mathrm{a}[1]+\mathrm{a}[2]) / \mathrm{umax}[1])^{(1-\alpha) / a}\right)$

The critical income level - as a function of the fixed monthly fee $\mathrm{m}$ - that only consumers with income at least equal to this level will get connected can be written as 
$\mathrm{y}=\mathrm{m} / \mu$

$\mu=1-((\mathrm{a}[1]+\mathrm{a}[2]) / \mathrm{umax}[1])^{(1-\mathrm{a}) / \alpha}$

Observe that $\mu$ is the fraction of income that a consumer is willing to pay for getting connected. For a fixed monthly fee $\mathrm{m}$, only the consumers with income $\mathrm{y} \geq \mathrm{m} / \mu$ will choose to get connected. The revenues obtained from the connection fees are then given by $\mathrm{m}(1-\mathrm{F}[\mathrm{m} / \mu])$.

$\mu=1-((\mathrm{a}[1]+\mathrm{a}[2]) / \mathrm{umax}[1])^{(1-\mathrm{\alpha}) / \alpha} /$.parameters $[0] / / \mathrm{N}$

0.0385003

The highest value of the fixed monthly fee that the incumbent can charge without any consumer choosing not to get connected is $\mathrm{m}_{0}=\mu$.

$\mathrm{m} 0=(100+\Delta \mathrm{y}) \mu$

4.63625

Observe that the total monthly fees collected from the consumers who choose to get connected decline when $\mathrm{m}$ exceeds the critical level $\mathrm{m}_{0}$. Furthermore, a higher monthly fee leaves a consumer with less residual income to pay for long-distance calls and the numéraire, and this means there will be fewer long-distance calls made, and a fortiori less revenues collected from the long-distance service. Thus, it is never optimal for the incumbent to set the monthly fee above the crtitical level $\mathrm{m}_{0}$.

\section{The Individual Demand for Long-Distance Calls:}

The solution of the first-order condition

foc $=-\alpha p /(y-m-p x)+((1-\alpha) d u[2]) /(\operatorname{umax}[1]+u[2]) /$ parameters $[0]$ 
$(1-x) /\left(4\left(9 / 8+x-x^{2} / 2\right)\right)-(3 p) /(4(-m-p x+y))$

foc $=$ foc//Together

$\left(-8 m-27 p+8 m x-32 p x+20 \mathrm{px}^{2}+8 y-8 x y\right) /\left(4\left(-9-8 x+4 x^{2}\right)(m+p x-y)\right)$

foc=Numerator[foc]//FullSimplify

$8 m(-1+x)+p(-27+4 x(-8+5 x))-8(-1+x) y$

The individual demand for long-distance calls, given the fixed monthly fee, its price, and income

$\mathrm{s} 3=$ Solve $[\mathrm{foc}==0, \mathrm{x}]$

$\left\{\left\{x \rightarrow 1 /(10 p)\left(-2 m+8 p+2 y-\backslash[S q r t]\left(4 m^{2}+8 m p+199 p^{2}-8 m y-8 p y+4 y^{2}\right)\right)\right\},\{x \rightarrow 1 /(10 p)\right.$

$\left.\left(-2 m+8 p+2 y+\left\lfloor[\operatorname{Sqrt}]\left(4 \mathrm{~m}^{2}+8 m p+199 \mathrm{p}^{2}-8 \mathrm{~m} \mathrm{y}-8 \mathrm{p} y+4 \mathrm{y}^{2}\right)\right)\right\}\right\}$

$\mathrm{s} 3 / .\{\mathrm{m} \rightarrow \mathrm{m} 0, \mathrm{p} \rightarrow 8, \mathrm{y} \rightarrow 100\}$

$\{\{x \rightarrow 0.591746\},\{x \rightarrow 5.77644\}\}$

$\mathrm{xmax}[2]$

1

The Individual Demand for Long-distance Calls:

$\mathrm{x} 0\left[\mathrm{~m}_{-}, \mathrm{p} \_, \mathrm{y}\right]:=$ Evaluate$[\mathrm{x} / . \mathrm{s} 3[[1]]]$

$\mathrm{x} 1\left[\mathrm{~m}_{-}, \mathrm{p}_{-}, \mathrm{y}\right]:=\mathrm{If}[\mathrm{x} 0[\mathrm{~m}, \mathrm{p}, \mathrm{y}]>0, \mathrm{x} 0[\mathrm{~m}, \mathrm{p}, \mathrm{y}], 0]$

\section{Instantaneous Individual Utilities}

$v\left[m_{-}, p_{-}, y\right]:=(y-m-p x l[m, p, y])^{\alpha}(u m a x[1]+(u[2] / x \rightarrow x 1[m, p, y]))^{1-\alpha} /$. parameters $[0]$

The utility obtained by an individual, given the combination of strategies ( $m, p I, p E)$

$\left.\omega\left[\mathrm{m}_{-}, \mathrm{pI}, \mathrm{pE}, \mathrm{y}\right]\right]:=\operatorname{Max}\left[\left\{\mathrm{v}[\mathrm{m}, \mathrm{pI}, \mathrm{y}],\left(\left(\mathrm{v}[\mathrm{m}, \mathrm{pE}, \mathrm{y}]-\in(\mathrm{y}-100-\Delta \mathrm{y})^{2}\right) / \cdot\right.\right.\right.$ parameters $\left.\left.\left.[0]\right)\right\}\right]$ 


\section{Instantaneous Consumers' Welfare}

$\Omega\left[\mathrm{m}_{-}, \mathrm{pI}, \mathrm{pE}\right]:=\sum_{\mathrm{i}=0}^{999} 0.001 \omega[\mathrm{m}, \mathrm{pI}, \mathrm{pE}, 100+\Delta \mathrm{y}+0.1 \mathrm{i}]$

\section{The Demand for Long-Distance Calls for Each Firm}

The binary decision variable $\delta$ :

$$
\begin{gathered}
\delta[\mathrm{m}, \mathrm{pI}, \mathrm{pE}, \mathrm{y}]=1: \text { subscribe to the incumbent's long-distance service } \\
\delta[\mathrm{m}, \mathrm{pI}, \mathrm{pE}, \mathrm{y}]=0: \text { subscribe to the entrant's long-distance service } \\
\delta\left[\mathrm{m}_{-}, \mathrm{pI}, \mathrm{pE}, \mathrm{y}\right]:=\mathrm{If}\left[\mathrm{v}[\mathrm{m}, \mathrm{pI}, \mathrm{y}] \geq\left(\mathrm{v}[\mathrm{m}, \mathrm{pE}, \mathrm{y}]-\left(\in(\mathrm{y}-100-\triangle \mathrm{y})^{2} / \text { parameters }[0]\right)\right), 1,0\right]
\end{gathered}
$$

The volume of long-distance calls provided by the incumbent, given a combination of price strategies $(\mathrm{m}, \mathrm{pI}, \mathrm{pE})$

$\mathrm{XI}\left[\mathrm{m} \_, \mathrm{pI}, \mathrm{pE}\right]:=\sum_{\mathrm{i}=0}^{999} 0.001 \delta[\mathrm{m}, \mathrm{pI}, \mathrm{pE}, 100+\Delta \mathrm{y}+0.1 \mathrm{i}] \mathrm{x} 1[\mathrm{~m}, \mathrm{pI}, 100+\Delta \mathrm{y}+0.1 \mathrm{i}]$ The volume of long-distance calls provided by the entrant, given a combination of price strategies (m,pl,pE)

$\mathrm{XE}\left[\mathrm{m} \_, \mathrm{pI} \_\mathrm{pE}\right]:=\sum_{\mathrm{i}=0}^{999} 0.001(1-\delta[\mathrm{m}, \mathrm{pI}, \mathrm{pE}, 100+\Delta \mathrm{y}+0.1 \mathrm{i}]) \mathrm{x} 1[\mathrm{~m}, \mathrm{pl}, 100+\Delta \mathrm{y}+$ $0.1 \mathrm{i}]$

\section{Profits of Incumbent}

The instantaneous profit earned by the entrant, given a combination of price strategies $(\mathrm{m}, \mathrm{pI}, \mathrm{pE})$.

$\pi \mathrm{E}\left[\mathrm{m}, \mathrm{pI}, \mathrm{pE} \_, \phi_{-}\right]:=(\mathrm{pE}-\phi) \mathrm{XE}[\mathrm{m}, \mathrm{pI}, \mathrm{pE}]$

The instantaneous revenue earned by the incumbent in each city, given a combination of price strategies $(\mathrm{m}, \mathrm{pI}, \mathrm{pE})$.

$\pi \mathrm{I}[\mathrm{m}, \mathrm{pI}, \mathrm{pE}, \phi]:=\mathrm{m}+\mathrm{pI} \mathrm{XI}[\mathrm{m}, \mathrm{pI}, \mathrm{pE}]+\phi \mathrm{XE}[\mathrm{m}, \mathrm{pI}, \mathrm{pE}]$ 
The Cost of Rreplacing theTtransmission Lines in the Long run for the Incumbent, given a Combination of Price Strategies (m,pI,pE):

CITrunk[m_,pI_pE_]:=If[XI[m,pl,pE] $>0, K+k$ XI[m,pl,pE],0]/parameters[1]

The Cost of Replacing the Local Switch in Each City in the Long-run for the Incumbent, given a Combination of Price Strategies (m,pI,pE):

$\mathrm{Q}\left[\mathrm{m} \_\mathrm{pI}, \mathrm{pE}\right]:=\mathrm{xmax}[1]+2(\mathrm{XI}[\mathrm{m}, \mathrm{pI}, \mathrm{pE}]+\mathrm{XE}[\mathrm{m}, \mathrm{pl}, \mathrm{pE}])$

The cost of replacing the local switch in a city

cISwitch[m_pI_pE]:=S+s Q[m,pl,pE]/parameters[1]

The cost of replacing the local switch in a city over a cycle

CISwitch[m_pI_pE]: $=\sum_{\mathrm{i}=0}^{4}\left(\operatorname{clSwitch}[\mathrm{m}, \mathrm{pI}, \mathrm{pE}] \mathrm{e}^{-\mathrm{ri} \sigma} /\right.$ parameters[1] $)$

\section{Profits of Incumbent}

The discounted profit earned by the incumbent for a cycle - net of the costs of capacity investment in the long run, with the stream of profits discounted to the beginning of the cycle

$\left.\Pi I\left[m_{-}, \mathrm{pI} \_\mathrm{pE}, \phi\right]\right]:=-(2$ LocalLoops/.parameters[1])-CITrunk[m,pI,pE]-2

CISwitch[m,pI,pE]+(2 $\int_{0}^{\mathrm{T}} \pi \mathrm{I}[\mathrm{m}, \mathrm{pI}, \mathrm{pE}, \phi] \mathrm{e}^{-\mathrm{rt}} \mathrm{dt} /$.parameters[1]/parameters[1]) 


\section{Profits of Entrant}

The cost of the transmission lines for the entrant

CETrunk[m_,pI_,pE_]:=If[XE[m,pI,pE] $>0, K+k$ XE[m,pI,pE],0]/.parameters[1]

The discounted profit earned by the entrant for a cycle in the long run, with the stream of profits discounted to the beginning of the cycle

$\Pi \mathrm{n}\left[\mathrm{m}_{-}, \mathrm{pI}, \mathrm{pE}, \phi\right]:=$

CETrunk[m,pI,pE] $+\left(2 \int_{0}^{\mathrm{T}} \pi \mathrm{E}[\mathrm{m}, \mathrm{pI}, \mathrm{pE}, \phi] \mathrm{e}^{-\mathrm{rt}} \mathrm{dt} /\right.$.parameters[1])/.parameters[1])

Trials and Errors: $\phi=11.75$

Stepsize 0.1

$\mathrm{f}\left[\left\{\xi_{-}, \eta_{-}\right\}\right]:=$Module $[\{\mathrm{tI} 0, \mathrm{tI} 1, \mathrm{tI} 2, \mathrm{tE} 0, \mathrm{tE} 1, \mathrm{tE} 2\}, \mathrm{tI} 0=$ Table $[\Pi I[\mathrm{~m} 0, \xi+0.1 \mathrm{i}, \eta, \phi],\{\mathrm{i}$, $-5,5\}] ; \mathrm{tI} 1$ = Position[tI0, Max[tro]] // Flatten;

$$
\mathrm{tI} 2=\xi+(\mathrm{tI} 1[[1]]-6) 0.1 ; \mathrm{tE} 0=\text { Table }[\mathrm{HE}[\mathrm{m} 0, \mathrm{t} \mathrm{l} 2, \eta+0.1 \mathrm{i}, \phi],\{\mathrm{i},-5,5\}] ; \mathrm{tE} 1=
$$

Position[tE0, Max[tE0]] // Flatten;

$\mathrm{tE} 2=\eta+(\mathrm{tE} 1[[1]]-6) 0.1$

$\{\mathrm{t}[2, \mathrm{tE} 2\}]$

Stepsize: 0.01

$\mathrm{f}\left[\left\{\xi_{-}, \eta_{-}\right\}\right]:=$Module[\{tI0, tI1, tI2, tE0, tE1, tE2 $\}, \operatorname{tI0}=$ Table[חIIm0, $\left.\xi+0.01 \mathrm{i}, \eta, \phi\right]$,

$\{\mathrm{i},-5,5\}] ; \mathrm{t} \mathrm{l} 1=$ Position[tI0, Max[tI0]] // Flatten;

$$
\mathrm{tI} 2=\xi+(\mathrm{tI} 1[[1]]-6) 0.01 ; \mathrm{tE} 0=\text { Table}[\mathrm{IIE}[\mathrm{m} 0, \mathrm{tI} 2, \eta+0.01 \mathrm{i}, \phi],\{\mathrm{i},-5,5\}] ; \mathrm{tE} 1
$$

$=$ Position[tE0, Max[tE0]]// Flatten;

$\mathrm{tE} 2=\eta+(\mathrm{tE} 1[[1]]-6) 0.01$ 
$\{\mathrm{tl} 2, \mathrm{tE} 2\}]$

Finer step size: 0.001

$\mathrm{f}\left[\left\{\xi_{-}, \eta_{-}\right\}\right]:=$Module $[\{\mathrm{tI} 0, \mathrm{tI} 1, \mathrm{tI} 2, \mathrm{tE} 0, \mathrm{tE} 1, \mathrm{tE} 2\}, \mathrm{tI} 0=\operatorname{Table}[\Pi \mathrm{I}[\mathrm{m} 0, \xi+0.001 \mathrm{i}, \eta, \phi]$,

$\{\mathrm{i},-5,5\}] ; \mathrm{tI} 1=$ Position[tI0, Max[tI0]] // Flatten;

$\mathrm{tI} 2=\xi+(\mathrm{tI} 1[[1]]-6) 0.001 ; \mathrm{tE} 0=$ Table $[\Pi \mathrm{E}[\mathrm{m} 0, \mathrm{tI} 2, \eta+0.001 \mathrm{i}, \phi],\{\mathrm{i},-5,5\}] ; \mathrm{tE} 1$

$=$ Position[tE0, Max[tE0]] // Flatten;

$\mathrm{tE} 2=\eta+(\mathrm{tE} 1[[1]]-6) 0.001$

$\{\mathrm{t} l 2, \mathrm{tE} 2\}]$

The access price used in computing the equilibrium

$\phi=11.75$

Initial guess for $\mathrm{pI}$ and $\mathrm{pE}$

$\{\mathrm{pl}, \mathrm{pE}\}=\left\{13.966487476265108^{`}, 13.124874762652693^{`}\right\}$

$\{13.9665,13.1249\}$

The computations

$\{\mathrm{pI}, \mathrm{pE}\}=\mathrm{f}[\{\mathrm{pI}, \mathrm{pE}\}]$

$\{13.9705,13.1199\}$

The Long-Run Equilibrium

The equilibrium price system

$\{\mathrm{m} 0, \mathrm{pI}, \mathrm{pE}\}$

$\{4.63625,13.9705,13.1199\}$

The equilibrium output of each firm

$\mathrm{XI}[\mathrm{m} 0, \mathrm{pI}, \mathrm{pE}]$ 
0.410032

$\mathrm{XE}[\mathrm{m} 0, \mathrm{pl}, \mathrm{pE}]$

0.179043

The equilibrium instantaneous profit of each firm in the long run

$\Pi \mathrm{I}[\mathrm{m} 0, \mathrm{pI}, \mathrm{pE}, \phi]$

20.103

$\Pi \mathrm{E}[\mathrm{m} 0, \mathrm{pI}, \mathrm{pE}, \phi]$

0.220184

Consumers' Welfare

Aggregate consumers' welfare flow

$\Omega[\mathrm{m} 0, \mathrm{pI}, \mathrm{pE}]$

49.4192

Industry Profits

Producers' surplus stock over a cycle converted into flow

$\mathrm{PS}=1 /((1-\mathrm{Exp}[-\mathrm{r}]) / \mathrm{r})(\Pi \mathrm{I}[\mathrm{m} 0, \mathrm{pI}, \mathrm{pE}, \phi]+\Pi \mathrm{E}[\mathrm{m} 0, \mathrm{pI}, \mathrm{pE}, \phi]) /$. parameters $[1]$

20.4249

Testing if the initial guess of $\eta$ is good

PS- $\triangle \mathrm{y}$

0.00366645

Results on welfare

$\phi \quad \Omega$

11.75

49.4192 
Chapter Two

\title{
ACCESS PRICING WITH CONGESTION AND LUMPY INFRASTRUCTURE
}

\author{
INVESTMENTS
}

\section{INTRODUCTION}

Much of the theoretical literature on access pricing of infrastructure prescribes that the access price be set at the marginal cost of the infrastructure. ${ }^{1}$ In proposing this rule of access pricing, the conventional analysis assumes that infrastructure investments are infinitely divisible so that it makes sense to talk about the marginal cost of investment. Often it is the case that investments in infrastructure are lumpy and can only be made in large chunks, and this renders the marginal cost concept meaningless. ${ }^{2}$ Furthermore, cost concept is the social cost which incorporates both the private cost of the investment and the congestion cost, which represents the negative externalities that users of the infrastructure impose on each other. The traditional literature on access pricing also adopts a long-run perspective by treating all investment costs are avoidable and ignores the serious issue of stranded costs. ${ }^{3}$

Additions to existing infrastructures are often lumpy. ${ }^{4}$ In air transport, the addition of a new runway to accommodate a growth in air travel is a lumpy investment. The construction of a second terminal represents an even lumpier investment. In electric

\footnotetext{
${ }^{1}$ For the authoritative exposition on the theory of access pricing, see Armstrong (2002)

${ }^{2}$ See, for example, Turvey (2002), who stressed the inappropriateness of the use of the marginal cost concept in analyzing infrastructure investments.

${ }^{3}$ See Sydee (2009) for a recent analysis of access pricing in telecommunications with stranded costs.

${ }^{4}$ See Turvey, op. cit, for a comprehensive discussion of the lumpiness of inftrastructure investments in air transport, rail transport, and electric transmissions.
} 
transmissions, manufacturers only provide wires at $66 \mathrm{kV}, 132 \mathrm{kV}, 330 \mathrm{kV}, 500 \mathrm{kV} \ldots$ The voltage carried by transmission lines is only able to take on a few levels. When demand for transmission grows, congestion sets in, and the thermal limit of the line might be reached, causing them to sag and fall on trees. An overloaded transmission line might cause voltage instability that leads to the collapse of part of the transmission network. In train operation, congestion takes the form of delays, which are caused by unpredictable events, such as points or signal failures, rolling stock defects, late arrivals of train crews... Passengers must consider possible delays in planning their journeys, and operators have to make allowances for possible delays in scheduling a timetable. Most important enhancements to a rail network involve track upgrades, realignments and recants, signaling upgrades, additional tracks and crossovers, bridge improvements and power supply upgrades. Obviously, some of these enhancements are lumpy investments. Some railway network enhancements are undertaken to increase safety or to allow trains to run at higher train speeds. Others are planned to relieve congestion in some parts of the network or to increase capacity to accommodate new planned services.

When demand for the service of an infrastructure, such as airports, railways, electric transmission system, grows, the capacity of the infrastructure cannot be raised smoothly to accommodate the gradual growth in demand. Because capacity additions can only be made in large chunks, and because capacity enhancements are costly, infrastructure investments are only made infrequently. As demand for the service of the infrastructure grows, the facility will become more and more congested, and a new addition to the existing infrastructure is only made when the congestion and the ensuing negative 
externalities it generates are considerable. From the economic point of view, the rising costs associated with the growing congestion should lead to a higher access price to allocate a scarce resource - the capacity of the existing infrastructure. In practice, congestion is often resolved through rationing of the scarce resource. Because of its lumpy nature, there is an excess capacity immediately after a new addition to the existing infrastructure has just been made. The excess capacity manifests itself through a fall in the access price after the new investment and will remain unchanged before congestion again sets in, and another new capacity addition will be made when the congestion reaches a new critical level. Given the lumpiness of the infrastructure investments, the number of new additions is necessarily bounded from above unless demand for the service of the infrastructure grows without bounds. The cost of a new capacity addition also depends on the improvement of the technology, and a delay in capacity enhancements might reduce costs. However, it is often the case that technological progress might involve lumpier infrastructure investments. Also, because the present value of the cost involved in a capacity addition declines smoothly with time as the investments are pushed further into the future, time has a positive impact in reducing the lumpiness of the costs associated with a new capacity enhancement.

In this paper, we formalize a model of access pricing with congestion and in which investments in infrastructure are lumpy. To fix ideas, we formulate the model in the context of airport infrastructure investments, which captures both the elements of congestion and the lumpiness involved in infrastructure investments. 
Air traffic delays in most of the major cities of the world increased dramatically in the late 1990s. Rapidly growing demand for use of airport runways in major US and European cities exceeded the existing capacity, leading to long delays. Although the delays are caused by many different factors, lack of runway capacity and lack of terminal passenger capacity are mainly responsible ${ }^{5}$ for the delays in air travel. Solutions to the delay problem are now widely discussed in policy circles and in the press. Rothengatter (2003) discussed in detail the limitations of applying the rule of marginal cost pricing in transport infrastructure, and Park (1989), who concluded that a constant optimal access price is subject to significant welfare loss, argued in favour of the need for a time-varying marginal social cost pricing rule. Oum and Zhang (1990) examined the relationship between total congestion tolls and capacity costs, and deduced that the total congestion costs and the total capacity costs depend on the time pattern of traffic growth. Although these authors make theoretically valid points in recognizing the need for a time-varying congestion pricing, they did not provide any formal model to determine the time path of the optimal access price. Rees (1986) analyzed the optimal timing of capacity investments. However, his assumption that all congestion costs are borne by the infrastructure provider is too restrictive. Turvey (2002), like Rees (1986), assumed that all congestion costs are borne by the infrastructure provider and also considered the timing of capacity investment as given instead of determining the timing within the model. Brueckner (2005) provides a theoretical framework for internalizing the congestion caused by air carriers and derives the optimal congestion tolls. His analysis did not address the issue of capacity enhancement and optimal timing of such

\footnotetext{
${ }^{5}$ See Brueckner (2002)
} 
enhancement. Our objective in this paper is to fill part of this lacuna in the literature by developing a dynamic model that takes both congestion costs and the lumpiness of capacity investments into account in determining the time path of the infrastructure investments and the time path of the access price.

Now increasing the size of the congested airport by building another runway or another terminal could be a solution. However, the incentive for an infrastructure provider to enhance the infrastructure is not always guaranteed, and therefore the solution is not that straightforward. A new carrier at a congested airport imposes further delays on all other flights. This delay costs the airline as well as the passengers. The airline incurs the cost in terms of extra salary paid to the crews, fuel costs for extra time flight, etc. while the delay costs the passengers their valuable time. The infrastructure provider may take into account the negative externalities caused by each flight into account and may raise the price to cover and/or reduce the congestion costs. Therefore, the price paid by the airlines will be higher, and this will lead to higher air fares for passengers. However, the problem is, once the infrastructure provider has made the investment, congestion will be reduced and that will lead to a fall in the access price. This fear of getting a lower price once the enhancement has been made discourages the infrastructure provider from taking any initiative for enhancing the infrastructure. A solution of this problem is to guarantee the infrastructure provider a decent rate of return on the investments, and this is the approach we take in this paper. The model of access pricing with congestion and lumpy infrastructure investments that we formulate in this paper is thus a Ramsey pricing problem. 
The paper is organized as follows. In Section 2, the basic model is presented. The model is formulated in continuous time, with quasi-linear preferences and instantaneous congestion costs that depend on both the volume of air travel and the capacity of the infrastructure at each instant. To make the calculations less burdensome, we have assumed that the sub-utility of air travel and the congestion costs are both quadratic. The evolution of demand for air travel is represented by the number of consumers - assumed to be a continuous variable - that rises smoothly with time, but is bounded from above. The boundedness of the number of consumers together with the fact that infrastructure investments are lumpy mean that the number of capacity units installed under the optimal investment program is bounded above. To describe an investment program we must specify the number of capacity units installed and the exact time each of these capacity units is installed. For our purpose, it is sufficient to consider the case in which it is not optimal to install more than three units of capacity. The case in which the optimal investment program requires the installment of more than three units of capacity is straightforward. The optimal infrastructure investment program under the assumption that no more than three units of capacity should be installed can be found by an induction argument on the number of units of capacity that the infrastructure provider chooses to install. In Section 3, we solve the access pricing problem when it is not optimal to install more than one unit of capacity. In Section 4, we solve the problem of access pricing when it is not optimal to install more than two units of capacity. In section 5 , we consider the case in which it is not optimal to install more than three capacity. Some concluding remarks are given in Section 6. 


\section{THE MODEL}

In the model, time is continuous and denoted by $t, t \geq 0$. The time horizon of the model is infinite. There are two symmetric airlines that use the infrastructure of the airport. At each time $t$, there is a continuum of consumers of measure $n_{t}$. To model the rising demand for air travel, we shall assume that $n_{t}$ rises continuously through time and $\lim _{t \rightarrow \infty} n_{t}=\bar{n}<\infty$

The two airlines compete by setting prices. Let $c$ denote their common marginal cost of operation and $\phi_{t}$ denote the access price the airlines must pay the owners of the airport infrastructure at time $t$ for each passenger they serve. For each airline, the marginal cost of serving a passenger at time $t$ is thus given by $c+\phi_{t}$. Under the Bertrand model of competition, the two symmetric airlines will set their prices equal to the marginal cost at each instant and make zero profits. If we let $p_{t}$ denote the price set by the two airlines at time $t$, then we have

$$
p_{t}=c+\phi_{t}
$$

\subsection{Preferences and Demand for Air Travel}

At each instant, the preferences of a consumer are represented by the following quasilinear utility function:

$$
v[y, x, X, K]=y+u[x]-x h[X, K]
$$


In (2), $y$ and $x$ represent, respectively, the consumption of the numeraire and the consumption of air travel. Also, $X$ represents the total volume of air travel that the consumer expects the airport infrastructure to accommodate, and $K$ represents the capacity of the airport infrastructure. On the right side of (2), $u[x]$ represents the subutility function of air travel, and $h[X, K]$ represents the congestion cost, say the time delay over the normal time needed to complete a trip due to congestion. The expression $x h[X, K]$ thus represents the total congestion cost for a consumer who makes $x$ trips. To keep the exposition simple, we shall assume that both the sub-utility function of air travel and the congestion cost of a flight are quadratic. More specifically, we assume that

$$
u[x]=x-\frac{1}{2} x^{2}
$$

and

$$
\begin{aligned}
h[X, K]= & 0 \text { for } 0 \leq X \leq a K, \\
& =\frac{b}{2}(X-a K)^{2} \text { for } a K<X \leq K .
\end{aligned}
$$

In (4), $a, 0<a<1$, and $b>0$ are constants. We interpret $a K$ as the threshold level of total volume of air travel at which congestion begins to set in. This is depicted in Figure-1. At each instant, a consumer solves the following utility maximization problem:

$$
\max _{x} v[y, x, X, K]
$$

subject to the budget constraint

(6) $y+p x=m$. 
In (5), $X$ represents the market volume of air travel that the consumer expects the airport infrastructure to accommodate, and $K$ represents the capacity of this infrastructure both at that instant. Also, $p$ is the price of an air ticket, and $m$ is her income.

Substituting the budget constraint (6) into the objective function (5), we can rewrite the utility maximization problem as follows:

$$
\max _{x} m+x-\frac{1}{2} x^{2}-x(p+h[X, K])
$$

The first-order condition that characterizes the solution of the preceding utility maximization problem is

$$
1-x-p-h[X, K] \leq 0
$$

with equality holding if $x>0$. Given $p, X$, and $K$, the demand for air travel at each instant by a single consumer is then given by

$$
\begin{aligned}
x[p, X, K] & =1-p-h[X, K] \text { if } p+h[X, K]<1 . \\
& =0, \text { otherwise. }
\end{aligned}
$$

Because the price of an air ticket must cover the unit cost of operation plus the access price, we must have $p \geq c+\phi \geq c$. To avoid the unpleasant corner solution that the total volume of air travel reaches the physical limit of the capacity of the airport infrastructure, we shall assume that

$$
p+h[K, K] \geq u^{\prime}[0]=1 \text {. }
$$


This simplifying assumption implies that at any instant, the real cost of a trip - the price of the air ticket plus the congestion cost per trip - exceeds the choke price of air travel when the airport is operating at the physical limit of its infrastructure capacity, with the ensuing consequence that the demand for air travel by each consumer will fall to 0 .

The individual demand for air travel at each instant has the following properties:

(i) $x[p, X, K]=0$ for all $p \geq 1-h[X, K]$;

(ii) it is decreasing in $p$;

(iii) it is decreasing in $X$; and

(iv) it is increasing in $K$.

Given $p, X$ and $K$, the instantaneous surplus enjoyed by a single consumer with a positive demand for air travel at time $t$ is

$$
c s[p, X, K]=\frac{1}{2}(1-p-h[X, K])^{2}
$$

Note that when the demand for air travel by a consumer is positive, the consumer surplus she enjoys is (i) decreasing in $p$; (ii) decreasing in $X$; and (iii) increasing in $K$.

\subsection{The Instantaneous Equilibrium Market Volume of Air Travel}

At each instant, the equilibrium market volume of air travel provided by the two airlines - as a function of the price of an air ticket $p$, the capacity of the airport infrastructure $K$, and the number of consumers $n-$ is the value of $X$ that satisfies the following condition: 
(12) $\frac{1}{n} X=1-p-h[X, K]$

Suppose that $1-p-h[0, K]=1-p>0$. Observe that in Figure-2, the curve

$$
X \rightarrow 1-p-h[X, K], 0 \leq X \leq K
$$

has the following properties:

(i) It is downward-sloping.

(ii) It is above the curve $X \rightarrow X / n$ at $X=0$.

(iii) It is below the horizontal axis at $X=K$.

Hence the curve $X \rightarrow 1-p-h[X, K], 0 \leq X \leq K$, must cross the curve $X \rightarrow X / n$ at a unique point, say $X[p, K, n]$, which is the equilibrium market volume of air travel at that instant, given the price $p$ of an air ticket, the capacity $K$ of the airport infrastructure, and the number $n$ of consumers at that instant.

The equilibrium market volume of air travel at each instant has the following properties:

(i) A rise in $p$ shifts the curve $X \rightarrow 1-p-h[X, K]$ downward, inducing a decline in $X[p, K, n]$.

(ii) A rise in $K$ shifts the curve $X \rightarrow n(1-p-h[X, K])$ upward, inducing a rise in $X[p, K, n]$.

(iii) A rise in $n$ rotates the curve $X \rightarrow X / n$ clockwise around the origin, inducing a rise in $X[p, K, n]$, but a fall in $X[p, K, n] / n$.

(iv) When $n \rightarrow 0, X[p, K, n] \rightarrow 0$. 


\subsection{Social Welfare}

Consider an instant at which the capacity of the airport infrastructure is $K$ and the number of consumers is $n$. If the price of an air ticket is $p$, then the equilibrium market volume of air travel at that instant is $X[p, K, n]$. The surplus enjoyed by a single consumer at that instant is

$$
\begin{aligned}
c s[p, X[p, K, n], K] & =\frac{1}{2}(1-p-h[X[p, K, n], K])^{2} \\
& =\frac{1}{2}(X[p, K, n] / n)^{2},
\end{aligned}
$$

and the global surplus at that instant is

$$
n c s[p, X[p, K, n], K]=\frac{1}{2 n} X[p, K, n]^{2} .
$$

Because the two airlines make zero profit at each instant, (14) also represents the equilibrium social welfare at that instant.

\subsection{Lumpy Infrastructure Investments}

Let $K_{t}$ denote the capacity of the airport infrastructure at time $t$. To capture the fact that investments in infrastructure are lumpy, we shall assume that $K_{t}$ can only take on values that are positive integers. The optimal program of infrastructure investments is the result of the interactions of three factors: the evolution of the number of consumers through time, the lumpiness of investments, and the cost of one unit of capacity. Because the demand for air travel by a consumer at each instant is bounded above by $1-c$, this would be the demand of each consumer if there were neither access fee nor congestion. In reality, the demand for air travel will be much lower than $1-c$ if the cost of investments 
and a fortiori the access fee is high. Thus the market demand at time $t$ is bounded above by $n_{t}(1-c)$, which is in turn bounded above by $\bar{n}(1-c)$. If we let $\bar{K}$ denote the smallest integer that is greater than or equal to $\bar{n}(1-c) / a$, then $\bar{K}$ represents the minimum infrastructure capacity that can meet the market demand for air travel at all times without any congestion, and it is never optimal to install a capacity that is greater than $\bar{K}$ even when the cost of a unit of capacity is low. When the cost of a unit of capacity is high, the optimal number of capacity units to be installed will be strictly less than $\bar{K}$. We shall take for granted that $\bar{n}(1-c) / a$ is not an integer so that $\bar{n}(1-c) / a<\bar{K}$. In what follows we shall assume that $n_{0}(1-c)<a$, which is certainly satisfied if the initial number of consumers is not too large. This simplifying assumption implies that one unit of capacity can meet initial demand without any congestion with the ensuing result that it is not optimal to install more than one unit of capacity at time 0 . We shall only consider the case $\bar{K} \leq 3$; that is, the number of consumers and the marginal cost of operations are such that it is not optimal to install more than three units of capacity. Generalization of the model to the case the number of consumers is large enough to justify the installment of more than three units of capacity is straightforward.

\section{ACCESS PRICING WHEN IT IS NOT OPTIMAL TO INSTALL MORE THAN}

\section{ONE UNIT OF CAPACITY}

When $\bar{K}=1$, the regulator has two choices: (i) do not carry out any infrastructure investment program or (ii) install one unit of capacity. The social welfare obtained under the first choice is obviously 0 . If the second choice is taken, then one unit of capacity is 
installed at time $0,{ }^{6}$ and the only problem that remains is to find a time path, say $\left(\phi_{t}\right)_{t \geq 0}$, for the access price that maximizes discounted social welfare under the constraint that the access fees collected from the two airlines allow the owners of the airport infrastructure to recover their investments. If we let $\left(X_{t}\right)_{t \geq 0}$ denote the time path of the equilibrium market volume of air travel induced by $\left(\phi_{t}\right)_{t \geq 0}$, then according to $(12), \phi_{t}$ and $X_{t}$ are linked by the following relation:

$$
\begin{aligned}
& \phi_{t}=1-c-h\left[X_{t}, K_{t}\right]-\frac{1}{n_{t}} X_{t} \\
&=1-c-h\left[X_{t}, 1\right]-\frac{1}{n_{t}} X_{t} .
\end{aligned}
$$

Because it is technically simpler to use $\left(X_{t}\right)_{t \geq 0}$ than to use $\left(\phi_{t}\right)_{t \geq 0}$, we shall state the regulator's problem under the following form: Find a time path of the market volume of air travel $\left(X_{t}\right)_{t \geq 0}$ to

$$
\max _{\left(X_{t}\right)_{i z 0}} \int_{0}^{\infty} e^{-r t} \frac{1}{2 n_{t}} X_{t}^{2} d t
$$

subject to the revenue constraint

$$
\int_{0}^{\infty} e^{-r t}\left(1-c-h\left[X_{t}, K_{t}\right]-\frac{1}{n_{t}} X_{t}\right) X_{t} d t \geq \gamma
$$

where $\gamma$ is the cost of one unit of capacity. The revenue constraint (17) ensures that the infrastructure provider recovers the cost of her investments.

\footnotetext{
${ }^{6}$ There is the possibility that the initial number of consumers is very low and that at the beginning the number of consumers rises very slowly. Under this scenario, it might be optimal to wait for the number of consumers to rise sufficiently before making any infrastructure investment. This possibility can easily be handled by taking the time that the investment will be made as the starting point of the regulator's problem.
} 
Note that under the optimal solution the revenue constraint must hold with equality. Indeed, if this were not true, then a slight reduction of the access price - or equivalently a slight increase in the equilibrium market volume of air travel - at each instant will raise social welfare at each instant without violating the revenue constraint. Also, in the present case that we are considering, one unit of capacity can serve the market demand for all times without congestion, and the revenue constraint (17) is reduced to

$$
\int_{0}^{\infty} e^{-r t}\left(1-c-\frac{1}{n_{t}} X_{t}\right) X_{t} d t=\gamma
$$

Observe that at any instant if the access price were set equal to 0 then the demand for air travel by a single consumer is $1-c$, and the total access fee collected from a single consumer is also 0 . As the access price rises from 0 , the total access fee collected from a single consumer also rises from 0 , and reaches a maximum equal to $(1-c)^{2} / 4$ when the access fee is equal to $(1-c) / 2$. When the access price rises beyond $(1-c) / 2$, the total access fee collected from a single consumer begins to decline, and falls to 0 when the access price reaches the level $(1-c)$. As for the consumer surplus enjoyed by a single consumer, it declines steadily as the access price rises. Thus, it is never optimal for the regulator to set an access price higher than $(1-c) / 2$ in her efforts to help the owners of the airport infrastructure recover their investments. Let

$$
\bar{\gamma}=\frac{1}{4} \int_{0}^{\infty} e^{-r t} n_{t}(1-c)^{2} d t
$$

denote the present value of the stream of access fees that the owners of the airport infrastructure can extract from the two airlines if they were allowed to exercise their 
monopoly power. The revenue constraint (17) can only be satisfied if $\gamma \leq \bar{\gamma}$, and when $\gamma>\bar{\gamma}$, the owners of the airport infrastructure will not be able to recover the cost of the investment, and no infrastructure investment will ever be carried out. Thus in what follows we shall assume that $\gamma \leq \bar{\gamma}$. Note that as $\gamma$ rises from 0 to $\bar{\gamma}$, the demand for air travel by a single consumer falls from $(1-c)$ to $(1-c) / 2$.

To solve the maximization problem constituted by (16) and (18), let

$$
Z_{t}=\int_{0}^{t} e^{-r s}\left(1-c-\frac{1}{n_{s}} X_{s}\right) X_{s} d s
$$

denote the present value of the stream of revenues be paid by the two airlines to the owners of the airport infrastructure from time 0 up to time $t$. The revenue constraint (18) can be equivalently represented by the following differential equation:

$$
\begin{aligned}
& \frac{d Z}{d t}=e^{-r t}\left(1-c-\frac{1}{n_{t}} X_{t}\right) X_{t}, \\
& Z_{0}=0, \lim _{t \rightarrow \infty} Z_{t}=\gamma .
\end{aligned}
$$

The problem constituted by (16) and (21) is a simple problem in optimal control, and can be solved as follows. First, for any number $\varsigma$ - which can be negative, 0 , or positive and any number $\sigma \geq 0$, let

$$
W_{1}[\varsigma, \sigma, \gamma]=\max _{\left(X_{t}\right)_{2 z t}} \int_{\tau}^{\infty} e^{-r t} \frac{1}{2 n_{t}} X_{t}^{2} d t
$$

subject to 


$$
\begin{aligned}
& \frac{d Z}{d t}=e^{-r t}\left(1-c-\frac{1}{n_{t}} X_{t}\right) X_{t}, \\
& Z_{\sigma}=\varsigma, \lim _{t \rightarrow \infty} Z_{t}=\gamma .
\end{aligned}
$$

As defined, $W_{1}[\varsigma, \sigma, \gamma]$ gives the present value of the stream of social welfare under the optimal solution, given that the system begins at time $\sigma$ and that the present value of the stream of access fees already paid to the owners of the airport infrastructure is equal to $\varsigma$. Note that for $\varsigma=0, \sigma=0$, the optimal-value function $W_{1}[\varsigma, \tau, \gamma]$ gives the maximum present value of the stream of social welfare for the problem constituted by (16) and (21). Note that $\gamma-\varsigma$ is the present value of the stream of access fees that the two airlines pay to the owners of the airport infrastructure during the time interval $[\sigma, \infty)$, which can exceed $\gamma$ if $\varsigma<0$.

Let $X_{t}^{*}$ denote the optimal market volume of air travel at time $t, t \geq 0$, for the problem constituted by (16) and (21). Also, let $Z_{t}^{*}$ denote the present value of the stream of access fees paid by the two airlines to the owner of the airport infrastructure from time 0 up to time $t$ under the optimal solution to the problem constituted by (16) and (21). The evolution of $Z_{t}^{*}$ is governed by the following differential equation

$$
\begin{aligned}
& \frac{d Z^{*}}{d t}=\left(1-c-\frac{1}{n_{t}} X_{t}^{*}\right) X_{t}^{*}, \\
& Z_{0}^{*}=0, \lim _{t \rightarrow \infty} Z_{t}^{*}=\gamma .
\end{aligned}
$$


Next, let

$$
\lambda_{t}=D_{1} W_{1}\left[Z_{t}^{*}, t, \gamma\right]
$$

be the shadow price of the present value of the stream of access fees paid by the two airlines to the owners of the airport infrastructure from time 0 up to time $t$ along the optimal trajectory. Economically, $\lambda_{t}$ represents the rise in discounted social welfare, given that the present value of the stream of access fees paid by the two airlines from time 0 until time $t$ is raised by one dollar, or, equivalently, the rise in discounted social welfare if, say technological progress, happens to lower the present value of the costs of the investment program by one dollar. Clearly, $\lambda_{t}$ is positive.

To continue, define the Hamiltonian

$$
\mathcal{H}[Z, X, \lambda, t]=e^{-r t} \frac{X^{2}}{2 n_{t}}+\lambda e^{-r t}\left(1-c-\frac{1}{n_{t}} X\right) X .
$$

The evolution of $\lambda_{t}$ is governed by the following adjoint equation:

$$
\frac{d \lambda}{d t}=-D_{1} \mathcal{H}\left[Z_{t}^{*}, X_{t}^{*}, \lambda_{t}, t\right]=0
$$

which implies that $\lambda_{t}=\lambda=$ constant.

At each instant, $X_{t}^{*}$ is the value of $X$ that maximizes the following Hamiltonian

$$
\mathcal{H}\left[Z_{t}^{*}, X, \lambda_{t}, t\right]=e^{-r t} \frac{1}{2 n_{t}} X^{2}+\lambda e^{-r t}\left(1-c-\frac{1}{n_{t}} X\right) X
$$

The first-order condition that characterizes the maximization of the Hamiltonian is 


$$
\frac{1}{n_{t}} X+\lambda\left(-\frac{1}{n_{t}} X+1-c-\frac{1}{n_{t}} X\right)=0
$$

which can also be written as

(29) $\frac{1}{n_{t}} X=\frac{\lambda}{2 \lambda-1}(1-c)$.

Thus at each instant the optimal market volume of air travel satisfies the following condition:

$$
\frac{1}{n_{t}} X_{t}^{*}=\frac{\lambda}{2 \lambda-1}(1-c)
$$

According to (30), the demand for air travel by a consumer is constant along the optimal trajectory. Because $X_{t}^{*}>0$, we must have $\lambda /(2 \lambda-1)>0$. Furthermore, we know that $\lambda>0$. Hence $\lambda>1 / 2$. Also, note that $\lambda /(2 \lambda-1)$ is strictly decreasing when $\lambda$ rises.

Using (30), we obtain the following expression for the access price at each instant:

$$
\begin{aligned}
\phi_{t}^{*}= & 1-c-\frac{1}{n_{t}} X_{t}^{*} \\
& =\frac{\lambda-1}{2 \lambda-1}(1-c) .
\end{aligned}
$$

According to (31), the access price is constant along the optimal trajectory. Because $\phi_{t}^{*}>0$, we must have $(\lambda-1) /(2 \lambda-1)>0$. Furthermore, we have already argued that $\lambda>1 / 2$. Hence we must have $\lambda>1$. Also, note that $(\lambda-1) /(2 \lambda-1)$ rises with $\lambda$.

We summarize the results just obtained in the following proposition. 
PROPOSITION 1: When one unit of capacity can serve market demand at all times without congestion, the demand for air travel by a consumer and the access price are both constant through time.

The intuition behind Proposition 1 is not hard to understand. When one unit of capacity can serve demand at all times without congestion, the optimal pricing rule is to set the price of an air ticket equal to the marginal cost of operation plus the access price. Furthermore, the access price is constant through time, i.e., each trip is charged the same price for using the service of the infrastructure. It is worth noting that without congestion the access price serves only to recover the investment costs incurred by the owners of the airport.

To compute the access price, we need to compute the shadow price $\lambda$ from the data of the problem. To this end, using (30) and (31), we can rewrite the revenue constraint (18) as follows:

$$
\begin{gathered}
\int_{0}^{\infty} e^{-r t}\left(\frac{\lambda-1}{2 \lambda-1}(1-c) n_{t} \frac{\lambda}{2 \lambda-1}(1-c)\right) d t=\frac{\lambda(\lambda-1)}{(2 \lambda-1)^{2}}(1-c)^{2} \int_{0}^{\infty} e^{-r t} n_{t} d t \\
=\gamma
\end{gathered}
$$

or equivalently as follows:

$$
\begin{gathered}
q[\lambda]=\frac{\gamma}{(1-c)^{2} \int_{0}^{\infty} e^{-r t} n_{t} d t} \\
=\frac{\gamma}{4 \bar{\gamma}}
\end{gathered}
$$

where we have let 
(33) $\quad q[\lambda]=\frac{\lambda(\lambda-1)}{(2 \lambda-1)^{2}}$

Note that the derivative of the map $q: \lambda \rightarrow q[\lambda], \lambda>1$, is $1 /(2 \lambda-1)^{2}>0$. Hence $q[\lambda], \lambda>1$, is strictly increasing. Furthermore, as $\lambda$ rises from 1 to infinity, $q[\lambda]$ rises from 0 to $1 / 4$. Hence if the revenue constraint (18) is satisfied, (32) determines $\lambda$ uniquely, and the value of $\lambda$ that satisfies (32) is an increasing function of $\gamma$.

As can be seen from (31), the access price depends on the marginal cost of operation $c$ and the shadow price $\lambda$. As can be seen from (32), the shadow price $\lambda$ in turn depends on $\gamma$, the cost of one unit of capacity, $c$, the marginal cost of operation, $n_{t}, t \geq 0$ the evolution of the number of consumers through time, and $r$, the market rate of interest. As already explained, $\lambda$ is the rise in discounted social welfare induced by a decline of one dollar in the cost of the investment program. When investments are lumpy, a marginal increase in capacity cannot be made, and thus the rule of marginal-cost pricing for infrastructure access is not well defined. As such, (31) can be considered as a generalization of the marginal cost pricing rule for infrastructure access. In the presence of lumpy investments, the access price depends in a complex manner on two types of marginal cost - the marginal cost of serving a traveler $(c)$ and the rise in discounted social welfare $(\lambda)$ induced by a fall of one dollar in the cost of the investment program. Furthermore, because the main function of the access price is to recover the investment costs for the infrastructure provider, the shadow price $\lambda$ depends both on the cost of one unit of capacity $(\gamma)$ and on the evolution of demand $\left(n_{t}\right)$. 


\section{ACCESS PRICING WHEN IT IS NOT OPTIMAL TO INSTALL MORE THAN}

TWO UNITS OF CAPACITY

When $\bar{K}=2$, the regulator has two choices: (i) install only one unit of capacity, or (ii) install two units of capacity.

\subsection{Access Pricing when Only One Unit of Capacity is Installed.}

If the owners of the airport infrastructure choose to install only one unit of capacity, then this unit of capacity should be installed at time 0 . The time path of the infrastructure capacity is then given by

$$
K_{t}=1, t \geq 0
$$

The problem of the regulator, given this investment program, is to find a time path of the market volume of air travel $\left(X_{t}\right)_{t \geq 0}$ to

$$
\max _{\left(X_{t}\right)_{t \geq 0}} \int_{0}^{\infty} e^{-r t} \frac{1}{2 n_{t}} X_{t}^{2} d t
$$

subject to the revenue constraint

$$
\int_{0}^{\infty} e^{-r t}\left(1-c-h\left[X_{t}, K_{t}\right]-\frac{1}{n_{t}} X_{t}\right) X_{t} d t=\gamma
$$

The problem constituted by (35) and (36) is a simple problem in optimal control, and can be solved as follows. First, for any number $\varsigma$ - which can be negative, 0 , or positive and any number $\sigma \geq 0$, let 


$$
W_{2}[\varsigma, \sigma, 1, \gamma]=\max _{\left(X_{t}\right)_{2 \geq \tau}} \int_{\tau}^{\infty} e^{-r t} \frac{1}{2 n_{t}} X_{t}^{2} d t
$$

subject to

$$
\begin{aligned}
& \frac{d Z}{d t}=e^{-r t}\left(1-c-h\left[X_{t}, K_{t}\right]-\frac{1}{n_{t}} X_{t}\right) X_{t} \\
& Z_{\sigma}=\varsigma, \lim _{t \rightarrow \infty} Z_{t}=\gamma .
\end{aligned}
$$

As defined, $W_{2}[\varsigma, \sigma, 1, \gamma]$ gives the present value of the stream of social welfare obtained under the optimal solution, given that

(i) it is not optimal to install more than 2 units of capacity;

(ii) only 1 unit of capacity is installed;

(iii) the system begins at time $\sigma$ and that the present value of the stream of access fees already paid to the owners of the airport infrastructure is equal to $\varsigma$.

Note that for $\varsigma=0, \sigma=0$, the optimal-value function $W_{2}[\varsigma, \tau, 1, \gamma]$ gives the maximum present value of the stream of social welfare for the problem constituted by (35) and (36).

Let $X_{t}^{*}$ denote the optimal market volume of air travel at time $t, t \geq 0$, for the problem constituted by (35) and (36). Also, let $Z_{t}^{*}$ denote the present value of the stream of access fees paid by the two airlines to the owner of the airport infrastructure from time 0 up to time $t$ under the optimal solution to the problem constituted by (35) and (36). The evolution of $Z_{t}^{*}$ is governed by the following differential equation

$$
\frac{d Z^{*}}{d t}=\left(1-c-h\left[X_{t}^{*}, K_{t}\right]-\frac{1}{n_{t}} X_{t}^{*}\right) X_{t}^{*}
$$




$$
Z_{0}^{*}=0, \lim _{t \rightarrow \infty} Z_{t}^{*}=\gamma
$$

Next, let

$$
\lambda_{t}=D_{1} W_{2}\left[Z_{t}^{*}, t, 1, \gamma\right]
$$

be the shadow price of the present value of the stream of access fees paid by the two airlines to the owners of the airport infrastructure from time 0 up to time $t$ along the optimal trajectory. Economically, $\lambda_{t}$ represents the rise in discounted social welfare, given that the present value of the stream of access fees paid by the two airlines from time 0 until time $t$ is raised by one dollar, or, equivalently, the rise in discounted social welfare if, say technological progress, happens to lower the present value of the costs of the investment program by one dollar. Clearly, $\lambda_{t}$ is positive.

To continue, define the Hamiltonian

$$
\mathcal{H}[Z, X, \lambda, t]=e^{-r t} \frac{X^{2}}{2 n_{t}}+\lambda e^{-r t}\left(1-c-h\left[X, K_{t}\right]-\frac{1}{n_{t}} X\right) X
$$

The evolution of $\lambda_{t}$ is governed by the following adjoint equation:

$$
\frac{d \lambda}{d t}=-D_{1} \mathcal{H}\left[Z_{t}^{*}, X_{t}^{*}, \lambda_{t}, t\right]=0
$$

which implies that $\lambda_{t}=\lambda=$ constant. Furthermore, at each instant, $X_{t}^{*}$ is the value of $X$ that maximizes the following Hamiltonian

$$
\mathcal{H}\left[Z_{t}^{*}, X, \lambda_{t}, t\right]=e^{-r t} \frac{1}{2 n_{t}} X^{2}+\lambda e^{-r t}\left(1-c-h\left[X, K_{t}\right]-\frac{1}{n_{t}} X\right) X .
$$


The first-order condition that characterizes the maximization of the Hamiltonian (43) is

$$
\frac{1}{n_{t}} X+\lambda\left(\left(-D_{1} h\left[X, K_{t}\right]-\frac{1}{n_{t}}\right) X+1-c-h\left[X, K_{t}\right]-\frac{1}{n_{t}} X\right)=0
$$

which can also be written as

$$
\frac{1}{n_{t}} X=\frac{\lambda}{2 \lambda-1}\left(1-c-\left(h\left[X, K_{t}\right]+D_{1} h\left[X, K_{t}\right] X\right)\right) .
$$

Observe that for a given value of $K_{t}$ the curve $f\left[., \lambda, K_{t}\right]: X \rightarrow f\left[X, \lambda, K_{t}\right]$, where

$$
f\left[X, \lambda, K_{t}\right]=\frac{\lambda}{2 \lambda-1}\left(1-c-\left(h\left[X, K_{t}\right]+D_{1} h\left[X, K_{t}\right] X\right)\right)
$$

is a horizontal line at level $\lambda(1-c) /(2 \lambda-1)$ for $0 \leq X \leq a K_{t}$, and is downward-sloping for $X>a K_{t}$. As for the curve $X \rightarrow X / n_{t}, X \geq 0$, it is a straight line, with slope $1 / n_{t}$, emanating from the origin. The intersection of these two curves - for the case $K_{t}=1, t \geq 0$, gives the optimal market volume of air travel at time $t$, given the capacity of the airport infrastructure and the number of consumers at that instant. Figure- 3 depicts the determination of $X_{t}^{*}$.

At each instant the optimal market volume of air travel satisfies the following condition:

$$
\frac{1}{n_{t}} X_{t}^{*}=\frac{\lambda}{2 \lambda-1}\left(1-c-\left(h\left[X_{t}^{*}, 1\right]+D_{1} h\left[X_{t}^{*}, 1\right] X_{t}^{*}\right)\right)
$$

Using (46), we obtain the following expression for the access price at each instant:

$$
\begin{aligned}
\phi_{t}^{*}= & 1-c-h\left[X_{t}^{*}, 1\right]-\frac{1}{n_{t}} X_{t}^{*} \\
& =\frac{\lambda-1}{2 \lambda-1}(1-c)+\frac{\lambda-1}{2 \lambda-1}\left(D_{1} h\left[X_{t}^{*}, 1\right] X_{t}^{*}-h\left[X_{t}^{*}, 1\right]\right)+\frac{1}{2 \lambda-1} D_{1} h\left[X_{t}^{*}, 1\right] X_{t}^{*}
\end{aligned}
$$


Using the assumption that one unit of installed capacity can meet initial demand without congestion, we can assert that $h\left[X_{t}^{*}, 1\right]=0$ and $D_{1} h\left[X_{t}^{*}, 1\right]=0$ for small values of $t$. Thus for small values of $t,(46)$ and (47) are, respectively, reduced to

$$
\frac{1}{n_{t}} X_{t}^{*}=\frac{\lambda}{2 \lambda-1}(1-c)>0
$$

and

$$
\phi_{t}^{*}=\frac{\lambda-1}{2 \lambda-1}(1-c)
$$

As in the case $\bar{K}=1$ we can show that $\lambda>1$.

LEMMA 1: Suppose that the unit cost of capacity is high, say $\gamma$ is in a small left neighbourhood of $\bar{\gamma}$.If only one unit of capacity is installed, then the access price will be high enough to discourage the use of the infrastructure so that the single unit of capacity installed will meet demand at all times without congestion. Under this scenario, the demand for air travel by a consumer and the access price will not vary through time and are given, respectively, by (48) and (49).

PROOF: In the preceding section, we have argued that if the cost of one unit capacity is close to $\bar{\gamma}$, then the access price must be close to its monopoly level make it possible for the infrastructure provider to recover her investment costs. Under such a scenario, the demand for air travel at each instant by a single consumer will be close to $(1-c) / 2$, then using the assumption $1<\bar{n}(1-c) / a<2$, we can assert that $n_{t}(1-c) / 2<\bar{n}(1-c) / 2<a$ for all $t \geq 0$, and this means that the single unit of capacity installed can meet demand at all 
times without congestion. Furthermore, when there is no congestion, the demand for air travel by a consumer and the access price are constant through time and are given, respectively, by (48) and (49).

LEMMA 2: Suppose the unit cost of capacity $\gamma$ is low. If only one unit of capacity is installed, then congestion will set in when the number of consumers has risen sufficiently.

PROOF: Indeed, if congestion never sets in, then the access price is given by (49). Furthermore, the shadow price $\lambda=q^{-1}[\gamma / 4 \bar{\gamma}]$ is close to 1 because $\gamma$ is low, and this means, according to (48), that the demand for air travel by a single consumer at each instant is close to $(1-c)$. The market demand for air travel at time $t$ will then be close to $n_{t}(1-c)$. Now in the case we are considering, $\bar{n}(1-c) / a>1$. Thus, when $t$ is large, the market demand for air travel at time $t$ will exceed the threshold level $a$, contradicting the hypothesis of the reduction ad absurdum argument.

For the case congestion will eventually sets in, let $t_{1}[\lambda]$ be the value of $t$ that satisfies the following condition:

$$
a=n_{t} \frac{\lambda}{2 \lambda-1}(1-c)>0
$$

As defined, $t_{1}[\lambda]$ is the exact time congestion sets in when only one unit of capacity is installed and when the unit capacity cost is not too high. The following proposition describes the evolution through time of the access price and the demand for air travel - 
both at the individual and the global levels - when the infrastructure provider chooses to install only one unit of capacity.

PROPOSITION 2: Suppose that the infrastructure provider chooses to install only one unit of capacity and that congestion eventually sets in. Under this scenario, we have the following results:

(i) The global demand for air travel rises through time.

(ii) Before congestion sets in the access price is constant and given by

$$
\phi_{t}^{*}=\frac{\lambda-1}{2 \lambda-1}(1-c), \quad t \leq t_{1}[\lambda]
$$

After congestion has set in, the access price is given by

$$
\begin{aligned}
\phi_{t}^{*}= & \frac{\lambda-1}{2 \lambda-1}(1-c) \\
& \quad+\frac{\lambda-1}{2 \lambda-1}\left(D_{1} h\left[X_{t}^{*}, 1\right] X_{t}^{*}-h\left[X_{t}^{*}, 1\right]\right)+\frac{1}{2 \lambda-1} D_{1} h\left[X_{t}^{*}, 1\right] X_{t}^{*}, t>t_{1}[\lambda] .
\end{aligned}
$$

which is obtained by imposing a congestion surcharge

$$
\frac{\lambda-1}{2 \lambda-1}\left(D_{1} h\left[X_{t}^{*}, 1\right] X_{t}^{*}-h\left[X_{t}^{*}, 1\right]\right)+\frac{1}{2 \lambda-1} D_{1} h\left[X_{t}^{*}, 1\right] X_{t}^{*}
$$

on top of the basic access charge $\frac{\lambda-1}{2 \lambda-1}(1-c)$. Furthermore, the congestion surcharge rises with the level of congestion.

(iii) The demand for air travel by a consumer before congestion sets in is constant and given by

$$
\frac{1}{n_{t}} X_{t}^{*}=\frac{\lambda}{2 \lambda-1}(1-c), t \leq t_{1}[\lambda] \text {, }
$$


After congestion has set in, the demand for air travel by a consumer is strictly decreasing through time and is defined implicitly by

$$
\frac{1}{n_{t}} X_{t}^{*}=\frac{\lambda}{2 \lambda-1}\left(1-c-\left(h\left[X_{t}^{*}, 1\right]+D_{1} h\left[X_{t}^{*}, 1\right] X_{t}^{*}\right)\right), t \leq t_{1}[\lambda]
$$

PROOF: As time goes on, the curve $X \rightarrow X / n_{t}$ rotates clockwise around the origin, while the curve $f[., \lambda, 1]: X \rightarrow f[X ., \lambda, 1]$ remains stationary. The intersection of these two curves moves steadily to the right as time goes on. This explains why the global demand for air travel rises through time. Before congestion sets in, the two curves intersect on the horizontal part of the latter curve, and this means that the demand for air travel by a consumer is constant before congestion sets in. The demand for air travel by a consumer before congestion sets in is given by (48). The access price before congestion is also constant; it is given by (49). Observe that before congestion sets in, global demand for air travel is driven by the growth in the number of air travelers.

After congestion has set in, i.e., for $t>t_{1}[\lambda]$, the two curves intersect each other on the falling part of the latter curve. Hence for $t>t_{1}[\lambda], X_{t}^{*}$ must still be rising, but $X_{t}^{*} / n_{t}$, the demand for air travel by a single consumer, must be falling. After congestion has set in, the access price is given by (47), which consists of two components. The first component is $(\lambda-1)(1-c) /(2 \lambda-1)$, which represents the base access price that is charged when there is no congestion. The second component is

$$
\frac{\lambda-1}{2 \lambda-1}\left(D_{1} h\left[X_{t}^{*}, 1\right] X_{t}^{*}-h\left[X_{t}^{*}, 1\right]\right)+\frac{1}{2 \lambda-1} D_{1} h\left[X_{t}^{*}, 1\right] X_{t}^{*},
$$


which represents a surcharge over and beyond the base access price $(\lambda-1)(1-c) /(2 \lambda-1)$. The main function of the surcharge is to price the negative externalities that a consumer's demand for air travel exerts on all the other consumers. Because for $X>a$, both $D_{1} h[X, 1]$ and $D_{1} h[X, 1] X-h[X, 1]$ rise with $X$, the surcharge is strictly increasing through time after congestion has set in. That is, the higher the congestion level, the higher will be the surcharge.

\subsection{Access Pricing when Two Units of Capacity are Installed and Given the Time the}

Second Unit of Capacity is Installed

If the owners of the airport infrastructure choose to install two units of capacity, then one unit of capacity will be installed at time 0 , and the second unit of capacity at some later date, say $\tau>0$. The reason why two units of capacity are not both installed at time 0 is that one unit of capacity can more than meet initial market demand without congestion, and thus the present value of the cost of the investment program is lower when the instalment of the second unit of capacity is delayed. The time path of the infrastructure capacity under this investment program can be described as follows.

$$
\begin{gathered}
K_{t}=1 \text { for } 0 \leq t<\tau, \\
=2 \text { for } t \geq \tau .
\end{gathered}
$$

Given the time path of the capacity of the infrastructure, the regulator then solves the following welfare maximization problem: Find a time path of the market volume of air travel $\left(X_{t}\right)_{t \geq 0}$ to

$$
\max _{\left(X_{t}\right)_{r \geq 0}} \int_{0}^{\infty} e^{-r t} \frac{1}{2 n_{t}} X_{t}^{2} d t
$$


subject to the revenue constraint

$$
\begin{aligned}
& \frac{d Z}{d t}=e^{-r t}\left(1-c-h\left[X_{t}, K_{t}\right]-\frac{1}{n_{t}} X_{t}\right) X_{t} \\
& Z_{0}=0, \lim _{t \rightarrow \infty} Z_{t}=\gamma\left(1+e^{-r \tau}\right) .
\end{aligned}
$$

The problem constituted by (52) and (53) is a simple problem in optimal control, and can be solved as follows. First, for any number $\varsigma$ - which can be negative, 0 , or positive and any number $\sigma \geq 0$, let

$$
W_{2}[\varsigma, \sigma, 2, \tau, \gamma]=\max _{\left(X_{t}\right)_{t \geq \tau}} \int_{\tau}^{\infty} e^{-r t} \frac{1}{2 n_{t}} X_{t}^{2} d t
$$

subject to

$$
\begin{aligned}
& \frac{d Z}{d t}=e^{-r t}\left(1-c-h\left[X_{t}, K_{t}\right]-\frac{1}{n_{t}} X_{t}\right) X_{t} \\
& Z_{\sigma}=\varsigma, \lim _{t \rightarrow \infty} Z_{t}=\gamma\left(1+e^{-r \tau}\right) .
\end{aligned}
$$

As defined, $W_{2}[\varsigma, \sigma, 2, \tau, \gamma]$ gives the present value of the stream of social welfare obtained under the optimal solution, given that

(i) it is not optimal to install more than 2 units of capacity;

(ii) two units of capacity are installed, one at time 0 and one at time $\tau$;

(iii) the system begins at time $\sigma$ and that the present value of the stream of access fees already paid to the owners of the airport infrastructure is equal to $\varsigma$. 
Note that for $\varsigma=0, \sigma=0$, the optimal-value function $W_{2}[\varsigma, \sigma, 2, \tau, \gamma]$ gives the maximum present value of the stream of social welfare for the problem constituted by (52) and (53).

To solve the problem constituted by (52) and (53), define the Hamiltonian

$$
\mathcal{H}[Z, X, \lambda, t]=e^{-r t} \frac{X^{2}}{2 n_{t}}+\lambda e^{-r t}\left(1-c-h\left[X, K_{t}\right]-\frac{1}{n_{t}} X\right) X .
$$

Next, let $X_{t}^{*}$ denote the optimal market volume of air travel at time $t, t \geq 0$, for the problem constituted by (52) and (53). Also, let $Z_{t}^{*}$ denote the present value of the stream of access fees paid by the two airlines to the owner of the airport infrastructure from time 0 up to time $t$ under the optimal solution to the problem constituted by (52) and (53). The evolution of $Z_{t}^{*}$ is governed by the following differential equation

$$
\begin{aligned}
& \frac{d Z^{*}}{d t}=\left(1-c-h\left[X_{t}^{*}, K_{t}\right]-\frac{1}{n_{t}} X_{t}^{*}\right) X_{t}^{*}, \\
& Z_{0}^{*}=0, \lim _{t \rightarrow \infty} Z_{t}^{*}=\gamma\left(1+e^{-r \tau}\right) .
\end{aligned}
$$

To continue, let

$$
\lambda_{t}=D_{1} W_{2}\left[Z_{t}^{*}, t, 2, \tau, \gamma\right]
$$

be the shadow price of the present value of the stream of access fees paid by the two airlines to the owners of the airport infrastructure from time 0 up to time $t$ along the optimal trajectory. Economically, $\lambda_{t}$ represents the rise in discounted social welfare, given that the present value of the stream of access fees paid by the two airlines from 
time 0 until time $t$ is raised by one dollar, or, equivalently, the rise in discounted social welfare if, say technological progress, happens to lower the present value of the costs of the investment program by one dollar. Clearly, $\lambda_{t}$ is positive. The evolution of $\lambda_{t} \square$ is governed by the following adjoint equation:

$$
\frac{d \lambda}{d t}=-D_{1} \mathcal{H}\left[Z_{t}^{*}, X_{t}^{*}, \lambda_{t}, t\right]=0
$$

which implies that $\lambda_{t}=\lambda=$ constant. Furthermore, at each instant, $X_{t}^{*}$ is the value of $X$ that maximizes the Hamiltonian

$$
\mathcal{H}\left[Z_{t}^{*}, X, \lambda_{t}, t\right]=e^{-r t} \frac{1}{2 n_{t}} X^{2}+\lambda e^{-r t}\left(1-c-h\left[X, K_{t}\right]-\frac{1}{n_{t}} X\right) X .
$$

The first-order condition that characterizes the maximization of the Hamiltonian is

$$
\frac{1}{n_{t}} X+\lambda\left(\left(-D_{1} h\left[X, K_{t}\right]-\frac{1}{n_{t}}\right) X+1-c-h\left[X, K_{t}\right]-\frac{1}{n_{t}} X\right)=0,
$$

which can also be written as

$$
\frac{1}{n_{t}} X=\frac{\lambda}{2 \lambda-1}\left(1-c-\left(h\left[X, K_{t}\right]+D_{1} h\left[X, K_{t}\right] X\right)\right)
$$

Observe that for a given value of $K_{t}$ the curve $f\left[., \lambda, K_{t}\right]: X \rightarrow f\left[X, \lambda, K_{t}\right]$ is a horizontal line at level $\lambda(1-c) /(2 \lambda-1)$ for $0 \leq X \leq a K_{t}$, and is downward-sloping for $X>a K_{t}$. As for the curve $X \rightarrow X / n_{t}, X \geq 0$, it is a straight line with slope $1 / n_{t}$, emanating from the origin. The intersection of these two curves gives the optimal market volume of air travel at time $t$, given the capacity of the airport infrastructure and the number of consumers at that instant. The Figure- 4 depicts the determination of $X_{t}^{*}$. In 
the figure, both the curve $f\left[., \lambda, K_{t}\right]: X \rightarrow f\left[X, \lambda, K_{t}\right]$ with $K_{t}=1$, which applies before the second unit of capacity is installed, and the curve $f\left[., \lambda, K_{t}\right]: X \rightarrow f\left[X, \lambda, K_{t}\right]$ with $K_{t}=2$, which applies after the second unit of capacity is installed, are depicted.

Figure 4 depicts the optimal market volume of air travel at three instants: $t, \tau$, and $t^{\prime}$, with $t<\tau<t^{\prime}$. Here $t$ represents an instant before the second unit of capacity is installed, and $t^{\prime}$ represents an instant after the second unit of capacity is installed. Note that the optimal market volume of air travel, given the time path of the infrastructure investments, experiences a jump at time $\tau$, when the second unit of capacity is installed. In the figure, $X_{\tau-}^{*}$ denotes the optimal market volume of air travel immediately before the second unit of capacity is installed. Because in the case we are analyzing two units of capacity can meet demand at all times without congestion, for all $t^{\prime} \geq \tau$, the curve $X \rightarrow X / n_{t^{\prime}}$ crosses the curve $X \rightarrow f[X, \lambda, 2]$ at a point on the horizontal part of the latter curve. The figure also depicts the case there is congestion after the initial phase and before the second unit of capacity is installed: the curve $X \rightarrow X / n_{t}$ crosses the curve $X \rightarrow f[X, \lambda, 1]$ at a point on the falling part of the latter curve.

At each instant the optimal market volume of air travel satisfies the following condition:

$$
\frac{1}{n_{t}} X_{t}^{*}=\frac{\lambda}{2 \lambda-1}\left(1-c-\left(h\left[X_{t}^{*}, K_{t}\right]+D_{1} h\left[X_{t}^{*}, K_{t}\right] X_{t}^{*}\right)\right)
$$

Using (62), we obtain the following expression for the access price at each instant:

$$
\begin{aligned}
\phi_{t}^{*}= & -c-h\left[X_{t}^{*}, K_{t}\right]-\frac{1}{n_{t}} X_{t}^{*} \\
& =\frac{\lambda-1}{2 \lambda-1}(1-c)+\frac{\lambda-1}{2 \lambda-1}\left(D_{1} h\left[X_{t}^{*}, K_{t}\right] X_{t}^{*}-h\left[X_{t}^{*}, K_{t}\right]\right)+\frac{1}{2 \lambda-1} D_{1} h\left[X_{t}^{*}, K_{t}\right] X_{t}^{*} .
\end{aligned}
$$


Using the assumption that one unit of installed capacity can meet initial demand without congestion, we can assert that $h\left[X_{t}^{*}, K_{t}\right]=0$ and $D_{1} h\left[X_{t}^{*}, K_{t}\right]=0$ for small values of $t$. Thus for small values of $t(62)$ and (63) are, respectively, reduced to

$$
\frac{1}{n_{t}} X_{t}^{*}=\frac{\lambda}{2 \lambda-1}(1-c)>0,
$$

and

$$
\phi_{t}^{*}=\frac{\lambda-1}{2 \lambda-1}(1-c)
$$

Because 2 units of capacity can meet market demand at all times without congestion, (64) and (65) also represent, respectively, the demand for air travel by a single consumer and the access price after the second unit of capacity is installed. Also, note that if there is no congestion before the second unit of capacity is installed, then the timing of the installment of the second unit of capacity is not optimal: a delay of the installment of the second unit of capacity will reduce the present value of the cost of the investment program without lowering discounted welfare. Thus the second unit of capacity should only be installed after congestion has set in. The following proposition summarizes the results just obtained.

PROPOSITION 3: Suppose that it is not optimal to install more than two units of capacity and that the infrastructure provider chooses to install two units of capacityone at time 0 , the other at time $\tau>0$. Also, suppose that given this decision, $\tau$ is chosen optimally. Under this scenario, we have the following results: 
(i) The second unit of capacity is only installed after congestion has set in. That is, $\tau \geq t_{1}(\lambda)$ where $t_{1}(\lambda)$ is the time congestion first sets in.

(ii) The global demand for air travel rises through time.

(iii) Before congestion sets in the access price is constant and given by

$$
\phi_{t}^{*}=\frac{\lambda-1}{2 \lambda-1}(1-c), \quad t \leq t_{1}[\lambda]
$$

After congestion has set in and before the installment of the second unit of capacity, the access price is given by

$$
\begin{aligned}
\phi_{t}^{*}= & \frac{\lambda-1}{2 \lambda-1}(1-c) \\
& +\frac{\lambda-1}{2 \lambda-1}\left(D_{1} h\left[X_{t}^{*}, 1\right] X_{t}^{*}-h\left[X_{t}^{*}, 1\right]\right)+\frac{1}{2 \lambda-1} D_{1} h\left[X_{t}^{*}, 1\right] X_{t}^{*}, t_{1}[\lambda]<t<\tau, .
\end{aligned}
$$

which is obtained by imposing a congestion surcharge

$$
\frac{\lambda-1}{2 \lambda-1}\left(D_{1} h\left[X_{t}^{*}, 1\right] X_{t}^{*}-h\left[X_{t}^{*}, 1\right]\right)+\frac{1}{2 \lambda-1} D_{1} h\left[X_{t}^{*}, 1\right] X_{t}^{*}
$$

on top of the basic access charge $\frac{\lambda-1}{2 \lambda-1}(1-c)$. Furthermore, the congestion surcharge rises with the level of congestion.

After the installment of the second unit of capacity, the access price falls back to the basic level, i.e.,

$$
\phi_{t}^{*}=\frac{\lambda-1}{2 \lambda-1}(1-c), \quad t \geq \tau
$$

(iv) The demand for air travel by a consumer before congestion sets in is constant and given by 


$$
\frac{1}{n_{t}} X_{t}^{*}=\frac{\lambda}{2 \lambda-1}(1-c), \quad t \leq t_{1}[\lambda]
$$

After congestion has set in and before the installment of the second unit of capacity, the demand for air travel by a consumer is strictly decreasing through time and is defined implicitly by

$$
\frac{1}{n_{t}} X_{t}^{*}=\frac{\lambda}{2 \lambda-1}\left(1-c-\left(h\left[X_{t}^{*}, 1\right]+D_{1} h\left[X_{t}^{*}, 1\right] X_{t}^{*}\right)\right), t_{1}[\lambda]<t<\tau .
$$

After the installment of the second unit of capacity, the demand for air travel by a consumer returns to the level that prevails before congestion sets in. That is,

$$
\frac{1}{n_{t}} X_{t}^{*}=\frac{\lambda}{2 \lambda-1}(1-c), \tau \leq t \text {. }
$$

\subsection{Lumpy Investments when it is not Optimal to Install more than Two Units of}

\section{Capacity}

The decision of whether to install one or two units of capacity depends on the unit capacity cost. Intuitively, we expect that two units of capacity will be installed if the unit capacity cost is low, and only one unit of capacity will be installed if the unit capacity cost is high.

Now it is optimal to install 2 units of capacity if and only if there exists a finite value of $\tau$ such that $W_{2}[0,0,2, \tau, \gamma]>W_{2}[0,0,1, \gamma]$. Furthermore, recall that when 2 units of capacity are installed, the present value of the investment programs is $\gamma\left(1+e^{-r \tau}\right)$, which tends to 
$\gamma$ when $\tau$ tends to infinity. Thus when 2 units of capacity are installed, with the second unit of capacity being installed far in the future, the present value of the cost of such an investment program will be close to that of the investment program under which only one unit of capacity is installed. Also, the capacity of the infrastructure at each instant associated with the former investment program is at least as high as that associated with the latter investment program. Hence $\lim _{\tau \rightarrow \infty} W_{2}[0,0,2, \tau, \gamma]=W_{2}[0,0,1, \gamma]$ for all $\gamma$, and this means

$$
\sup _{\tau} W_{2}[0,0,2, \tau, \gamma] \geq W_{2}[0,0,1, \gamma]
$$

with strict inequality holding - and a fortiori it is optimal to install 2 units of capacity - if there exists a finite value of $\tau$ such that $W_{2}[0,0,2, \tau, \gamma]>W_{2}[0,0,1, \gamma]$.

Intuitively, we expect that if the unit capacity cost is low, then two units of capacity should be installed. On the other hand, if the unit capacity is high, then only one unit of capacity should be installed. In particular, when the unit capacity cost is quite high, say $\gamma$ is in a small left neighbourhood of $\bar{\gamma}$, then the revenue constraint will dictate a high access price that discourages consumers from flying. In this case, the one unit installed will meet demand at all times without congestion. If the unit capacity cost is high, but not too high, then the revenue constraint is slightly relaxed. In this case, only one unit of capacity is installed, but this installed unit of capacity will experience congestion some time in the future. The following proposition confirms the intuition. Its proof is quite technical and is relegated to Appendix A. 
PROPOSITION 4: Suppose that it is not optimal to install more than two units of capacity. There exists two critical values of $\gamma$, say $\underline{\gamma}_{12}$ and $\bar{\gamma}_{12}$, with $0<\underline{\gamma}_{12} \leq \bar{\gamma}_{12}<\bar{\gamma}$, that have the following properties:

(i) If $\gamma \geq \underline{\gamma}_{12}$, then it is optimal to install only one unit of capacity. Furthermore, if $\bar{\gamma}_{12} \leq \gamma<\bar{\gamma}$, then the one unit installed will meet demand for the infrastructure service at all times without congestion. On the other hand, if $\underline{\gamma}_{12} \leq \gamma<\bar{\gamma}_{12}$, then there will be congestion with the one unit installed.

(ii) If $\gamma<\underline{\gamma}_{12}$, then it is optimal to install two units of capacity. Furthermore, the exact time the second unit of capacity is installed is obtained by solving the maximization problem $\max _{\tau} W_{2}[0,0,2, \tau, \gamma]$.

\section{ACCESS PRICING AND LUMPY INVESTMENTS WHEN IT IS NOT OPTIMAL}

\section{TO INSTALL MORE THAN THREE UNITS OF CAPACITY}

When it is not optimal to install more than three units of capacity, the regulator has three choices: (i) install only one unit of capacity; (ii) install two units of capacity; or (iii) install three units of capacity. The access pricing problem for the case the infrastructure provider chooses to install one unit of capacity or the case she chooses to install two units of capacity can be solved as in Section 3 and Section 4, respectively. However, in the case we are considering the optimal investment program might require the installment of up to three units of capacity, and this means that the system might be congested if fewer than three units of capacity are installed. Of course, installing fewer than three units of capacity might be optimal if the unit capacity cost is substantial. The optimal number of 
capacity units to be installed and the exact time that each capacity addition is made involves a trade-off between congestion cost and capacity costs. The following proposition, which is the version of Proposition 4, describes the trade-off.

PROPOSITION 5: Suppose that it is not optimal to install more than three units of capacity. There exists four critical values of $\gamma$, say $\underline{\gamma}_{13}, \bar{\gamma}_{13}, \underline{\gamma}_{23}$, and $\bar{\gamma}_{23}$, with

$$
0<\underline{\gamma}_{23}<\bar{\gamma}_{23} \leq \underline{\gamma}_{13}<\bar{\gamma}_{13}<\bar{\gamma}
$$

which have the following properties:

(i) If $\gamma \geq \underline{\gamma}_{13}$, then it is optimal to install only one unit of capacity. Furthermore, if $\bar{\gamma}_{13} \leq \gamma<\bar{\gamma}$, then the one unit installed will meet demand for the infrastructure service at all times without congestion. On the other hand, if $\underline{\gamma}_{13} \leq \gamma<\bar{\gamma}_{13}$, then there will be congestion with the one unit installed.

(ii) If $\underline{\gamma}_{23} \leq \gamma<\underline{\gamma}_{13}$, then it is optimal to install two units of capacity. Furthermore, if $\bar{\gamma}_{23} \leq \gamma<\underline{\gamma}_{13}$, then there will not be congestion in the long run. On the other hand, if $\underline{\gamma}_{23} \leq \gamma<\bar{\gamma}_{23}$, then there will be congestion in the long run.

(iii) If $\gamma<\bar{\gamma}_{23}$, then three units of capacity will be installed, and there will be no congestion after the third unit of capacity has been installed..

PROOF: When the unit capacity cost is low, it is optimal to install three units of capacity. As the unit capacity cost rises, there comes a point when it is optimal to install two units 
of capacity. At high levels of capacity costs, one unit of capacity is the optimal number. Furthermore, at the lower end of the unit capacity cost for one or two units of installed capacity, the access price will not be excessive, and thus air travelers will experience some congestion in the long run. At the higher end of the unit capacity cost for one or two units of installed capacity, the access price must be sufficient for the infrastructure provider to recover investment costs, and this means there will be no congestion in the long run. We have just presented the economic logic that explains why (i), (ii), and (iii) of Proposition 5 are true. A more rigorous demonstration of Proposition 5 is quite technical and can be patterned after the proof of Proposition 4 .

Because we have already solved the access pricing for the case the infrastructure provider chooses to install one unit of capacity and the case she chooses to install two units of capacity, we shall now only consider the case it is optimal to install three units of capacity.

If the owners of the airport infrastructure choose to install three units of capacity, then one unit of capacity will be installed at time 0 ; the second unit of capacity at some time, say $\tau_{1}>0$; and the third unit at some time $\tau_{2} \geq \tau_{1}$. The time path of the infrastructure capacity under this investment program can be described as follows.

$$
\begin{aligned}
K_{t} & =1 \text { for } 0 \leq t<\tau_{1}, \\
& =2 \text { for } \tau_{1} \leq t<\tau_{2}, \\
& =3 \text { for } t \geq \tau_{2} .
\end{aligned}
$$


Given the time path of the capacity of the infrastructure, the regulator then solves the following welfare maximization problem: Find a time path of the market volume of air travel $\left(X_{t}\right)_{t \geq 0}$ to

$$
\max _{\left(X_{i}\right)_{t \geq 0}} \int_{0}^{\infty} e^{-r t} \frac{1}{2 n_{t}} X_{t}^{2} d t
$$

subject to the constraint

$$
\begin{aligned}
& \frac{d Z}{d t}=e^{-r t}\left(1-c-h\left[X_{t}, K_{t}\right]-\frac{1}{n_{t}} X_{t}\right) X_{t}, \\
& Z_{0}=0, \lim _{t \rightarrow \infty} Z_{t}=\gamma\left(1+e^{-r \tau_{1}}+e^{-r \tau_{2}}\right)
\end{aligned}
$$

The problem constituted by (68) and (69) is a simple problem in optimal control, and can be solved as follows. First, for any number $\varsigma-$ which can be negative, 0 , or positive and any number $\sigma \geq 0$, let

$$
W_{3}\left[\varsigma, \sigma, 3, \tau_{1}, \tau_{2}, \gamma\right]=\max _{\left(X_{1}\right)_{r \geq t}} \int_{\tau}^{\infty} e^{-r t} \frac{1}{2 n_{t}} X_{t}^{2} d t
$$

subject to

$$
\begin{aligned}
& \frac{d Z}{d t}=e^{-r t}\left(1-c-h\left[X_{t}, K_{t}\right]-\frac{1}{n_{t}} X_{t}\right) X_{t} \\
& Z_{\sigma}=\varsigma, \lim _{t \rightarrow \infty} Z_{t}=\gamma\left(1+e^{-r t_{1}}+e^{-r \tau_{2}}\right) .
\end{aligned}
$$

As defined, $W_{3}\left[\varsigma, \sigma, 3, \tau_{1}, \tau_{2}, \gamma\right]$ gives the present value of the stream of social welfare obtained under the optimal solution, given that

(i) it is not optimal to install more than 3 units of capacity; 
(ii) three units of capacity are installed, the first one at time 0 ; the second one at time $\tau_{1} ;$ and the third one at time $\tau_{2}$;

(iii) the system begins at time $\sigma$ and that the present value of the stream of access fees already paid to the owners of the airport infrastructure is equal to $\varsigma$.

Note that for $\varsigma=0, \sigma=0$, the optimal-value function $W_{3}\left[\varsigma, \sigma, 3, \tau_{1}, \tau_{2}, \gamma\right]$ gives the maximum present value of the stream of social welfare for the problem constituted by (68) and (69). To solve this problem, define the Hamiltonian

$$
\mathcal{H}[Z, X, \lambda, t]=e^{-r t} \frac{X^{2}}{2 n_{t}}+\lambda e^{-r t}\left(1-c-h\left[X, K_{t}\right]-\frac{1}{n_{t}} X\right) X
$$

Next, let $X_{t}^{*}$ denote the optimal market volume of air travel at time $t, t \geq 0$, for the problem constituted by (68) and (69). Also, let $Z_{t}^{*}$ denote the present value of the stream of access fees paid by the two airlines to the owner of the airport infrastructure from time 0 up to time $t$ under the optimal solution to the problem constituted by (68) and (69). The evolution of $Z_{t}^{*}$ is governed by the following differential equation

$$
\begin{aligned}
& \frac{d Z^{*}}{d t}=\left(1-c-h\left[X_{t}^{*}, K_{t}\right]-\frac{1}{n_{t}} X_{t}^{*}\right) X_{t}^{*} \\
& Z_{0}^{*}=0, \lim _{t \rightarrow \infty} Z_{t}^{*}=\gamma\left(1+e^{-r \tau_{1}}+e^{-r \tau_{2}}\right)
\end{aligned}
$$

To continue, let

$$
\lambda_{t}=D_{1} W_{2}\left[Z_{t}^{*}, t, 2, \theta, \gamma\right]
$$


be the shadow price of the present value of the stream of access fees paid by the two airlines to the owners of the airport infrastructure from time 0 up to time $t$ along the optimal trajectory. Clearly, $\lambda_{t}$ is positive. The evolution of $\lambda_{t} \square$ is governed by the following adjoint equation:

$$
\frac{d \lambda}{d t}=-D_{1} \mathcal{H}\left[Z_{t}^{*}, X_{t}^{*}, \lambda_{t}, t\right]=0
$$

which implies that $\lambda_{t}=\lambda=$ constant. Furthermore, at each instant, $X_{t}^{*}$ is the value of $X$ that maximizes the Hamiltonian

$$
\mathcal{H}\left[Z_{t}^{*}, X, \lambda_{t}, t\right]=e^{-r t} \frac{1}{2 n_{t}} X^{2}+\lambda e^{-r t}\left(1-c-h\left[X, K_{t}\right]-\frac{1}{n_{t}} X\right) X
$$

The first-order condition that characterizes the maximization of the Hamiltonian is

$$
\frac{1}{n_{t}} X+\lambda\left(\left(-D_{1} h\left[X, K_{t}\right]-\frac{1}{n_{t}}\right) X+1-c-h\left[X, K_{t}\right]-\frac{1}{n_{t}} X\right)=0
$$

which can also be written as

$$
\frac{1}{n_{t}} X=\frac{\lambda}{2 \lambda-1}\left(1-c-\left(h\left[X, K_{t}\right]+D_{1} h\left[X, K_{t}\right] X\right)\right)
$$

Observe that for a given value of $K_{t}$ the curve $f\left[., \lambda, K_{t}\right]: X \rightarrow f\left[X, \lambda, K_{t}\right]$ is a horizontal line at level $\lambda(1-c) /(2 \lambda-1)$ for $0 \leq X \leq a K_{t}$, and is downward-sloping for $X>a K_{t}$. As for the curve $X \rightarrow X / n_{t}, X \geq 0$, it is a straight line with slope $1 / n_{t}$, emanating from the origin. The intersection of these two curves gives the optimal market volume of air travel at time $t$, given the capacity of the airport infrastructure and the 
number of consumers at that instant. Because three units of capacity can meet demand at all times without congestion, for all $t^{\prime} \geq \tau_{2}$, the curve $X \rightarrow X / n_{t^{\prime}}$ crosses the curve $X \rightarrow f[X, \lambda, 3]$ at a point on the horizontal part of the latter curve.

At each instant the optimal market volume of air travel satisfies the following condition:

$$
\frac{1}{n_{t}} X_{t}^{*}=\frac{\lambda}{2 \lambda-1}\left(1-c-\left(h\left[X_{t}^{*}, K_{t}\right]+D_{1} h\left[X_{t}^{*}, K_{t}\right] X_{t}^{*}\right)\right)
$$

Using (78), we obtain the following expression for the access price at each instant:

$$
\begin{aligned}
\phi_{t}^{*}= & -c-h\left[X_{t}^{*}, K_{t}\right]-\frac{1}{n_{t}} X_{t}^{*} \\
& =\frac{\lambda-1}{2 \lambda-1}(1-c)+\frac{\lambda-1}{2 \lambda-1}\left(D_{1} h\left[X_{t}^{*}, K_{t}\right] X_{t}^{*} \cdot-h\left[X_{t}^{*}, K_{t}\right]\right)+\frac{1}{2 \lambda-1} D_{1} h\left[X_{t}^{*}, K_{t}\right] X_{t}^{*}
\end{aligned}
$$

Using the assumption that one unit of installed capacity can meet initial demand without congestion, we can assert that $h\left[X_{t}^{*}, K_{t}\right]=0$ and $D_{1} h\left[X_{t}^{*}, K_{t}\right]=0$ for small values of $t$. Thus for small values of $t(78)$ and (79) are, respectively, reduced to

$$
\frac{1}{n_{t}} X_{t}^{*}=\frac{\lambda}{2 \lambda-1}(1-c)>0
$$

and

$$
\phi_{t}^{*}=\frac{\lambda-1}{2 \lambda-1}(1-c)
$$

Because 3 units of capacity can meet market demand at all times without congestion, (80) and (81) also represent, respectively, the demand for air travel by a single consumer and 
the access price after the third unit of capacity is installed. Also, note that if there is no congestion before the second unit of capacity is installed, then the timing of the installment of the second unit of capacity is not optimal: a delay of the installment of the second unit of capacity will reduce the present value of the cost of the investment program without lowering discounted welfare. Thus the second unit of capacity should only be installed after congestion has set in. The same argument also applies for the timing of the installment of the third unit of capacity.

Let $t_{1}[\lambda]$ denote the time congestion first sets in before the second unit of capacity is installed. Then $0<t_{1}[\lambda]<\tau$, and $t_{1}[\lambda]$ is the value of $t$ such that $a=n_{t}(1-c) \lambda /(2 \lambda-1)$. Let $t_{2}[\lambda]$ denote the time congestion sets in after the second unit of capacity is installed. Then $t_{2}[\lambda]$ is the value of $t$ such that $2 a=n_{t}(1-c) \lambda /(2 \lambda-1)$.

The following proposition gives a characterization of the optimal solution of the access pricing problem for the case it is not optimal to install more than three units of capacity.

PROPOSITION 6: Suppose that it is not optimal to install more than three units of capacity. Suppose also that the unit capacity cost is low so that the infrastructure provider chooses to install three units of capacity - the first one at time 0 , the second one at time $\tau_{1}$, and the third one at time $\tau_{2}$. The optimal program of infrastructure investments has the following properties.

(i) The global demand for air travel rises through time. 
(ii) Before congestion first sets in and after the third unit of capacity has been installed, the access price is at the basic level and is given by $\phi_{t}^{*}=\frac{\lambda-1}{2 \lambda-1}(1-c), \quad 0 \leq t<t_{1}[\lambda], t \geq \tau_{2}$

During the time interval between the time congestion first sets in and the time the third unit of capacity is installed, the access price is given by

$$
\begin{aligned}
& \phi_{t}^{*}=\frac{\lambda-1}{2 \lambda-1}(1-c) \\
& \quad+\frac{\lambda-1}{2 \lambda-1}\left(D_{1} h\left[X_{t}^{*}, K_{t}\right] X_{t}^{*} \cdot-h\left[X_{t}^{*}, K_{t}\right]\right) \\
& \quad+\frac{1}{2 \lambda-1} D_{1} h\left[X_{t}^{*}, K_{t}\right] X_{t}^{*}, \mathrm{t}_{1}[\lambda] \leq t<\tau_{2},
\end{aligned}
$$

which consists of the basic access price and a congestion surcharge.

At the instant that the second capacity unit is installed, the access price takes a downward jump. The access price jumps down to the basic level at the time the third capacity unit is installed.

(iii) Before congestion first sets in and after the third capacity unit has been installed, the demand for air travel by a single consumer is constant and given $b y$

$$
\frac{1}{n_{t}} X_{t}^{*}=\frac{\lambda}{2 \lambda-1}(1-c), \mathrm{t}<\mathrm{t}_{1}[\lambda], t \geq \tau .
$$

During the time interval between the time congestion first sets in and the time the third unit of capacity is installed, the demand for air travel by a single consumer is given by 


$$
\frac{1}{n_{t}} X_{t}^{*}=\frac{\lambda}{2 \lambda-1}\left(1-c-\left(h\left[X_{t}^{*}, K_{t}\right]+D_{1} h\left[X_{t}^{*}, K_{t}\right] X_{t}^{*}\right)\right), \mathrm{t}_{1}[\lambda] \leq t<\tau_{2},
$$

which is strictly decreasing until an infrastructure enhancement is made.

PROOF: Except for the fact that the access price takes a downward jump at the time a capacity addition is made, all the other statements of Proposition 4 can be proved as in the case it is not optimal to install more than two units of capacity. Note that when a capacity addition is made, congestion is alleviated, but not necessarily eliminated. Thus, the access price does not necessarily fall to the basic level when the second unit of capacity is installed. The proof of this result requires some computational efforts and is relegated to Appendix B.

\section{CONCLUDING REMARKS}

We have formulated and analyzed a model of access pricing with congestion and lumpy infrastructure investments. The optimal investment program suggests how many units of capacity should be installed and at which times. Because time is continuous in the model, the discounted cost - despite the lumpiness of capacity additions - can be made to vary continuously by varying the time a capacity addition is made. The main results that emerge from the analysis can be described as follows.

First, the global demand for air travel rises with time and experiences an upward jump whenever a capacity addition is made. 
Second, the access price is constant and stays at the basic level whenever the system is not congested. When the system is congested, a congestion surcharge is imposed on top of the basic level and the congestion surcharge rises with the level of congestion until the next capacity addition takes place at which time the access price takes a downward jump.

Third, the individual demand for air travel is constant before congestion sets in and after the last capacity addition takes place. During a time interval in which congestion rises, the individual demand for travel is below the level that prevails when there is no congestion and declines as congestion worsens.

Our analysis demonstrates that the optimal infrastructure investment depends on both the lumpiness of capacity additions and the unit capacity cost. The trade-off between congestion cost and capacity costs might lead to an optimal infrastructure investment program that alleviates congestion, but not eliminate congestion. 


\section{REFERENCES}

Armstrong, Mark 2002: "The Theory of Access Pricing and Interconnection," Chapter 8 in Handbook of Telecommunications Economics, Volume 1, Ed. by Martin E. Cave, Sumit K. Majumdar, and Ingo Vogelsang, First Edition, 2002, North Holland.

Brueckner, Jan K. 2002: "Airport Congestion When Carriers Have Market Power", American Economic Review, Vol. 92, No. 5, Dec. 2002, pp. 1357-1375.

Brueckner, Jan K. 2005: "Internalization of Airport Congestion: A Network Analysis", International Journal of Industrial Organizations, Vol. 23, 2005, pp. 599-614.

Oum, Tae Hoon and Zhang, Yimin 1990: "Airport Pricing: Congestion Tolls, Lumpy Investment, and Cost Recovery", Journal of Public Economics, Vol: 43, pp. 353374.

Park, R.E. 1989: "Incremental Costs and Efficient Prices with Lumpy Capacity: The Single Product Case"; The RAND Corporation, Santa Monica, CA.

Rees, Ray 1986: "Indivisibilities, Pricing and Investment: The Case of the Second 
Best"Journal of Economics, Zeitschrift für Nationalökonomie, 1986, Vol. 5 (supp).

Rothengatter, Werner 2003: "How Good is First best? Marginal Cost and Other Pricing Principles for User Charging in Transport", Transport Policy, Vol. 10, pp 121130.

Sydee, Ahmed 2010: "Stranded Costs and One-Way Access Pricing - A Dynamic Analysis"; Ph.D. Thesis Chapter, Department of Economics, Carleton University, April 2010.

Turvey, Ralph 2002: “Infrastructure Access Pricing and Lump Investments", Regulation Initiative Discussion Paper Series, Number 46 ,London Business School ,January 2002. 


\section{FIGURE 1- THE CONGESTION COST PER TRIP}

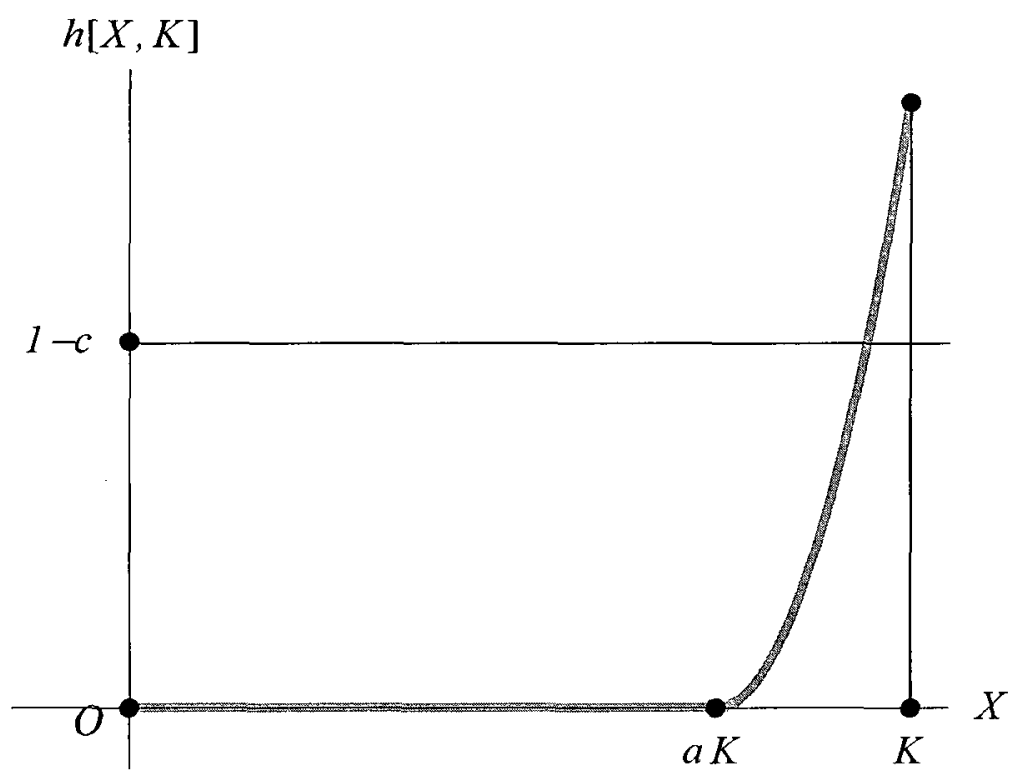

FIGURE 2- THE INSTANTANEOUS EQUILIBRIUM MARKET VOLUME OF AIR TRAVEL

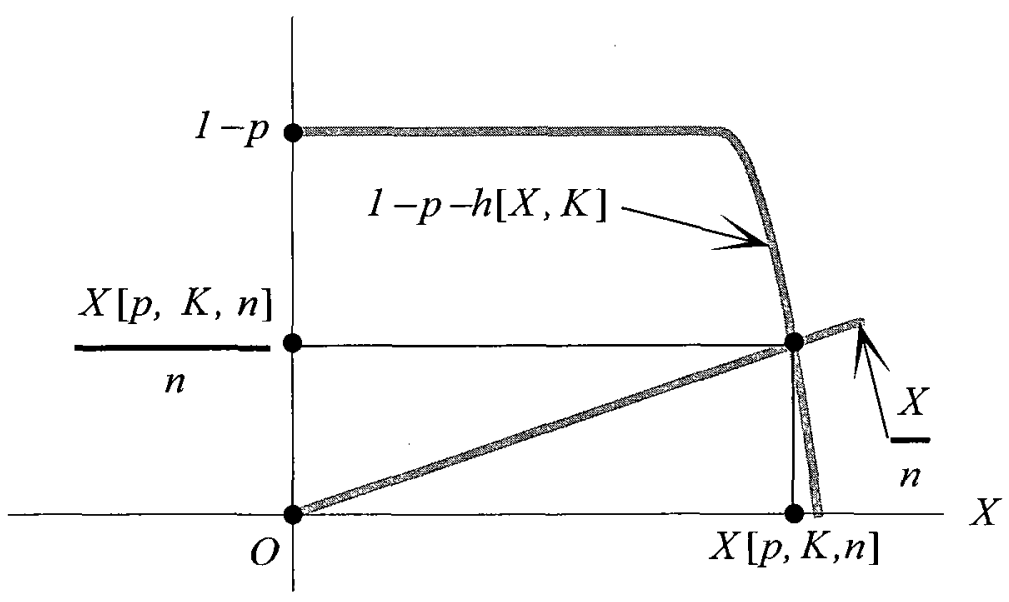


FIGURE- 3.THE OPTIMAL MARKET VOLUME OF AIR TRAVEL AT EACH INSTANT WHEN ONLY ONE UNIT OF CAPACITY IS INSTALLED: THE CASE

$$
\bar{K}=2
$$

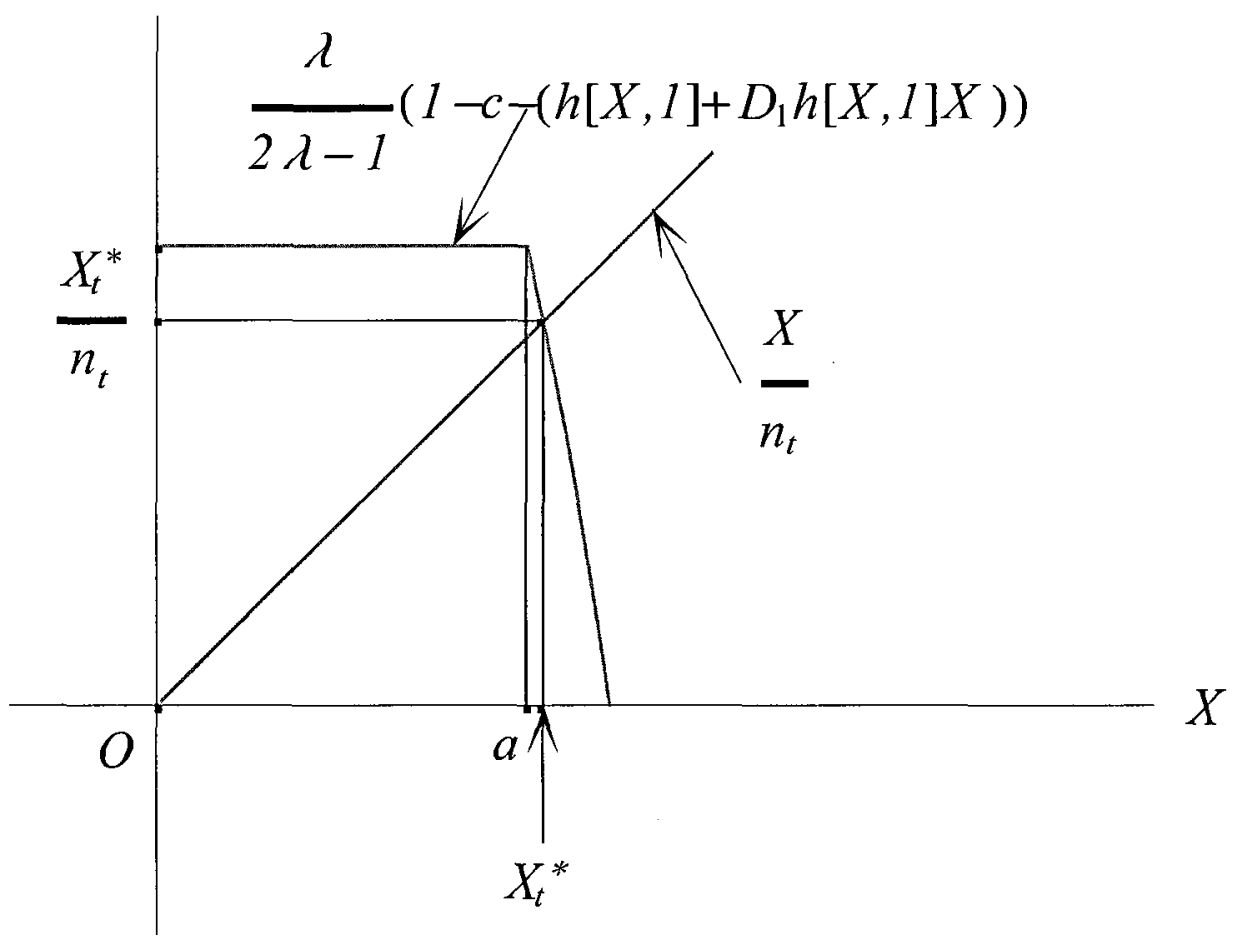


FIGURE -4. THE OPTIMAL MARKET VOLUME OF AIR TRAVEL AT EACH INSTANT WHEN TWO UNITS OF CAPACITY ARE INSTALLED: THE CASE

$$
\bar{K}=2
$$

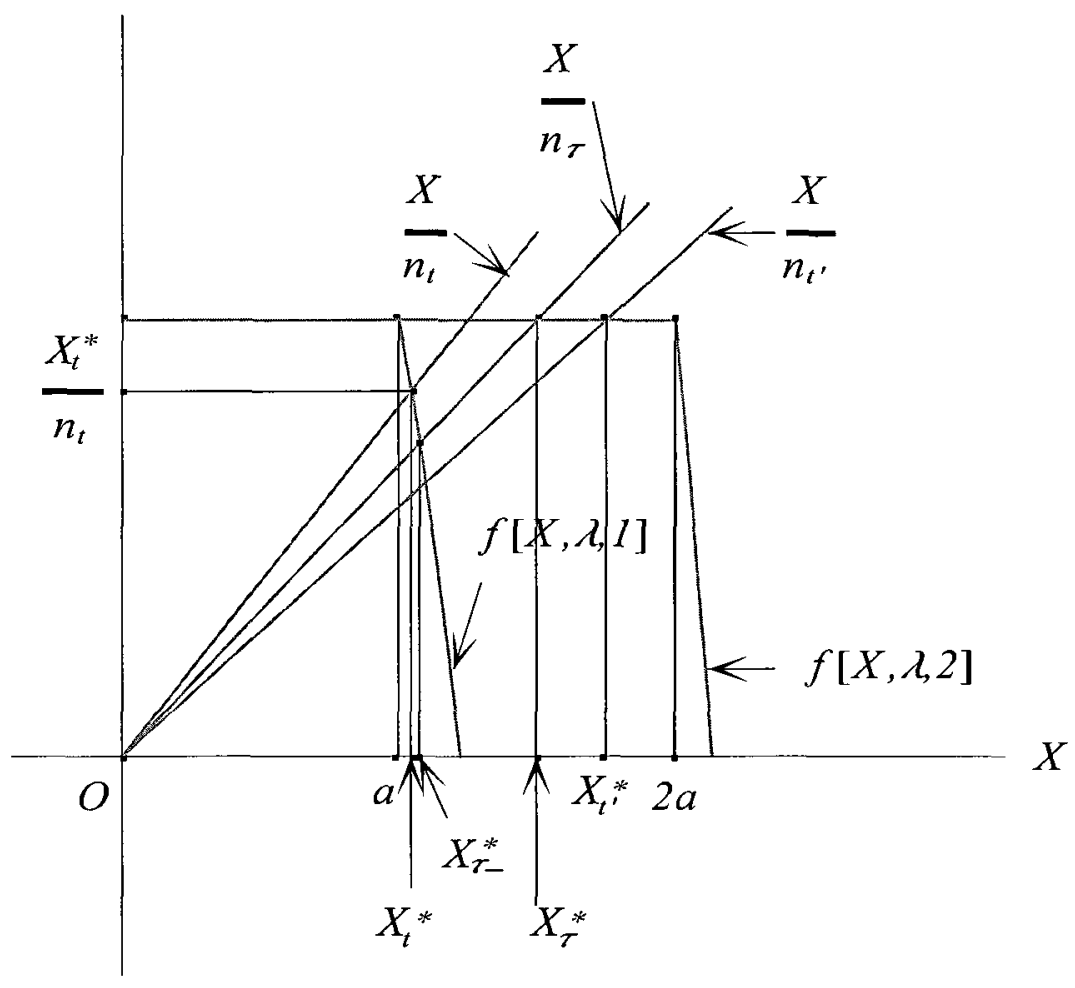




\section{APPENDIX A}

\section{THE PROOF OF PROPOSITION 4}

\section{A.1 The Existence of $\underline{\gamma}_{12}$}

Let

$$
J[\gamma]=\sup _{\tau} W_{2}[0,0,2, \tau, \gamma]-W_{2}[0,0,1, \gamma]
$$

According to Lemmas 1 and 2, $J[\gamma]>0$ for small values of $\gamma$ and $J[\gamma]=0$ for high values of $\gamma$. Now as $\gamma$ rises from 0 , let $\underline{\gamma}_{12}$ be the first value of $\gamma$ such that $J[\gamma]$ falls to 0 . We claim that $J[\gamma]=0$ for all $\gamma \geq \underline{\gamma}_{12}$.

Indeed, if the claim were not true, then we would be able to find a value of $\gamma$, say $\gamma^{\#}>\underline{\gamma}_{12}$, and a value of $\tau$, say $\tau^{\#}$, such that

(A.1) $W_{2}\left[0,0,2, \tau^{\#}, \gamma^{\#}\right]>W_{2}\left[0,0,1, \gamma^{\#}\right]$.

Next, note that because $J\left[\underline{\gamma}_{12}\right]=0$, we must have

(A.2) $W_{2}\left[0,0,2, \tau^{\#}, \underline{\gamma}_{12}\right] \leq W_{2}\left[0,0,1, \underline{\gamma}_{12}\right]$

Using (A.1) and (A.2), we can assert - by using a continuity argument - that there exists a value of $\gamma$, say $\underline{\gamma}_{12} \leq \gamma^{0} \leq \gamma^{\#}$, such that

(A.3) $W_{2}\left[0,0,2, \tau^{\#}, \gamma^{0}\right]=W_{2}\left[0,0,1, \gamma^{0}\right]$,

and
(A.4) $W_{2}\left[0,0,2, \tau^{\sharp}, \gamma\right]>W_{2}[0,0,1, \gamma]$,
$\left(\gamma^{0}<\gamma \leq \gamma^{\#}\right)$. 
Let

$$
\lambda^{0}[1]=D_{1} W_{2}\left[0,0,1, \gamma^{0}\right]
$$

be the value assumed by the shadow price $\lambda$ of the welfare maximization problem constituted by (35) and (36) for $\gamma=\gamma^{0}$. For this welfare maximization problem, the optimal market volume of air travel at time $t$ is given by (46) and depicted in Figure 3.

Similarly, let

$$
\lambda^{0}[2]=D_{1} W_{2}\left[0,0,2, \tau^{\#}, \gamma^{0}\right]
$$

be the value assumed by the shadow price $\lambda$ of the welfare maximization problem constituted by (52) and (53) for $\gamma=\gamma^{0}$. For this welfare maximization problem, the optimal market volume of air travel at time $t$ is given by (62) and depicted in Figure 4. We want to show that

$$
\text { (A.5) } \lambda^{0}[2]>\lambda^{0}[1]
$$

Indeed, if $\lambda^{0}[2] \leq \lambda^{0}[1]$, then $\lambda^{0}[1] /\left(2 \lambda^{0}[1]-1\right) \leq \lambda^{0}[2] /\left(2 \lambda^{0}[2]-1\right)$, and the optimal market volume of air travel at each instant under the solution of the welfare maximization problem constituted by (52) and (53) is greater than or equal to that under the solution of the welfare maximization problem constituted by (35) and (36) for $t<\tau^{\#}$. For $t>\tau^{\#}$, the optimal market volume of air travel at each instant under the solution of the welfare maximization problem constituted by (53) and (54) is strictly greater than that under the solution of the welfare maximization problem constituted by (35) and (36). Together, these results imply that for $\gamma=\gamma^{0}$, the discounted social welfare is higher under the 
welfare maximization problem constituted by (52) and (53) than under the welfare maximization problem constituted by (35) and (36); that is, $W_{2}\left[0,0,2, \tau^{\#}, \gamma^{0}\right]>W_{2}\left[0,0,1, \gamma^{0}\right]$, contradicting (A.3).

To complete the proof of Proposition 4, let $\varepsilon$ be a small positive number, and then apply (A.4) to $\gamma=\gamma^{0}+\varepsilon$ to obtain (A.6) $W_{2}\left[0,0,2, \tau^{\#}, \gamma^{0}+\varepsilon\right]>W_{2}\left[0,0,1, \gamma^{0}+\varepsilon\right]$.

Next, note that

(A.7) $W_{2}\left[0,0,1, \gamma^{0}+\varepsilon\right]=W_{2}\left[-\varepsilon, 0,1, \gamma^{0}\right]$

and

(A.8) $W_{2}\left[0,0,2, \tau^{\#}, \gamma^{0}+\varepsilon\right]=W_{2}\left[-\varepsilon\left(1+e^{-r \tau^{\#}}\right), 0,2, \tau^{\#}, \gamma^{0}\right]$.

By first-order approximation, we have

$$
W_{2}\left[-\varepsilon, 0,1, \gamma^{0}\right]=W_{2}\left[0,0,1, \gamma^{0}\right]-\varepsilon \lambda^{0}[1]
$$

and

(A.10) $W_{2}\left[-\varepsilon\left(1+e^{-r \tau^{\#}}\right), 0,2, \tau^{\#}, \gamma^{0}\right]=W_{2}\left[0,0,2, \tau^{\#}, \gamma^{0}\right]-\varepsilon\left(1+e^{-r \tau^{\sharp}}\right) \lambda^{0}[2]$.

Using (A.5) and (A.7) in (A.8), (A.9), and (A.10), we can then assert that

(A.11) $W_{2}\left[-\varepsilon\left(1+e^{-r \tau^{\sharp}}\right), 0,2, \tau^{\#}, \gamma^{0}\right]<W_{2}\left[-\varepsilon, 0,1, \gamma^{0}\right]$.

However, (A.11) contradicts (A.6), and the existence of $\underline{\gamma}_{12}$ is established.

\section{A.2. The Existence of $\bar{\gamma}_{12}$}

Recall that if the unit capacity cost is high, then 1 unit of capacity can meet market demand at all times without congestion, with the demand for air travel by a single 
consumer at each instant given by (30). Let $\bar{\gamma}_{12}$ be the value of $\gamma$ that satisfies the following relation:

$$
\bar{n}(1-c) \frac{q^{-1}[\gamma / 4 \bar{\gamma}]}{2 q^{-1}[\gamma / 4 \bar{\gamma}]-1}=a
$$

Then for all $\gamma \in\left[\bar{\gamma}_{12}, \bar{\gamma}\right]$ it is optimal to install only 1 unit of capacity, and the unit of capacity installed will be able to meet market demand at all times without congestion. Furthermore, it follows immediately from the definition of $\bar{\gamma}_{12}$ that $\underline{\gamma}_{12} \leq \bar{\gamma}_{12}$. If $\underline{\gamma}_{12}<\bar{\gamma}_{12}$. then when for $\gamma \in\left[\underline{\gamma}_{12}<\bar{\gamma}_{12}\right)$, the one unit of capacity installed serves the market with congestion. 


\section{APPENDIX B}

\section{THE DOWNWARD JUMP OF THE ACCESS PRICE}

To prove this property of the access price, let $X\left[K_{t}\right]$ denote the value of $X$ that solves

(77). The access price at time $t$ is then given by

$$
\begin{aligned}
\phi\left[K_{t}\right]=1 & -c-h\left[X\left[K_{t}\right], K_{t}\right]-\frac{1}{n_{t}} X\left[K_{t}\right] \\
= & 1-c-\frac{b}{2}\left(X\left[K_{t}\right]-a K_{t}\right)^{2}-\frac{1}{n_{t}} X\left[K_{t}\right]
\end{aligned}
$$

To study the comparative static effect of $K_{t}$ on the access price at time $t$, let us imagine that the infrastructure capacity can be treated as a continuous variable although in practice investments are lumpy. Differentiating (B.1) with respect to $K_{t}$, we obtain

$$
\phi^{\prime}\left[K_{t}\right]=b\left(X\left[K_{t}\right]-a K_{t}\right)\left(X^{\prime}\left[K_{t}\right]-a\right)-\frac{1}{n_{t}} X^{\prime}\left[K_{t}\right]
$$

Suppose now that the infrastructure capacity rises by a small amount from $K_{t}$ to $K_{t}+\varepsilon$. If $X\left[K_{t}\right] \leq a K_{t}$, then there is no congestion before or after the change in the infrastructure capacity, and the access price remains at the base level. So suppose that $X\left[K_{t}\right]>a K_{t}$, i.e., there is congestion before the change. Under this scenario, (B.2) will be negative if we can show that $X^{\prime}\left[K_{t}\right] \leq a$. To this end, note that before the change we have

$$
\begin{aligned}
\frac{1}{n_{t}} X\left[K_{t}\right] & =f\left[X\left[K_{t}\right], \lambda, K_{t}\right] \\
& =\frac{\lambda}{2 \lambda-1}\left(1-c-\left(\frac{b}{2}\left(X\left[K_{t}\right]-a K_{t}\right)^{2}+b\left(X\left[K_{t}\right]-a K_{t}\right) X\left[K_{t}\right]\right)\right)
\end{aligned}
$$

After the change, we have 


$$
\begin{aligned}
& \frac{1}{n_{t}} X\left[K_{t}+\varepsilon\right]=f\left[X\left[K_{t}+\varepsilon\right], \lambda, K_{t}+\varepsilon\right] \\
& =\frac{\lambda}{2 \lambda-1}\left(\begin{array}{l}
1-c \\
\left.-\left(\frac{b}{2}\left(X\left[K_{t}+\varepsilon\right]-a\left(K_{t}+\varepsilon\right)\right)^{2}+b\left(X\left[K_{t}+\varepsilon\right]-a\left(K_{t}+\varepsilon\right)\right) X\left[K_{t}+\varepsilon\right]\right)\right)
\end{array}\right.
\end{aligned}
$$

Furthermore, we know that $X\left[K_{t}+\varepsilon\right] / n_{t}>X\left[K_{t}\right] / n_{t}$, and this implies that the expression on the right side of (B.4) is greater than the expression on the right side of (B.3).

Next, note that

$$
\begin{gathered}
\frac{b}{2}\left(X\left[K_{t}\right]+a \varepsilon-a\left(K_{t}+\varepsilon\right)\right)^{2}+b\left(X\left[K_{t}\right]+a \varepsilon-a\left(K_{t}+\varepsilon\right)\right)\left(X\left[K_{t}\right]+a \varepsilon\right) \\
>\frac{b}{2}\left(X\left[K_{t}\right]-a K_{t}\right)^{2}+b\left(X\left[K_{t}\right]-a K_{t}\right) X\left[K_{t}\right]
\end{gathered}
$$

from which we obtain

$$
f\left[X\left[K_{t}\right]+a \varepsilon, \lambda, K_{t}+\varepsilon\right]<f\left[X\left[K_{t}\right], \lambda, K_{t}\right]
$$

It follows from (B.6), the inequality $X\left[K_{t}\right] / n_{t}<X\left[K_{t}+\varepsilon\right] / n_{t}$, (B.3), and (B.4) that

$$
f\left[X\left[K_{t}\right]+a \varepsilon, \lambda, K_{t}+\varepsilon\right]<f\left[X\left[K_{t}+\varepsilon\right], \lambda, K_{t}+\varepsilon\right]
$$

Because $f\left[X, \lambda, K_{t}+\varepsilon\right]$ is decreasing in $X$, the inequality (88) implies that (B.8) $X\left[K_{t}+\varepsilon\right]<X\left[K_{t}\right]+a \varepsilon$,

From which it follows that $X^{\prime}\left[K_{t}\right] \leq a$, and we have just proved that the access price take a downward jump every time a capacity addition is made. 
Chapter Three

\section{ACCESS PRICING FOR NATURAL GAS PIPELINES}

\section{INTRODUCTION}

Natural gas is a gas that consists mainly of methane. It is found associated with fossil fuels in coal beds, and is a major feedstock for fertilizers. It is also a source of greenhouse gases. Natural gas is used in homes for cooking and heating. In transport, compressed natural gas is an alternative source of fuel for gasoline and diesel. In the electricity sector, natural gas is an important generating fuel besides oil and coal. Because it generates less greenhouse gases than coal, which is currently the dominant generating fuel in the electric sector, natural gas is taking on an increasing role in the fight against climate change. At the present time, the rising demand for natural gas is mainly driven by the growing demand by electric utilities for a cleaner generating fuel.

In North America, natural gas is bought and sold via a large, integrated continental market with multiple pricing hubs. Through an extensive pipeline network, buyers and sellers transport natural gas from numerous different supply sources around the continent. The price consumers pay is by and large the sum of three parts: the commodity cost of the natural gas, the pipeline transportation cost, and the distribution cost. ${ }^{1}$

Unlike crude oil, natural gas is generally delivered directly to consumers by pipelines.

\footnotetext{
${ }^{1}$ In Ontario, transport cost adds about 1 dollar per gigajoule to the commodity price; distribution costs adds about $\$ 1.50$. In Canada, transport and distribution costs are regulated by provincial and/or federal regulatory boards. The commodity price, which changes in response to supply and demand, makes up the greater part of the price paid by consumers of less than $\$ 2$ per gigajoule.
} 
However, it begins that journey in a manner similar to crude oil. Gas wells are connected to small-diameter ( 5 centimeters to 15 centimeters or 2 inches to 6 inches) gathering systems that take the gas to a gas processing facility. Gas processing facilities, usually referred to as gas plants, vary in size from small compression facilities that are mounted on moveable platforms and that remove impurities and water from the gas, to large gas plants that also remove sulphur and carbon dioxide. Some gas plants also extract ethane, propane, and butane, which are referred to as natural gas liquids or NGLs. The generally dry gas may then be compressed prior to moving into the transmission system which consists of steel pipe from 50 centimeters (20 inches) to more than a meter (39.4 inches) in diameter.

Natural gas is transmitted under pressure (10-80 bar) and compressed in compressor stations about every 100-400 km. Pipeline diameters are between 100 and 1,400 mm (corresponding to 4 and 56 inches). The flow capacity of a cylindrical pipe increases as its diameter increases; however, the increase is more than linear (to the 2.65 exponent, Recknagel, 1990, 137; for details see Hirschhausen et al. (2007)). For example, if the diameter of pipe $A$ is twice that of pipe $B$ then the flow through pipe $A$ will be considerably more than twice the flow through pipe B, all other things being equal. Gas pipelines can also be used for storage purposes, and this is an important network character because the localization of the storage facility can be handled flexibly within a meshed network. 
Gas flows ${ }^{2}$ through the system from areas of high pressure to areas of low pressure through the use of compressors, turbines similar to jet engines that increase the pressure of the gas up to 10,300 kilopascals (1,500 pounds per square inch). Compressor stations are placed at regular intervals at about $100 \mathrm{~km}$ to $400 \mathrm{~km}$ along the pipeline to increase line pressure which is reduced due to friction of the gas moving through the pipe. Transmission line compressors are most often driven by gas turbines with the necessary fuel being taken from the pipeline. Where electricity is preferable, electric motors may be used to drive compressors. Transmission systems move the gas across great distances to local distribution companies or gas utilities, where the pressure is reduced and the gas enters a distribution main for local delivery to service lines connected to individual homes or businesses.

Pipeline networks have all the properties of a natural monopoly: high capital costs and low variable costs. Most of the investment costs are sunk. Transmission pipelines have long lives (35-60 years), and technical progress is slow. The total costs incurred in operating a natural gas pipeline network consist of fixed costs (the pipelines, compressor stations, metering) and operational costs (maintenance, variable fuel costs of compressor stations). The high sunk costs constitute a serious barrier of entry, and competitive behaviour in the transmission pipeline sector cannot be expected. Hirschhausen et al. (2007) found that there is a small numbers of pipeline operators in Germany's pipeline transmission network, and that these pipeline operators behave strategically in not invading the geographical markets of each other. These researchers recommend that

\footnotetext{
2 Our discussion of the economic and technical fundamentals of natural gas pipelines draws on Hirschhausen et al. (2007).
} 
Germany follows the example of Canada and the US, and regulates Germany's natural gas pipeline transmission sector.

Most of the economic analyses of access pricing for natural gas transmission pipelines are carried out from the regulatory perspective, and the access price paid by shippers are cost-based. An exception is Spulber and Sidak (1997), who formulated a model of access pricing for telecommunications networks, railroads, electric power networks, and natural gas pipeline networks in which network operators behave strategically. In this paper, we formalize and analyze a model of access pricing for natural gas transmission pipelines both when pipeline operators are regulated and when they behave strategically.

Telecommunications systems, electric power grids, and natural gas pipelines are very large networks with many components that interact with each other in a complex manner. There is a vast literature on the economics of networks, especially telecommunications and electric power networks. The dominant approach in analyzing networks treats each constituent component as an isolated network and focuses on the size - not the topology - of the network as a proxy for the network externalities. The model we formulate in this paper follows the suggestions of Spulber and Yoo (2005), and is intended to capture some essential characteristics of networks in which components interact with one another when combined into an integrated system. Given that networks of natural gas transmission pipelines are very large and complex systems, we have chosen to formulate and analyze a network with a very simple topology. We believe that the simple network we formulate captures some essential features of natural gas pipeline transmission 
networks and can be looked at as the starting point for analyzing networks with more complex topological structures.

The paper is organized as follows. In Section 2, the model, which is a network with two supply sources upstream and two demand sources downstream, is presented. The two supply sources are linked to the first demand source by two pipelines connected in parallel. The second demand source is connected to the first demand source by a third pipeline. The analysis of the model when the pipeline operators behave strategically is carried out step by step in several sections. In Section 3, a two-node sub-network that contains one supply source and the first demand source is analyzed. In Section 4, the three-node sub-network that contains the two supply sources and the first demand source is analyzed. In Section 5, the three-node sub-network that contains a supply source and the two demand sources are analyzed. The global network is analyzed in Section 6 . The analysis of the model for the case the pipeline operators are regulated is carried out in Section 7. Some concluding remarks are given in Section 8 . Because the model we formalize has a linear-quadratic structure, it has a closed-form solution, and all the equilibria can be explicitly computed. To alleviate the computational burden, we have taken advantage of the powerful symbolic computational capability of Mathematica to find the equilibrium of the model. 


\section{THE MODEL}

Consider a simple natural gas pipeline network depicted by the tree in Figure-1. ${ }^{3}$ The tree has 4 nodes - called $n_{1}, n_{2}, n_{3}, n_{4}$. In the tree, $n_{1}$ and $n_{2}$ represent two sources of supply, while $n_{3}$ and $n_{4}$ represent two sources of demand. The branches of the tree are represented by arrows which depict the direction of flow. The branches have different lengths and thickness, which represent, respectively, the lengths and the capacities of the pipelines. Let $\ell_{13}$ and $k_{13}$ denote, respectively, the length and the capacity of the pipeline that links $n_{1}$ with $n_{3}$. The length and the capacity of the pipeline that links $n_{2}$ with $n_{3}$ are denoted, respectively, by $\ell_{23}$ and $k_{23}$. Similarly, the length and the capacity of the pipeline that links $n_{3}$ with $n_{4}$ are denoted, respectively, by $\ell_{34}$ and $k_{34}$. In what follows, we shall use $\left[n_{i}, n_{j}\right]$ to denote the pipeline that connects node $n_{i}$ with node $n_{j}$. Furthermore, we shall assume that each pipeline is owned by a different pipeline operator and refer the pipeline operator that owns the pipeline $\left[n_{i}, n_{j}\right]$ as firm $f_{i j}$.

At each of the supply sources there are many competitive gas producers, and the supply curve at node $n_{i}, i=1,2$, is given by $y_{i}=\gamma_{i} p_{i}$, where $\gamma_{i}>0$ is a parameter; $p_{i}$ is the price of natural gas at that node; and $y_{i}$ is the market supply at that node when $p_{i}$ prevails. Alternatively, we can express the supply offered by natural gas producers at

\footnotetext{
${ }^{3}$ The upper part of the Portland Natural Gas Transmission System (PNGTS) has the topology depicted in Figure 1. The PNGTS serves the New England area connecting the Trans-Quebec and Maritimes Pipeline (owned by TransCanada Pipelines and Gaz Metro) at the Canadian border and the Maritimes and Northeast Pipeline at Westbrook, ME (owned by Duke Energy, Exxon Mobil and NS Power Holdings) with the Tennessee Gas Pipeline System (owned by El Paso Energy Corporation) near Boston, MA, PNGTS is strategically situated between three major pipeline networks.
} 
node $i$ as $p_{i}=\frac{1}{\gamma_{i}} y_{i}$, which is the marginal cost curve of the natural gas producers as a whole at node $i, i=1,2$.

Let $x_{i}=a_{i}-b_{i} p_{i}, i=3,4$, denote the market demand for natural gas at node $n_{i}$, where $a_{i}>0$ and $b_{i}>0$ are parameters; $p_{i}$.is the price of natural gas that prevails at that node; and $x_{i}$ is the market demand at that node when $p_{i}$ prevails. Note that the choke price for end-users at node $i, i=3,4$, is $\frac{a_{i}}{b_{i}}$.

We shall let $\tau_{i j}$ denote the toll that firm $f_{i j}$ charges shippers for transporting one unit volume of natural gas one unit distance along the pipeline $\left[n_{i}, n_{j}\right]$. Also, let $c_{i j}$ denote the cost incurred by the pipeline operator $f_{i j}$ for transporting one unit volume of gas by a unit distance along the pipeline $\left[n_{i}, n_{j}\right]$. The profit margin per unit of gas volume per unit distance of the pipeline operator $f_{i j}$ is then given by by $\tau_{i j}-c_{i j}$. The profit earned by firm $f_{i j}$ for transporting one unit volume of natural gas along the whole length of the pipeline $\left[n_{i}, n_{j}\right]$ is thus given by $q_{i j}=\left(\tau_{i j}-c_{i j}\right) \ell_{i j}$. Without any loss in generality, we shall assume in what follows that $c_{i j}=0$. Under this simplifying assumption, $q_{i j}$ becomes the toll that firm $f_{i j}$ charges shippers for transporting one unit volume of natural gas the entire length of the pipeline $\left[n_{i}, n_{j}\right]$.

To find out how the topology of a network influences the access prices in different parts of the network, we shall analyze the sub-networks under the assumption that they stand alone as networks in their own right. The analysis begins with the smallest sub-network 
Next, we enlarge this sub-network to obtain successively sub-networks of larger sizes until the global network - as depicted in Figure 1 - is finally arrived at.

\section{THE ACCESS PRICE FOR A TWO-NODE NETWORK: ONE SOURCE OF SUPPLY AND ONE SOURCE OF DEMAND}

The starting point of our analyses is a two-node pipeline transmission network where a single pipeline operator connects a source of supply to a source of demand. The network depicted in Figure 1 contains two two-node sub-networks. The first two-node subnetwork contains node $n_{1}$ and node $n_{3}$; the second two-node sub-network contains node $n_{2}$ and node $n_{3}$. We analyze only the first two-node sub-network. The analysis of the second two-node sub-network is similar. The two-node network $\left\{n_{1}, n_{3}\right\}$ consists of one source of supply $\left(n_{1}\right)$ and one source of demand $\left(n_{3}\right)$ linked by a single pipeline, namely $\left[n_{1}, n_{3}\right]$, and is depicted in Figure-2.

Let $q_{13}$ denote the toll charged to shippers by the pipeline operator $f_{13}$. A choice of $q_{13}$ induces an equilibrium in the network in the following manner.

Let $p_{1}$ be the price of natural gas at node $n_{1}$ and $p_{3}$ be price of natural gas at node $n_{3}$ that are induced by $q_{13}$. The market-clearing condition at node $n_{3}$ is

$$
\gamma_{1} p_{1}=a_{3}-b_{3} p_{3} .
$$

Furthermore, the arbitrage condition that links the price of natural gas at node $n_{1}$ and the price of natural gas at node $n_{3}$ is

$$
p_{3}=p_{1}+q_{13} .
$$


Together, (1) and (2) constitute a linear system of two equations in the two unknowns $p_{1}$ and $p_{3}$ the solution of which is given by

$$
p_{1}=\frac{a_{3}-b_{3} q_{13}}{b_{3}+\gamma_{1}}
$$

(4) $p_{3}=\frac{a_{3}+\gamma_{3} q_{13}}{b_{3}+\gamma_{1}}$

The profit of the monopoly pipeline operator $f_{13}$, as a function of the toll it charges shippers on the pipeline $\left[n_{1}, n_{3}\right]$ is then given by

$$
\pi_{13}\left[q_{13}\right]=q_{13}\left(a_{3}-b_{3} p_{3}\right)=q_{13}\left(a_{3}-b_{3} \frac{a_{3}+\gamma_{3} q_{13}}{b_{3}+\gamma_{1}}\right)
$$

The monopoly toll on the pipeline $\left[n_{1}, n_{3}\right]$ is the value of $q_{13}$ that maximizes (5). A simple calculation yields the following expression for the monopoly toll on the pipeline $\left[n_{1}, n_{3}\right]:$

$$
q_{13}\left[\left\{n_{1}, n_{3}\right\}\right]=\frac{a_{3}}{2 b_{3}}
$$

The equilibrium prices of natural gas at nodes $n_{1}$ and $n_{3}$ are given, respectively, by

$$
p_{1}\left[\left\{n_{1}, n_{3}\right\}\right]=\frac{a_{3}}{2\left(b_{3}+\gamma_{1}\right)}
$$

and

$$
p_{3}\left[\left\{n_{1}, n_{3}\right\}\right]=\frac{a_{3}\left(1+\frac{\gamma_{1}}{2 b_{3}}\right)}{b_{3}+\gamma_{1}}
$$

4. THE ACCESS PRICES FOR A THREE-NODE NETWORK: TWO SUPPLY SOURCES AND ONE DEMAND SOURCE LINKED BY TWO PIPELINES

\section{CONNECTED IN PARALLEL}

Consider the sub-network that consists of the two supply sources $n_{1}, n_{2}$, and the demand source $n_{3}$. This sub-network, as it stands alone, is depicted in Figure 3. Let $q_{13}$ and 
$q_{23}$ denote the toll charged to shippers by the pipeline operators $f_{13}$. and $f_{23}$, respectively. The combination strategy $\left(q_{13}, q_{23}\right)$ induces an equilibrium in the network $\left\{n_{1}, n_{2}, n_{3}\right\}$ in the following manner.

Let $p_{1}, p_{2}$, and $p_{3}$ be the prices of natural gas at nodes $n_{1}, n_{2}$, and $n_{3}$, respectively. The market-clearing condition at node $n_{3}$ is

(9) $\quad \gamma_{1} p_{1}+\gamma_{2} p_{2}=a_{3}-b_{3} p_{3}$.

The arbitrage condition that links the price of natural gas at node $n_{1}$ and the price of natural gas at node $n_{3}$ is

$$
p_{1}=p_{3}-q_{13} .
$$

The arbitrage condition that links the price of natural gas at node $n_{2}$ and the price of natural gas at node $n_{3}$ is

$$
p_{2}=p_{3}-q_{23}
$$

Together, (9), (10), and (11) constitute a linear system of three equations in the three unknowns $p_{1}, p_{2}$, and $p_{3}$ the solution of which is given by

$$
\begin{aligned}
& p_{1}=-q_{13}+\frac{a_{3}+q_{13} \gamma_{1}+q_{23} \gamma_{2}}{b_{3}+\gamma_{1}+\gamma_{2}}, \\
& p_{2}=-q_{23}+\frac{a_{3}+q_{13} \gamma_{1}+q_{23} \gamma_{2}}{b_{3}+\gamma_{1}+\gamma_{2}} \\
& p_{3}=\frac{a_{3}+q_{13} \gamma_{1}+q_{23} \gamma_{2}}{b_{3}+\gamma_{1}+\gamma_{2}}
\end{aligned}
$$

Using (12), we obtain the following expression for the profit of the pipeline operator $f_{13}$, as a function of the combination of strategies $\left(q_{13}, q_{23}\right)$ :

$$
\pi_{13}\left[q_{13}, q_{23}\right]=q_{13} \gamma_{1} p_{1}
$$




$$
=q_{13} \gamma_{1}\left(-q_{13}+\frac{a_{3}+q_{13} \gamma_{1}+q_{23} \gamma_{2}}{b_{3}+\gamma_{1}+\gamma_{2}}\right)
$$

Using (13), we obtain the following expression for the profit of the pipeline operator $f_{23}$, as a function of the combination of strategies $\left(q_{13}, q_{23}\right)$ :

$$
\begin{aligned}
\pi_{23}\left[q_{13}, q_{23}\right] & =q_{23} \gamma_{2} p_{2} \\
& =q_{23} \gamma_{2 .}\left(-q_{23}+\frac{a_{3}+q_{13} \gamma_{1}+q_{23} \gamma_{2}}{b_{3}+\gamma_{1}+\gamma_{2}}\right) .
\end{aligned}
$$

The first-order condition that characterizes the best response of the pipeline operator $f_{13}$ to the toll $q_{23}$ that is charged by the pipeline operator $f_{23}$ is

$$
\frac{\partial \pi_{13}}{\partial q_{13}}\left[q_{13}, q_{23}\right]=\gamma_{1}\left(-q_{13}+\frac{a_{3}+q_{13} \gamma_{1}+q_{23} \gamma_{2}}{b_{3}+\gamma_{1}+\gamma_{2}}\right)+\gamma_{1} q_{13}\left(-1+\frac{\gamma_{1}}{b_{3}+\gamma_{1}+\gamma_{2}}\right)=0 .
$$

The first-order condition that characterizes the best response of the pipeline operator $f_{23}$ to the toll $q_{13}$ that is charged by the pipeline operator $f_{13}$ is

$$
\frac{\partial \pi_{23}}{\partial q_{23}}\left[q_{13}, q_{23}\right]=\gamma_{2}\left(-q_{23}+\frac{a_{3}+q_{13} \gamma_{1}+q_{23} \gamma_{2}}{b_{3}+\gamma_{1}+\gamma_{2}}\right)+\gamma_{2} q_{23}\left(-1+\frac{\gamma_{2}}{b_{3}+\gamma_{1}+\gamma_{2}}\right)=0 .
$$

Together, (17) and (19) constitute a system of two linear equations in the two unknowns $q_{13}$ and $q_{23}$. Solving this system, we obtain the equilibrium tolls charged by the two pipeline operators:

$$
q_{13}\left[\left\{n_{1}, n_{2}, n_{3}\right\}\right]=\frac{2 a_{3} b_{3}+2 a_{3} \gamma_{1}+a_{3} \gamma_{2}}{4 b_{3}^{2}+4 b_{3} \gamma_{1}+4 b_{3} \gamma_{2}+3 \gamma_{1} \gamma_{2}}
$$




$$
q_{23}\left[\left\{n_{1}, n_{2}, n_{3}\right\}\right]=\frac{2 a_{3} b_{3}+a_{3} \gamma_{1}+2 a_{3} \gamma_{2}}{4 b_{3}^{2}+4 b_{3} \gamma_{1}+4 b_{3} \gamma_{2}+3 \gamma_{1} \gamma_{2}}
$$

Using the equilibrium tolls given by (19) and (20) in (12), (13), and (14), we obtain the following equilibrium price system at the three nodes of the network $\left\{n_{1}, n_{2}, n_{3}\right\}$.

$$
p_{1}\left[\left\{n_{1}, n_{2}, n_{3}\right\}\right]=\frac{a_{3}\left(b_{3}+\gamma_{2}\right)\left(2\left(b_{3}+\gamma_{1}\right)+\gamma_{2}\right)}{\left(b_{3}+\gamma_{1}+\gamma_{2}\right)\left(4 b_{3}^{2}+4 b_{3} \gamma_{1}+4 b_{3} \gamma_{2}+3 \gamma_{1} \gamma_{2}\right)}
$$

$$
p_{2}\left[\left\{n_{1}, n_{2}, n_{3}\right\}\right]=\frac{a_{3}\left(b_{3}+\gamma_{1}\right)\left(2\left(b_{3}+\gamma_{2}\right)+\gamma_{1}\right)}{\left(b_{3}+\gamma_{1}+\gamma_{2}\right)\left(4 b_{3}^{2}+4 b_{3} \gamma_{1}+4 b_{3} \gamma_{2}+3 \gamma_{1} \gamma_{2}\right)^{\prime}}
$$

$$
p_{3}\left[\left\{n_{1}, n_{2}, n_{3}\right\}\right]=\frac{a_{3}\left(2\left(b_{3}+\gamma_{1}\right)+\gamma_{2}\right)\left(2 b_{3}+\gamma_{1}+2 \gamma_{2}\right)}{\left(b_{3}+\gamma_{1}+\gamma_{2}\right)\left(4 b_{3}^{2}+4 b_{3} \gamma_{1}+4 b_{3} \gamma_{2}+3 \gamma_{1} \gamma_{2}\right)}
$$

The following proposition gives a comparison of the tolls along two pipelines connected in parallel to a demand node.

PROPOSITION 1: We have

$$
q_{13}\left[\left\{n_{1}, n_{2}, n_{3}\right\}\right]-q_{23}\left[\left\{n_{1}, n_{3}\right\}\right]=\frac{a_{3}\left(\gamma_{1}-\gamma_{2}\right)}{\left.4 b_{3}^{2}+4 b_{3} \gamma_{1}+4 b_{3} \gamma_{2}+3 \gamma_{1} \gamma_{2}\right)}
$$

That is, the equilibrium toll along the pipeline that connects the node with more efficient natural gas producers with end-users located at node $n_{3}$ is higher than that along the pipeline that connects the node with less efficient natural gas producers with end-users located at node $n_{3}$. 
Intuitively, we expect that the firm that owns the pipeline $\left[n_{1}, n_{3}\right]$ will lower its toll when a new supply source $\left(n_{2}\right)$ is connected by another competiting pipeline to the demand node $\left(n_{3}\right)$. The following proposition confirms this intuition.

PROPOSITION 2: We have

$$
q_{13}\left[\left\{n_{1}, n_{2}, n_{3}\right\}\right]-q_{13}\left[\left\{n_{1}, n_{3}\right\}\right]=-\frac{2 a_{3} b_{3} \gamma_{2}+3 a_{3} \gamma_{1} \gamma_{2}}{2 b_{3}\left(4 b_{3}^{2}+4 b_{3} \gamma_{1}+4 b_{3} \gamma_{2}+3 \gamma_{1} \gamma_{2}\right)}<0
$$

That is, facing the competition from a pipeline connected in parallel the pipeline operator charges shippers a toll that is lower than the monopoly toll that it would charge shippers if it were the only pipeline operator in the market.

We also expect a decline in the price of natural gas paid by end-users with the entry into the network $\left\{n_{1}, n_{3}\right\}$ of a new supply source $\left(n_{2}\right)$ and a new pipeline $\left(\left[n_{2}, n_{3}\right]\right)$, as asserted by the following proposition

PROPOSITION 3: We have

$$
p_{3}\left[\left\{n_{1}, n_{2}, n_{3}\right\}\right]-p_{3}\left[\left\{n_{1}, n_{3}\right\}\right]=-\frac{A_{1}}{B_{1}}<0,
$$

where

$$
\begin{aligned}
& A_{1}=a_{3} \gamma_{2}\left(4 b_{3}^{3}+3 \gamma_{1}^{2}\left(\gamma_{1}+\gamma_{2}\right)+4 b_{3}^{2}\left(2 \gamma_{1}+\gamma_{2}\right)+b_{3} \gamma_{1}\left(7 \gamma_{1}+6 \gamma_{2}\right)\right)>0 \\
& A_{2}=2 b_{3}\left(b_{3}+\gamma_{1}\right)\left(b_{3}+\gamma_{1}+\gamma_{2}\right)\left(4 b_{3}^{2}+4 b_{3} \gamma_{1}+4 b_{3} \gamma_{2}+3 \gamma_{1} \gamma_{2}\right)>0
\end{aligned}
$$

The following proposition gives the variation of the price of natural gas obtained by the producers, and indirectly the volume of natural gas shipped along the pipeline $\left[n_{1}, n_{3}\right]$, 
with the entry into the market of a new supply source $\left(n_{2}\right)$ and a new pipeline $\left(\left[n_{2}, n_{3}\right]\right)$ connected to the demand node in parallel with the pipeline $\left(\left[n_{1}, n_{3}\right]\right)$.

PROPOSITION 4: We have

$$
p_{1}\left[\left\{n_{1}, n_{2}, n_{3}\right\}\right]-p_{1}\left[\left\{n_{1}, n_{3}\right\}\right]=-\frac{a_{3} \gamma_{2}\left(2 b_{3}^{2}+\gamma_{1}\left(-\gamma_{1}+\gamma_{2}\right)+b_{3}\left(\gamma_{1}+2 \gamma_{2}\right)\right)}{2\left(b_{3}+\gamma_{1}\right)\left(b_{3}+\gamma_{1}+\gamma_{2}\right)\left(4 b_{3}^{2}+4 b_{3} \gamma_{1}+4 b_{3} \gamma_{2}+3 \gamma_{1} \gamma_{2}\right)}
$$

which can be positive or negative depending on the values of the parameters.

Because the toll along the pipeline $\left[n_{1}, n_{3}\right]$ and the price of natural gas paid by end-users at the demand node $n_{3}$ both decline with the entry of a new supply source and a new pipeline, it is not clear whether more or less natural gas will be transported along the pipeline $\left[n_{1}, n_{3}\right]$. However, the price differential in Proposition 4 will certainly be negative if $\gamma_{2} \geq \gamma_{1}$. Indeed, this result still holds if $\gamma_{2}<\gamma_{1}$ and if the difference $\gamma_{1}-\gamma_{2}$ is not too great. That is, if the marginal cost of the gas producers at node $n_{2}$ is not much higher than that at node $n_{1}$, then the price differential in Proposition 4 will be negative, with the ensuing consequence that competition from the new supply source will displace part of the original volume of natural gas flowing along the pipeline $\left[n_{1}, n_{3}\right]$. On the other hand, if the marginal cost of natural gas producers at node $n_{1}$ is very low, then the fall in the toll along the pipeline $\left[n_{1}, n_{3}\right]$ will be more pronounced than the fall in the price of natural gas paid by end-users at node $n_{3}$, and this will induce a rise in the output of the natural gas producers at node $n_{1}$. 


\section{THE ACCESS PRICE FOR A THREE-NODE NETWORK WITH ONE SOURCE OF SUPPLY AND TWO SOURCES OF DEMAND CONNECTED IN}

\section{SERIES}

We now consider the case of a three-node pipeline transmission network in which the two pipelines are connected in series; one pipeline connecting nodes $n_{1}$ with node $n_{3}$, while the other one connects nodes $n_{3}$ with node $n_{4}$. The network $\left\{n_{1}, n_{3}, n_{4}\right\}$ is depicted in Figure-4. The analysis of the sub-network $\left\{n_{2}, n_{3}, n_{4}\right\}$ is the same.

Observe that the pipeline $\left[n_{1}, n_{3}\right]$ is upstream and the pipeline $\left[n_{3}, n_{4}\right]$ is downstream. Also, there is only one source of supply upstream. The structure of the network gives the pipeline operator $f_{13}$ a first-mover advantage over the pipeline operator $f_{34}$.

Let $q_{13}$ and $q_{34}$ denote the toll charged to shippers by the pipeline operators $f_{13}$. and $f_{34}$, respectively. The combination strategy $\left(q_{13}, q_{34}\right)$ induces an equilibrium in the network $\left\{n_{1}, n_{3}, n_{4}\right\}$ in the following manner.

Let $p_{1}, p_{3}$, and $p_{4}$ denote the prices of natural gas that prevail at node $n_{1}$, node $n_{3}$, and node $n_{4}$, respectively. The global market-clearing condition is

$$
\gamma_{1} p_{1}=a_{3}-b_{3} p_{3}+a_{4}-b_{4} p_{4}
$$

The arbitrage condition that links the price of natural gas at node $n_{1}$ and the price of natural gas at node $n_{3}$ is

$$
p_{3}=p_{1}+q_{13}
$$

The arbitrage condition that links the price of natural gas at node $n_{3}$ and the price of natural gas at node $n_{4}$ is 


$$
p_{4}=p_{3}+q_{34}=p_{1}+q_{13}+q_{34}
$$

Together, (24), (25), and (26) constitute a linear system of three equations in the three unknowns $p_{1}, p_{3}$, and $p_{4}$ the solution of which is given by

$$
\begin{aligned}
& p_{1}=\frac{a_{3}+a_{4}-b_{3} q_{13}-b_{4} q_{13}-b_{4} q_{34}}{b_{3}+b_{4}+\gamma_{1}} \\
& p_{3}=\frac{a_{3}+a_{4}-b_{4} q_{34}+\gamma_{1} q_{13}}{b_{3}+b_{4}+\gamma_{1}} \\
& p_{4}=\frac{a_{3}+a_{4}+\gamma_{1} q_{13}+q_{34}\left(b_{3}+\gamma_{1}\right)}{b_{3}+b_{4}+\gamma_{1}}
\end{aligned}
$$

Using (29), we obtain the following expression for the profit of the pipeline operator $f_{34}$, as a function of the combination of strategies $\left(q_{13}, q_{34}\right)$ :

$$
\pi_{34}\left[q_{13}, q_{34}\right]=q_{34}\left(a_{4}-b_{4} \frac{a_{3}+a_{4}+\gamma_{1} q_{13}+q_{34}\left(b_{3}+\gamma_{1}\right)}{b_{3}+b_{4}+\gamma_{1}}\right)
$$

The following first-order condition characterizes the best response of the pipeline operator $f_{34}$ to the toll set by the pipeline operator $f_{13}$ :

$$
\frac{\partial \pi_{34}}{\partial q_{34}}\left[q_{13}, q_{34}\right]=\frac{a_{4}\left(b_{3}+\gamma_{1}\right)-b_{4}\left(a_{3}+\gamma_{1} q_{13}+2 q_{34}\left(b_{3}+\gamma_{1}\right)\right)}{b_{3}+b_{4}+\gamma_{1}}=0
$$

Solving (31) for $q_{34}$, we obtain the following best response of the pipeline operator $f_{34}$ to the toll set by the pipeline operator $f_{13}$, the Stackelberg leader:

$$
q_{34}\left[q_{13}\right]=\frac{a_{4} b_{3}-a_{3} b_{4}+a_{4} \gamma_{1}-b_{4} \gamma_{1} q_{13}}{2 b_{4}\left(b_{3}+\gamma_{1}\right)}
$$


Using (27) and (32), we obtain the following expression for the profit earned by the pipeline operator $f_{13}$, as a function of its toll

$$
\pi_{13}\left[q_{13}\right]=q_{13} \gamma_{1} p_{1}=q_{13} \gamma_{1} \frac{a_{3}+a_{4}-b_{3} q_{13}-b_{4} q_{13}-b_{4} q_{34}\left[q_{13}\right]}{b_{3}+b_{4}+\gamma_{1}}
$$

The first-order condition that characterizes the toll set by the pipeline operator $f_{13}$ is

$$
\pi_{13}{ }^{\prime}\left[q_{13}\right]=0
$$

Solving (34) for $q_{13}$, we obtain the following expression for the equilibrium toll along the pipeline $\left[n_{1}, n_{3}\right]$ :

$$
q_{13}\left[\left\{n_{1}, n_{3}, n_{4}\right\}\right]=\frac{a_{4}\left(b_{3}+\gamma_{1}\right)+a_{3}\left(2 b_{3}+b_{4}+2 \gamma_{1}\right)}{4 b_{3}\left(b_{3}+b_{4}\right)+2 \gamma_{1}\left(2 b_{3}+b_{4}\right)}
$$

Using (35) in (32), we obtain the expression for the equilibrium toll along the pipeline $\left[n_{3}, n_{4}\right]:$

$$
q_{34}\left[\left\{n_{1}, n_{3}, n_{4}\right\}\right]=\frac{A_{2}}{B_{2}}
$$

where

$$
\begin{gathered}
A_{2}=4 a_{4} b_{3}{ }^{2}-4 a_{3} b_{3}{ }^{2} b_{4}+4 a_{4} b_{3}{ }^{2} b_{4}-4 a_{3} b_{3} b_{4}{ }^{2}+8 a_{4} b_{3}{ }^{2} \gamma_{1} \\
-6 a_{3} b_{3} b_{4} \gamma_{1}+5 a_{4} b_{3} b_{4} \gamma_{1}-3 a_{3} b_{4}{ }^{2} \gamma_{1}+4 a_{4} b_{3} \gamma_{1}{ }^{2} \\
-2 a_{3} b_{4} \gamma_{1}{ }^{2}+a_{4} b_{4} \gamma_{1}{ }^{2}
\end{gathered}
$$

and

$$
B_{2}=4 b_{4}\left(b_{3}+\gamma_{1}\right)\left(2 b_{3}^{2}+2 b_{3} b_{4}+2 b_{3} \gamma_{1}+b_{4} \gamma_{1}\right)
$$

Using (35) and (36) in (27), (28), and (29), we obtain the following equilibrium prices of natural gas at nodes $n_{1}, n_{2}$, and $n_{3}$, respectively, 


$$
\begin{aligned}
& p_{1}\left[\left\{n_{1}, n_{3}, n_{4}\right\}\right]=\frac{1}{4}\left(\frac{a_{3}}{b_{3}+\gamma_{1}}+\frac{a_{3}+a_{4}}{b_{3}+b_{4}+\gamma_{1}}\right) \\
& p_{3}\left[\left\{n_{1}, n_{3}, n_{4}\right\}\right]=\frac{A_{3}}{B_{3}}
\end{aligned}
$$

where

$$
\begin{gathered}
A_{3}=\left(4 b_{3}\left(b_{3}+b_{4}\right)+3\left(2 b_{3}+b_{4}\right) \gamma_{1}+2 \gamma_{1}^{2}\right) \times \\
\left(a_{4}\left(b_{3}+\gamma_{1}\right)+a_{3}\left(2 b_{3}+b_{4}+2 \gamma_{1}\right)\right), \\
B_{3}=\left(4\left(b_{3}+\gamma_{1}\right)\left(b_{3}+b_{4}+\gamma_{1}\right)\right) \times \\
\left(2 b_{3}\left(b_{3}+b_{4}\right)+\left(2 b_{3}+b_{4}\right) \gamma_{1}\right) . \\
p_{4}\left[\left\{n_{1}, n_{3}, n_{4}\right\}\right]=\frac{1}{4}\left(A_{41}+A_{42}\right),
\end{gathered}
$$

where

$$
\begin{aligned}
& A_{41}=\frac{2 a_{4}}{b_{4}}+\frac{2 a_{3}+a_{4}}{2 b_{3}+b_{4}}+\frac{a_{3}+a_{4}}{b_{3}+b_{4}+\gamma_{1}}, \\
& A_{42}=\frac{2 b_{3}\left(a_{4} b_{3}-a_{3} b_{4}\right)}{2 b_{3}\left(b_{3}+b_{4}\right)+\left(2 b_{3}+b_{4}\right) \gamma_{1}} .
\end{aligned}
$$

The variation in the toll along the pipeline $\left[n_{1}, n_{3}\right]$ due to the appearance of another demand node $\left(n_{4}\right)$ connected downstream to the demand node $\left(n_{3}\right)$ is

$$
q_{13}\left[\left\{n_{1}, n_{3}, n_{4}\right\}\right]-q_{13}\left[\left\{n_{1}, n_{3}\right\}\right]=\frac{\left(a_{4} b_{3}-a_{3} b_{4}\right)\left(b_{3}+\gamma_{1}\right)}{2 b_{3}\left(2 b_{3}^{2}+2 b_{3} b_{4}+2 b_{3} \gamma_{1}+b_{4} \gamma_{1}\right)}
$$

Observe that the price differential represented by (42) is positive (negative, nil) if the choke price $\frac{a_{4}}{b_{4}}$ at the demand node downstream is greater than (less than, equal to) the choke price $\frac{a_{3}}{b_{3}}$ at the demand node up stream. The intuition behind these results is not hard to see. When the choke price at the demand node downstream is higher than that upstream, end-users at the downstream demand node are more willing than those at the 
demand node upstream to buy natural gas at a higher price, and it is thus profitable for the owner of the pipeline upstream to raise its toll above the monopoly level that corresponds to the scenario that the network consists of only the source of supply $n_{1}$ and the source of demand at $n_{3}$. On the other hand, when the choke price at the demand node downstream is lower than that upstream, end-users at the downstream demand node are less willing than those at the demand node upstream to buy natural gas at a higher price, and it is thus profitable for the owner of the pipeline upstream to lower its toll above the monopoly level that corresponds to the scenario that the network consists of only the source of supply $n_{1}$ and the source of demand at $n_{3}$. When the choke prices at the two demand nodes are equal, the inclusion of the downstream demand node does not induce the pipeline operator upstream to depart from the original monopoly toll. We summarize the preceding discussion in the following proposition:

PROPOSITION 5: If the choke price at the demand node downstream $\frac{a_{4}}{b_{4}}$ is greater than (less than, equal to) the choke price $\frac{a_{3}}{b_{3}}$ at the demand node upstream, then when the demand node downstream is connected to the demand node upstream, the toll along the pipeline $\left[n_{1}, n_{3}\right]$ will rise (decline, not change).

The variation of the equilibrium price of natural gas at node $n_{1}$ due to the appearance of another demand node $\left(n_{4}\right)$ connected downstream to the demand node $\left(n_{3}\right)$ is

$$
p_{1}\left[\left\{n_{1}, n_{3}, n_{4}\right\}\right]-p_{1}\left[\left\{n_{1}, n_{3}\right\}\right]=\frac{a_{4} b_{3}-a_{3} b_{4}+a_{4} \gamma_{1}}{4\left(b_{3}+\gamma_{1}\right)\left(b_{3}+b_{4}+\gamma_{1}\right)}
$$


Observe that the price differential represented by (44) is positive if the choke price at the downstream demand node is not too much lower than that at the upstream demand node. We thus have the following proposition:

PROPOSITION 6: If the choke price at the demand node downstream $\frac{a_{4}}{b_{4}}$ is not much lower than the choke price $\frac{a_{3}}{b_{3}}$ at the demand node upstream, then when the demand node downstream is connected to the demand node upstream, the equilibrium price of natural gas at the supply source $n_{1}$ will rise, i.e., a greater volume of natural gas will flow through the pipeline $\left[n_{1}, n_{3}\right]$.

The following corollary gives the impact on the end-users at the upstream demand node when the downstream demand node is connected to it.

COROLLARY 1: If the choke price at the demand node downstream $\frac{a_{4}}{b_{4}}$ is greater than or equal to the choke price $\frac{a_{3}}{b_{3}}$ at the demand node upstream, then when the demand node downstream is connected to the demand node upstream, the price of natural gas at the upstream demand node will rise. .

\section{THE ACCESS PRICES IN DIFFERENT PARTS OF THE GLOBAL}

\section{NETWORK}

Having analyzed all the sub-networks - under the assumption that they stand alone - we now analyze the global network, which is as depicted in Figure - 1 . 
Let $q_{13}, q_{23}$, and $q_{34}$ denote, respectively, the tolls set by the pipeline operators $f_{13}, f_{23}$, and $f_{34}$. The combination of strategies $\left(q_{13}, q_{23}, q_{34}\right)$ induces an equilibrium in the global network in the following manner:

Let $p_{1}, p_{2}, p_{3}$ and $p_{4}$ denote, respectively, the prices of natural gas that the combination of strategies $\left(q_{13}, q_{23}, q_{34}\right)$ induces at the nodes $n_{1}, n_{2}, n_{3}$ and $n_{4}$. These prices are linked through the following arbitrage conditions:

$$
\begin{aligned}
& p_{3}=p_{1}+q_{13}, \\
& p_{2}=p_{3}-q_{23}, \\
& p_{4}=p_{3}+q_{34}
\end{aligned}
$$

Furthermore, the global market-clearing condition is

$$
p_{1} \gamma_{1}+p_{2} \gamma_{2}=a_{3}-b_{3} p_{3}+a_{4}-b_{4}
$$

Solving the system of linear equations constituted by (44)-(47), we obtain

$$
\begin{aligned}
& p_{1}=\frac{a_{3}+a_{4}-b_{3} q_{13}-b_{4} q_{13}-b_{4} q_{34}-q_{13} \gamma_{2}+q_{23} \gamma_{2}}{b_{3}+b_{4}+\gamma_{1}+\gamma_{2}} \\
& p_{2}=q_{13}-q_{23}+\frac{a_{3}+a_{4}-b_{3} q_{13}-b_{4} q_{13}-b_{4} q_{34}-q_{13} \gamma_{2}+q_{23} \gamma_{2}}{b_{3}+b_{4}+\gamma_{1}+\gamma_{2}} \\
& p_{3}=q_{13}+\frac{a_{3}+a_{4}-b_{3} q_{13}-b_{4} q_{13}-b_{4} q_{34}-q_{13} \gamma_{2}+q_{23} \gamma_{2}}{b_{3}+b_{4}+\gamma_{1}+\gamma_{2}} \\
& p_{4}=q_{13}+q_{34}+\frac{a_{3}+a_{4}-b_{3} q_{13}-b_{4} q_{13}-b_{4} q_{34}-q_{13} \gamma_{2}+q_{23} \gamma_{2}}{b_{3}+b_{4}+\gamma_{1}+\gamma_{2}}
\end{aligned}
$$

The profit of the pipeline operator $f_{13}$ under the equilibrium induced by the combination of strategies $\left(q_{13}, q_{23}, q_{34}\right)$ is given by

$$
\pi_{13}\left[q_{13}, q_{23}, q_{34}\right]=q_{13} \gamma_{1} \frac{a_{3}+a_{4}-b_{3} q_{13}-b_{4} q_{13}-b_{4} q_{34}-q_{13} \gamma_{2}+q_{23} \gamma_{2}}{b_{3}+b_{4}+\gamma_{1}+\gamma_{2}}
$$


The profit of the pipeline operator $f_{23}$ under the equilibrium induced by the combination of strategies $\left(q_{13}, q_{23}, q_{34}\right)$ is given by

$$
\begin{aligned}
& \pi_{23}\left[q_{13}, q_{23}, q_{34}\right] \\
& =q_{23} \gamma_{2}\left(q_{13}-q_{23}+\frac{a_{3}+a_{4}-b_{3} q_{13}-b_{4} q_{13}-b_{4} q_{34}-q_{13} \gamma_{2}+q_{23} \gamma_{2}}{b_{3}+b_{4}+\gamma_{1}+\gamma_{2}}\right)
\end{aligned}
$$

The profit of the downstream pipeline operator under the equilibrium induced by the combination of strategies $\left(q_{13}, q_{23}, q_{34}\right)$ is given by

$$
\begin{aligned}
& \pi_{34}\left[q_{13}, q_{23}, q_{34}\right] \\
& \quad=q_{34}\left(a_{4}-b_{4}\left(q_{13}+q_{34}+\frac{a_{3}+a_{4}-b_{3} q_{13}-b_{4} q_{13}-b_{4} q_{34}-q_{13} \gamma_{2}+q_{23} \gamma_{2}}{b_{3}+b_{4}+\gamma_{1}+\gamma_{2}}\right)\right) .
\end{aligned}
$$

The first-order condition that characterizes the best response of the downstream pipeline operator to the tolls set by the two upstream pipeline operators is

$$
\frac{\partial \pi_{34}}{\partial q_{34}}\left[q_{13}, q_{23}, q_{34}\right]=0
$$

Solving (55) for $q_{34}$, we obtain the following reaction function of the downstream pipeline operator:

$$
q_{34}\left[q_{13}, q_{23}\right]=\frac{A_{51}+A_{52}}{B_{5}}
$$

where

$$
\begin{aligned}
& A_{51}=-a_{4}+b_{4} q_{13}+\frac{a_{3} b_{4}}{b_{3}+b_{4}+\gamma_{1}+\gamma_{2}}+\frac{a_{4} b_{4}}{b_{3}+b_{4}+\gamma_{1}+\gamma_{2}}-\frac{b_{3} b_{4} q_{13}}{b_{3}+b_{4}+\gamma_{1}+\gamma_{2}}, \\
& A_{52}=-\frac{b_{4}{ }^{2} q_{13}}{b_{3}+b_{4}+\gamma_{1}+\gamma_{2}}-\frac{b_{4} q_{13} \gamma_{2}}{b_{3}+b_{4}+\gamma_{1}+\gamma_{2}}+\frac{b_{4} q_{23} \gamma_{2}}{b_{3}+b_{4}+\gamma_{1}+\gamma_{2}} \\
& B_{5}=-b_{4}+\frac{b_{4}{ }^{2}}{b_{3}+b_{4}+\gamma_{1}+\gamma_{2}}-b_{4}\left(1-\frac{b_{4}}{b_{3}+b_{4}+\gamma_{1}+\gamma_{2}}\right) .
\end{aligned}
$$


The profits of the two upstream pipeline operators - as a function of the tolls they set $\left(q_{13}, q_{23}\right)$ and taking into account the reaction $q_{34}\left[q_{13}, q_{23}\right]$ of the downstream pipeline operator - is then given, respectively, by

$$
\varphi_{13}\left[q_{13}, q_{23}\right]=\pi_{13}\left[q_{13}, q_{23}, q_{34}\left[q_{13}, q_{23}\right]\right]
$$

and

$$
\varphi_{23}\left[q_{13}, q_{23}\right]=\pi_{23}\left[q_{13}, q_{23}, q_{34}\left[q_{13}, q_{23}\right]\right] .
$$

The following first-order conditions characterize the best responses of the two upstream pipeline operators to each other, with both operators taking into consideration the reaction of the downstream pipeline operator to their joint strategies.

$$
\begin{aligned}
& \frac{\partial \varphi_{13}\left[q_{13}, q_{23}\right]}{\partial q_{13}}=0 \\
& \frac{\partial \varphi_{23}\left[q_{13}, q_{23}\right]}{\partial q_{23}}=0 .
\end{aligned}
$$

We shall let $q_{13}\left[\left\{n_{1}, n_{2}, n_{3}, n_{4}\right\}\right]$ and $q_{23}\left[\left\{n_{1}, n_{2}, n_{3}, n_{4}\right\}\right]$ denote, respectively, the values of $q_{13}$ and $q_{23}$ that solve the system constituted by (59) and (60). Also, let

$$
q_{34}\left[\left\{n_{1}, n_{2}, n_{3}, n_{4}\right\}\right]=q_{34}\left[q_{13}\left[\left\{n_{1}, n_{2}, n_{3}, n_{4}\right\}\right], q_{23}\left[\left\{n_{1}, n_{2}, n_{3}, n_{4}\right\}\right]\right] .
$$

As defined, the list

$$
\left(q_{13}\left[\left\{n_{1}, n_{2}, n_{3}, n_{4}\right\}\right], q_{23}\left[\left\{n_{1}, n_{2}, n_{3}, n_{4}\right\}\right], q_{34}\left[\left\{n_{1}, n_{2}, n_{3}, n_{4}\right\}\right]\right)
$$

Represents the equilibrium tolls set by the three pipeline operators, respectively, on the pipelines they own. We shall let

$$
\left(p_{1}\left[\left\{n_{1}, n_{2}, n_{3}, n_{4}\right\}\right], p_{2}\left[\left\{n_{1}, n_{2}, n_{3}, n_{4}\right\}\right], p_{3}\left[\left\{n_{1}, n_{2}, n_{3}, n_{4}\right\}\right], p_{4}\left[\left\{n_{1}, n_{2}, n_{3}, n_{4}\right\}\right]\right)
$$

denote the equilibrium price system induced by

$$
\left(q_{13}\left[\left\{n_{1}, n_{2}, n_{3}, n_{4}\right\}\right], q_{23}\left[\left\{n_{1}, n_{2}, n_{3}, n_{4}\right\}\right], q_{34}\left[\left\{n_{1}, n_{2}, n_{3}, n_{4}\right\}\right]\right) .
$$


Although Mathematica yields closed-form expressions for (61) and (62), these expressions are too long and will not be reproduced here.

To find out how the topology of the network affects the access prices in various components of the network, let us first compare the toll on the pipeline $\left[n_{1}, n_{3}\right]$ when the downstream node $n_{4}$ is added to the network $\left\{n_{1}, n_{2}, n_{3}\right\}$. To lessen the burden of the computations, we shall carry out the analysis for the special case $a_{3}=a_{4}=a, b_{3}=b_{4}=$ $b$, i.e., the demand curves of the end users at the two demand nodes are identical.

We have

$$
q_{13}\left[\left\{n_{1}, n_{2}, n_{3}, n_{4}\right\}\right]-q_{13}\left[\left\{n_{1}, n_{2}, n_{3}\right\}\right]=\frac{\mathrm{A}_{7}}{\mathrm{~B}_{7}}>0
$$

where

$$
\begin{gathered}
A_{7}=a \gamma_{2}\left(b+\gamma_{1}+\gamma_{2}\right) \times \\
\left(16 b^{2}+6 \gamma_{1}\left(\gamma_{1}+\gamma_{2}\right)\left(\gamma_{1}+2 \gamma_{2}\right)+6 b^{2}\left(9 \gamma_{1}+2 \gamma_{2}\right)+3 b \gamma_{1}\left(16 \gamma_{1}+13 \gamma_{2}\right)\right)>0 \\
B_{7}=\left(4 b^{2}+3 \gamma_{1} \gamma_{2}+4 b\left(\gamma_{1}+\gamma_{2}\right)\right) \times\left(B_{71}+B_{72}\right), \\
B_{71}=\left(64 b^{4}+144 b^{3}\left(\gamma_{1}+\gamma_{2}\right)+12 \gamma_{1} \gamma_{2}\left(\gamma_{1}+\gamma_{2}\right)^{2},\right. \\
\left.B_{72}=12 b\left(\gamma_{1}+\gamma_{2}\right)\right)\left(2 \gamma_{1}^{2}+7 \gamma_{1} \gamma_{2}+2 \gamma_{2}^{2}\right) \\
+b^{2}\left(104 \gamma_{1}^{2}+235 \gamma_{1} \gamma_{2}+104 \gamma_{2}^{2}\right) .
\end{gathered}
$$

The brute-force computations carried out by Mathematica also show that

$$
p_{1}\left[\left\{n_{1}, n_{2}, n_{3}, n_{4}\right\}\right]-p_{1}\left[\left\{n_{1}, n_{2}, n_{3}\right\}\right]>0 \text {. }
$$

The following proposition follows immediately from (63) and (64). 
PROPOSITION 7: If the market demand curves by end-users at the two nodes of demand are identical, then the tolls along the two pipelines upstream will rise when the downstream demand node $n_{4}$ is added to the network $\left\{n_{1}, n_{2}, n_{3}\right\}$, which is constituted by the two sources of supply and the upstream source of demand. Furthermore, the output of the natural gas producers at each supply node also rises.

\section{THE ACCESS PRICES FOR THE GLOBAL NETWORK UNDER}

\section{REGULATION}

Recognizing the natural monopoly character of the natural gas pipelines segment, the authorities in the US and Canada have chosen to regulate this segment by setting the tolls that pipeline operators are allowed to charge shippers who want to have access to their networks. The appropriate method for finding the optimal tolls that pipeline operators are allowed to charge shippers is to solve a Ramsey pricing problem, and this is our task in this section.

Let $q_{13}, q_{23}$, and $q_{34}$ denote, respectively, the tolls set by the regulator on the pipelines owned by the operators $f_{13}, f_{23}$, and $f_{34}$. The list $\left(q_{13}, q_{23}, q_{34}\right)$ induces a competitive equilibrium that has been described in Section 6. Under this equilibrium, the social welfare is given by

$$
\begin{array}{r}
W\left[q_{13}, q_{23}, q_{34}\right]=\frac{1}{2} \gamma_{1}\left(-q_{13}+\frac{\left(a_{3}+a_{4}-b_{4} q_{34}+q_{13} \gamma_{1}+q_{23} \gamma_{2}\right)}{\left(b_{3}+b_{4}+\gamma_{1}+\gamma_{2}\right)}\right)^{2} \\
+\frac{1}{2} \gamma_{2}\left(-q_{23}+\frac{\left(a_{3}+a_{4}-b_{4} q_{34}+q_{13} \gamma_{1}+q_{23} \gamma_{2}\right)}{\left(b_{3}+b_{4}+\gamma_{1}+\gamma_{2}\right)}\right)^{2} \\
+\frac{\left(a_{3}\left(b_{4}+\gamma_{1}+\gamma_{2}\right)-b_{3}\left(a_{4}-b_{4} q_{34}+q_{13} \gamma_{1}+q_{23} \gamma_{2}\right)\right)^{2}}{2 b_{3}\left(b_{3}+b_{4}+\gamma_{1}+\gamma_{2}\right)^{2}}
\end{array}
$$




$$
+\frac{\left(a_{4}\left(b_{3}+\gamma_{1}+\gamma_{2}\right)-b_{4}\left(a_{3}+q_{13} \gamma_{1}+q_{23} \gamma_{2}+q_{34}\left(b_{3}+\gamma_{1}+\gamma_{2}\right)\right)\right)^{2}}{2 b_{4}\left(b_{3}+b_{4}+\gamma_{1}+\gamma_{2}\right)^{2}} .
$$

In (66) and on the right side of the equation, the first line represents the profits of the gas producers at node $n_{1}$; the second line represents the profits of the gas producers at node $n_{2}$; the third and fourth lines represent, respectively, the consumer surplus at nodes $n_{3}$ and $n_{4}$. Because competition among shippers drives profits to zero, their contribution to social welfare is zero.

Let $Z_{13}, Z_{23}$ and $Z_{23}$ denote, respectively, the revenue required by the pipeline operators $f_{13}, f_{23}$, and $f_{34}$ to recover their investment costs and earn a decent rate of return on their investments. The global revenue requirement is thus given by $Z=Z_{13}+Z_{23}+Z_{34}$.

Given the regulated tolls $\left(q_{13}, q_{23}, q_{34}\right)$, the toll revenue collected from the transportation of natural gas through the pipeline that connects the nodes $n_{1}$ and $n_{3}$ is

$$
q_{13} y_{1}=q_{13} \gamma_{1}\left(-q_{13}+\frac{a_{3}+a_{4}-b_{4} q_{34}+q_{13} \gamma_{1}+q_{23} \gamma_{2}}{b_{3}+b_{4}+\gamma_{1}+\gamma_{2}}\right)
$$

The toll revenue collected from the transportation of natural gas through the pipeline that connects the nodes $n_{2}$ and $n_{3}$ is

$$
q_{23} y_{2}=q_{23} \gamma_{2}\left(-q_{23}+\frac{a_{3}+a_{4}-b_{4} q_{34}+q_{13} \gamma_{1}+q_{23} \gamma_{2}}{b_{3}+b_{4}+\gamma_{1}+\gamma_{2}}\right)
$$

The toll revenue collected from the transportation of natural gas through the pipeline that connects the nodes $n_{3}$ and $n_{4}$ can be written as,

$$
q_{34} x_{4}=q_{34}\left(a_{4}-b_{4}\left(q_{34}+\frac{a_{3}+a_{4}-b_{4} q_{34}+q_{13} \gamma_{1}+q_{23} \gamma_{2}}{b_{3}+b_{4}+\gamma_{1}+\gamma_{2}}\right)\right)
$$


Suppose that the regulator collects the toll revenues on the three pipelines, and then redistributes the global revenues collected to each of the pipeline operators the revenue they required. Then the global revenue constraint faced by the regulator is

$$
Z-q_{13} y_{1}-q_{23} y_{2}-q_{34} x_{4} \leq 0
$$

The regulated tolls on the three pipelines are obtained by solving the following Ramsey pricing problem:

$$
\max _{\left(q_{13}, q_{23}, q_{34}\right)} W\left[q_{13}, q_{23}, q_{34}\right]
$$

subject to

$$
Z-q_{13} y_{1}-q_{23} y_{2}-q_{34} x_{4} \leq 0
$$

The Lagrangian $\mathcal{L}$ for this problem can be written as,

$\mathcal{L}=$

$$
\begin{aligned}
& \frac{1}{2} \gamma_{1}\left(-q_{13}+\frac{\left(a_{3}+a_{4}-b_{4} q_{34}+q_{13} \gamma_{1}+q_{23} \gamma_{2}\right)}{\left(b_{3}+b_{4}+\gamma_{1}+\gamma_{2}\right)}\right)^{2}+\frac{1}{2} \gamma_{2}\left(-q_{23}+\frac{\left(a_{3}+a_{4}-b_{4} q_{34}+q_{13} \gamma_{1}+q_{23} \gamma_{2}\right)}{\left(b_{3}+b_{4}+\gamma_{1}+\gamma_{2}\right)}\right)^{2}+ \\
& \frac{\left(a_{3}\left(b_{4}+\gamma_{1}+\gamma_{2}\right)-b_{3}\left(a_{4}-b_{4} q_{34}+q_{13} \gamma_{1}+q_{23} \gamma_{2}\right)\right)^{2}}{2 b_{3}\left(b_{3}+b_{4}+\gamma_{1}+\gamma_{2}\right)^{2}}+ \\
& \frac{\left(a_{4}\left(b_{3}+\gamma_{1}+\gamma_{2}\right)-b_{4}\left(a_{3}+q_{13} \gamma_{1}+q_{23} \gamma_{2}+q_{34}\left(b_{3}+\gamma_{1}+\gamma_{2}\right)\right)\right)^{2}}{2 b_{4}\left(b_{3}+b_{4}+\gamma_{1}+\gamma_{2}\right)^{2}}-\lambda\left(Z-q_{13} \gamma_{1}\left(-q_{13}+\right.\right.
\end{aligned}
$$




$$
\begin{aligned}
& \left.\frac{a_{3}+a_{4}-b_{4} q_{34}+q_{13} \gamma_{1}+q_{23} \gamma_{2}}{b_{3}+b_{4}+\gamma_{1}+\gamma_{2}}\right)-q_{23} \gamma_{2}\left(-q_{23}+\frac{a_{3}+a_{4}-b_{4} q_{34}+q_{13} \gamma_{1}+q_{23} \gamma_{2}}{b_{3}+b_{4}+\gamma_{1}+\gamma_{2}}\right)-q_{34}\left(a_{4}-\right. \\
& \left.\left.b_{4}\left(q_{34}+\frac{a_{3}+a_{4}-b_{4} q_{34}+q_{13} \gamma_{1}+q_{23} \gamma_{2}}{b_{3}+b_{4}+\gamma_{1}+\gamma_{2}}\right)\right)\right)
\end{aligned}
$$

The first-order conditions that characterizes the solution of the preceding welfare maximization problem are

$$
\begin{aligned}
& \frac{\gamma_{1}\left(a_{3}(\lambda-1)+a_{4}(\lambda-1)-(2 \lambda-1)\left(b_{3} q_{13}+b_{4}\left(q_{13}+q_{34}\right)+\gamma_{2}\left(q_{13}-a_{23}\right)\right)\right)}{b_{3}+b_{4}+\gamma_{1}+\gamma_{2}}=0 \\
& \frac{\gamma_{2}\left(a_{3}(\lambda-1)+a_{4}(\lambda-1)-(2 \lambda-1)\left(b_{3} q_{23}+b_{4}\left(q_{23}+q_{34}\right)+\gamma_{1}\left(q_{23}-q_{13}\right)\right)\right)}{b_{3}+b_{4}+\gamma_{1}+\gamma_{2}}=0 \\
& \frac{\left(-a_{4}(\lambda-1)\left(b_{3}+\gamma_{1}+\gamma_{2}\right)+b_{4}\left(a_{3}(\lambda-1)+(2 \lambda-1)\left(\gamma_{1} q_{13}+\gamma_{2} q_{23}+q_{34}\left(b_{3}+\gamma_{1}+\gamma_{2}\right)\right)\right)\right)}{b_{3}+b_{4}+\gamma_{1}+\gamma_{2}}=0
\end{aligned}
$$

Solving the system of equations (73), (74), (75) and the revenue constraint (70), we obtain the optimal values of for $q_{13}, q_{23}$ and $q_{34}$. Although with the help of Mathematica we manage to obtain a closed form solution, the expressions for the optimal tolls $q_{13}, q_{23}$ and $q_{34}$ are too long, therefore, are left at the appendix and not re-produced here.

Because the first-order conditions and the constraint are quadratic in $q_{13}, q_{23}$ and $q_{34}$, there are two sets of roots. Just looking at the algebraic expressions for each set of roots will not allow us to discover which set of roots is the correct solution. To compare the two sets of roots, we assign numerical values to the parameters of the model. ${ }^{4}$ Suppose, the parameters assume the following randomly generated values:

$$
\begin{gathered}
\left\{\gamma_{1} \rightarrow 0.789612, \gamma_{2} \rightarrow 0.572919, a_{3} \rightarrow 0.707357, b_{3} \rightarrow 0.964127, \quad a_{4}\right. \\
\left.\rightarrow 0.653237, b_{4} \rightarrow 0.240858\right\}
\end{gathered}
$$

\footnotetext{
${ }^{4}$ Mathematica codings that have been used to derive the solutions with randomly generated numerical values for the parameters are given in the Appendix.
} 
Our computation with Mathematica reveals that when $Z$ is high relative to demand at each of the demand source, the roots involves imaginary number and this means that the regulator's problem has no solution. In other words, when the revenue requirement is high relative to the market demand, then there is no optimal toll a regulator can set that recovers the global costs of investment.

Suppose $Z \rightarrow 0.05$, then for the above set of parameter values Mathematica yields the following results for the two sets of roots:

$$
\left\{q_{13}=0.0241672, q_{23}=0.0241672, \lambda=1.03526, q_{34}=0.06517\right\},
$$

and

$$
\left\{q_{13}=0.709509, q_{23}=0.709509, \lambda=-0.035263, q_{34}=1.91328\right\}
$$

Note that, for the second set of roots, the value of the multiplier of the revenue requirement constraint is negative, and therefore we reject this set of roots. Hence, we accept the first set of roots as the optimal tolls set by the regulator. Given these solutions for the optimal tolls, we can also compute the optimal price and output at all four nodes of the global network. The complete set of solutions is thus as follows:

$$
\begin{aligned}
&\left\{q_{13}=0.0241672, q_{23}=0.0241672, \lambda=1.03526, q_{34}=0.06517, p_{1}\right. \\
&= 0.0174557, p_{2}=0.0174557, p_{3}=0.726965, p_{4}=2.64024, y_{1} \\
&\left.=0.0137833, y_{2}=0.0100007, x_{3}=0.00647075, x_{4}=0.0173132\right\}
\end{aligned}
$$


Note that the prices of natural gas at nodes $n_{1}$ and $n_{2}$ are equal $\left(p_{1}=p_{2}=0.0174557\right)$. The regulator collects the toll revenue and redistributes the revenue among the pipeline operators according to their individual revenue constraints.

We carry out the same exercise once again for another set of randomly generated values for the parameters. Suppose, now the parameters assume the following randomly generated values:

$$
\begin{gathered}
\left\{\gamma_{1} \rightarrow 0.169308, \gamma_{2} \rightarrow 0.73597, a_{3} \rightarrow 0.945559, b_{3} \rightarrow 0.937118, \quad a_{4}\right. \\
\left.\rightarrow 0.682555, b_{4} \rightarrow 0.268303\right\}
\end{gathered}
$$

With $Z \rightarrow 0.05$ for the above set of parameter values, Mathematica yields the following results for the two sets of roots:

$$
\left\{q_{13}=0.0364858, q_{23}=0.0364858, \lambda=1.03898, q_{34}=0.0555047\right\},
$$

and

$$
\left\{q_{13}=0.972521, q_{23}=0.972521, \lambda=-0.0389791, q_{34}=1.47947\right\}
$$

Once again for both set of roots the optimal toll on two upstream pipelines are equal. Note that, for the second set of roots, the value of the multiplier of the revenue requirement constraint, $\lambda$, is negative and therefore we reject this set of roots. Hence, we accept the first set of roots as the solution of the regulator's problem. The complete solution of the regulator's problem is thus as follows: 


$$
\begin{array}{r}
\left\{q_{13}=0.0364858, q_{23}=0.0364858, \lambda=1.03898, q_{34}=0.0555047, p_{1}\right. \\
=0.74347, p_{2}=0.74347, p_{3}=0.779956, p_{4}=0.835461, y_{1} \\
\left.=0.125875, y_{2}=0.547172, x_{3}=0.214648, x_{4}=0.458399\right\}
\end{array}
$$

Once again, the prices for per unit natural gas at nodes $n_{1}$ and $n_{2}$ are equal $\left(p_{1}=p_{2}=\right.$ $0.74347)$. Also, the price for per unit of gas at node $n_{4}$ is higher than that at node $n_{3}$.

PROPOSITION 8: If the global revenue requirement, $Z$, is very high relative to the demand at each of the demand source, the regulator's problem does not yield any solution, i.e. the regulator cannot find a set of optimal tolls that satisfy the global revenue constraint. However, if the global revenue requirement, $Z$, is not very high relative to the demand at each of the demand nodes, then the optimal tolls on both upstream pipelines are equal.

\section{CONCLUDING REMARKS}

In this paper, we have investigated the determination of the access prices in the different components of a network of natural gas pipelines in which each component is owned by a distinct pipeline operator and in which each pipeline operator behaves strategically in setting the toll along the pipeline it owns. We have shown how the topology of the network determines the access prices in different components of the network. The general results that emerge from the analysis can be summarized as follows. First, the monopoly power of a pipeline operator is reduced by the entry of a new source of supply connected in parallel to the same demand node by a new pipeline. When the pipelines are connected in series, the one upstream enjoys a first-move advantage over the one downstream, and 
the toll set by the upstream pipeline operator after entry by the downstream pipeline operator will rise above the original monopoly level if the choke price at the demand node downstream is greater than the choke price at the demand node upstream. We have also investigated the equilibrium prices of natural gas at the various nodes of the network. In general, the entry of a new source of demand downstream raises the prices of natural gas paid by upstream end-users. We have studied the case, when the pipelines are regulated. Under regulation, when the two pipelines are connected in parallel, the same amount of toll charged on both the pipelines for transporting one unit of natural gas. The topology of the network we have analyzed is rather simple. Yet, the computations are not possible without the powerful symbolic computational capability of Mathematica. Our analysis is only the first step in analyzing more realistic networks. 


\section{REFERENCES}

Hirschhausen, Christian von; Neumann, Anne; and Rüster, Sophia 2007:

"Competition in Natural Gas Transportation? Technical and Economic Fundamentals and an Application to Germany", Working paper reprinted from report for EFET Germany, July 2007.

"Natural Gas Regulation in Ontario: A Renewed Policy Framework", Report on the Ontario Energy Board Natural Gas Forum March 30, 2005

Spulber, Daniel F. \& Sidak, J. Gregory 1997 : “Network Access Pricing and Deregulation"; Industrial \& Corporate Change, Vol.6, Issue 4, 1997.

Spulber, Daniel F. \& Yoo, Christopher S. 2005: "On the Regulation of Networks as Complex Systems: A Graph Theory Approach", Northwestern University Law Review, Vol. 99, No. 4, 2005. 
FIGURE-1: THE TOPOLOGY OF THE NETWORK<smiles>[3H][C](C)C</smiles> 
FIGURE 2. - A TWO-NODE NETWORK: ONE SOURCE OF SUPPLY AND ONE SOURCE OF DEMAND

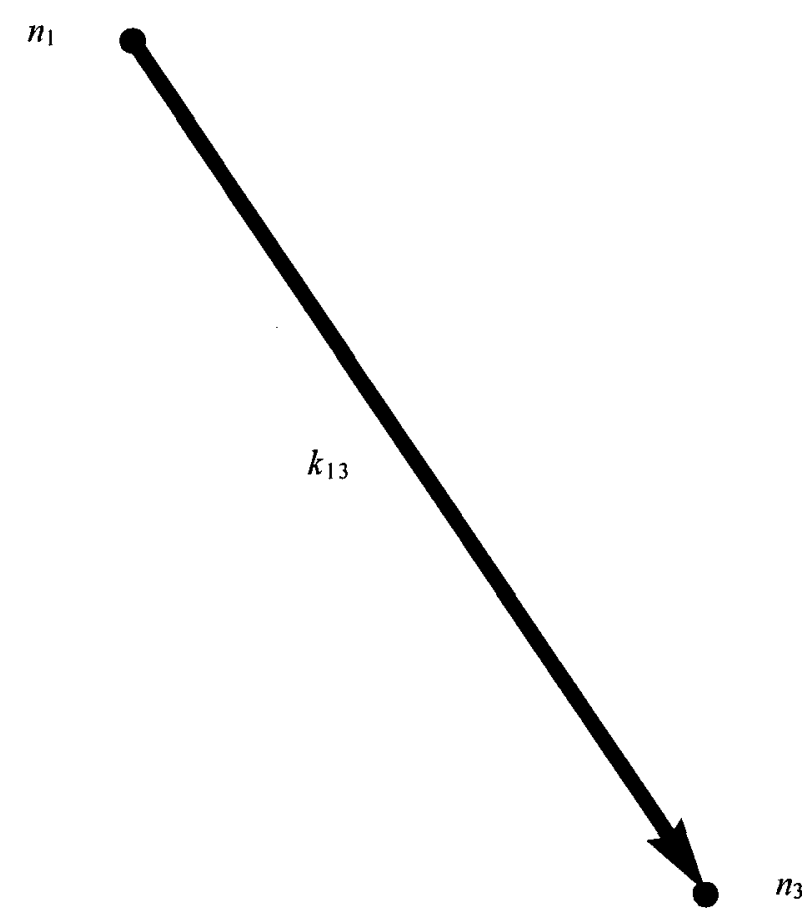


FIGURE 3. - TWO SOURCES OF SUPPLY CONNECTED BY TWO PIPELINES IN

PARALLEL TO ONE SOURCE OF DEMAND

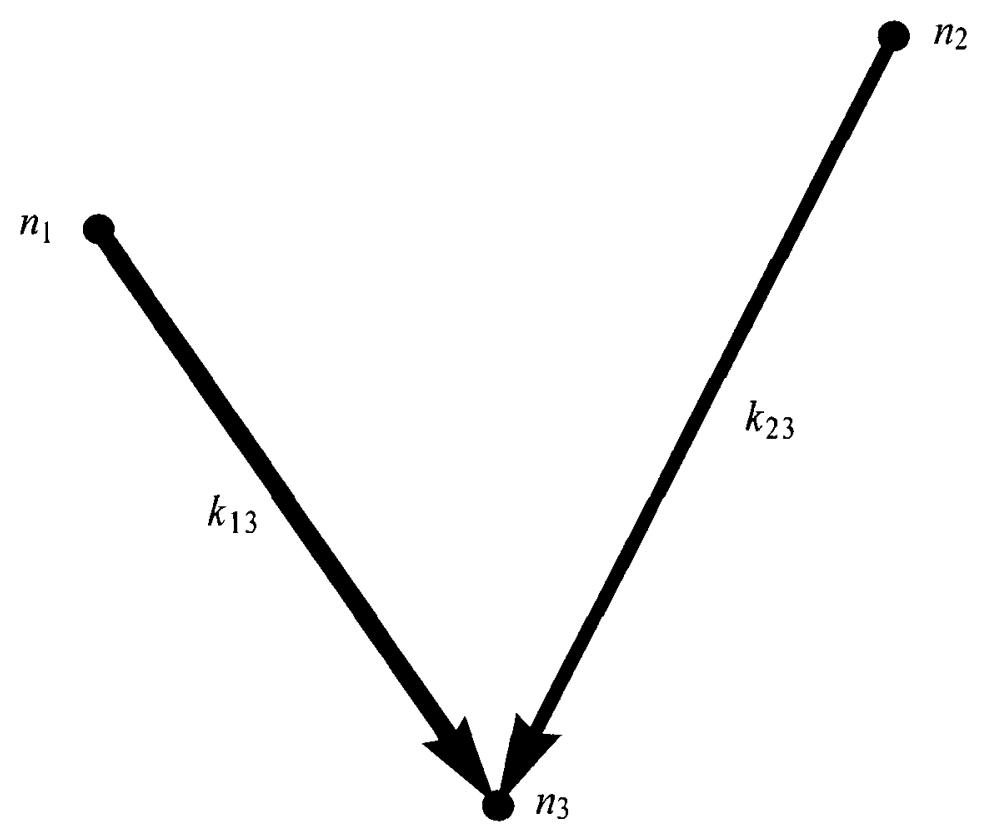


FIGURE -4: A THREE-NODE NETWORK: ONE SOURCE OF SUPPLY AND TWO

SOURCES OF DEMAND

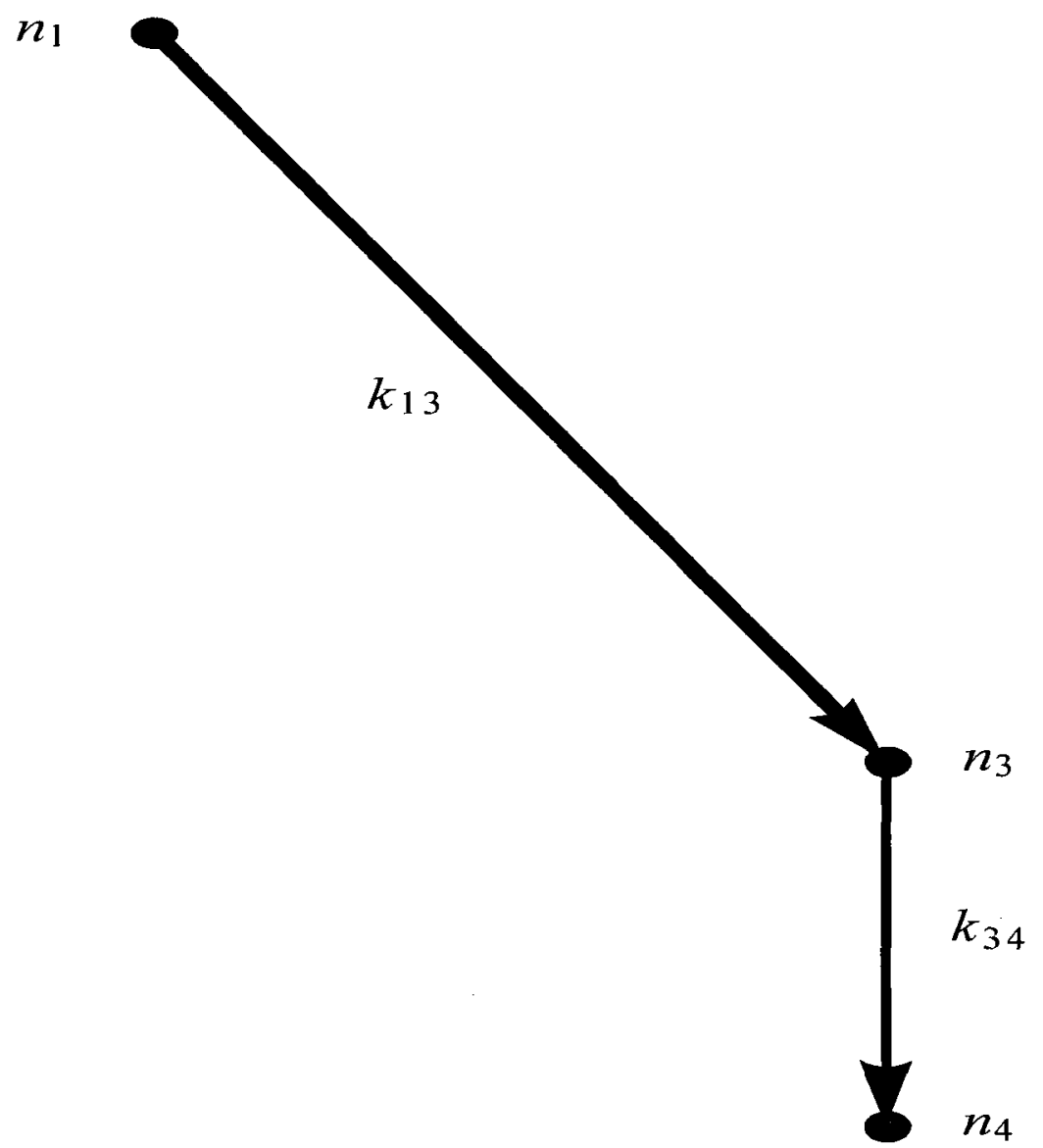




\section{APPENDIX}

\section{MATHEMATICA CODING FOR THE DETERMINATION OF THE ACCESS PRICE}

FOR THE GLOBAL NETWORK UNDER REGULATION

The supply curve at node $n_{1}$

$y[1]=\gamma[1] p[1]$

$\mathrm{p}[1] \gamma[1]$

The supply curve at node $\mathrm{n}_{2}$

$y[2]=\gamma[2] p[2]$

$\mathrm{p}[2] \gamma[2]$

The market demand at node $\mathrm{n}_{3}$

$x[3]=a[3]-b[3] p[3]$

$a[3]-b[3] p[3]$

The market demand at node $\mathrm{n}_{4}$

$x[4]=a[4]-b[4] p[4]$

$a[4]-b[4] p[4]$

The global market-clearing condition

$e q[0]=y[1]+y[2]==x[3]+x[4]$

$\mathrm{p}[1] \gamma[1]+\mathrm{p}[2] \gamma[2]=-\mathrm{a}[3]+\mathrm{a}[4]-\mathrm{b}[3] \mathrm{p}[3]-\mathrm{b}[4] \mathrm{p}[4]$ 
The arbitrage conditions

$\mathrm{p}[1]=\mathrm{p}[3]-\mathrm{q}[1,3]$

$\mathrm{p}[3]-\mathrm{q}[1,3]$

$\mathrm{p}[2]=\mathrm{p}[3]-\mathrm{q}[2,3]$

$\mathrm{p}[3]-\mathrm{q}[2,3]$

$p[4]=p[3]+q[3,4]$

$\mathrm{p}[3]+\mathrm{q}[3,4]$

The equilibrium induced by $\left(\mathrm{q}_{13} \cdot \mathrm{q}_{23} \cdot \mathrm{q}_{34}\right)$

eq[0]

$(p[3]-q[1,3]) \gamma[1]+(p[3]-q[2,3]) \gamma[2]==a[3]+a[4]-b[3] p[3]-b[4](p[3]+q[3,4])$

The equilibrium prices of natural gas induced by $\left(\mathrm{q}_{13} \cdot \mathrm{q}_{23}, \mathrm{q}_{34}\right)$

$\mathrm{s}[0]=$ Solve $[\mathrm{eq}[0], \mathrm{p}[3]] / /$ Flatten

$\{\mathrm{p}[3] \rightarrow(\mathrm{a}[3]+\mathrm{a}[4]-\mathrm{b}[4] \mathrm{q}[3,4]+\mathrm{q}[1,3] \gamma[1]+\mathrm{q}[2,3] \gamma[2]) /(\mathrm{b}[3]+\mathrm{b}[4]+\gamma[1]+\gamma[2])\}$

$\mathrm{p}[3]=\mathrm{p}[3] / \mathrm{s}[0]$

$(a[3]+a[4]-b[4] \mathrm{q}[3,4]+q[1,3] \gamma[1]+q[2,3] \gamma[2]) /(b[3]+b[4]+\gamma[1]+\gamma[2])$

$\mathrm{p}[1]$

$-\mathrm{q}[1,3]+(\mathrm{a}[3]+\mathrm{a}[4]-\mathrm{b}[4] \mathrm{q}[3,4]+\mathrm{q}[1,3] \gamma[1]+\mathrm{q}[2,3] \gamma[2]) /(\mathrm{b}[3]+\mathrm{b}[4]+\gamma[1]+\gamma[2])$ 
$-\mathrm{q}[2,3]+(\mathrm{a}[3]+\mathrm{a}[4]-\mathrm{b}[4] \mathrm{q}[3,4]+\mathrm{q}[1,3] \gamma[1]+\mathrm{q}[2,3] \gamma[2]) /(\mathrm{b}[3]+\mathrm{b}[4]+\gamma[1]+\gamma[2])$

$\mathrm{p}[4]$

$\mathrm{q}[3,4]+(\mathrm{a}[3]+\mathrm{a}[4]-\mathrm{b}[4] \mathrm{q}[3,4]+\mathrm{q}[1,3] \gamma[1]+\mathrm{q}[2,3] \gamma[2]) /(\mathrm{b}[3]+\mathrm{b}[4]+\gamma[1]+\gamma[2])$

\section{Producers' surplus}

$y[1]$

$\gamma[1](-\mathrm{q}[1,3]+(\mathrm{a}[3]+\mathrm{a}[4]-\mathrm{b}[4] \mathrm{q}[3,4]+\mathrm{q}[1,3] \gamma[1]+\mathrm{q}[2,3] \gamma[2]) /(\mathrm{b}[3]+\mathrm{b}[4]+\gamma[1]+\gamma[2]))$

$\mathrm{ps}[1]=1 / 2 \mathrm{p}[1] \mathrm{y}[1]$

$1 / 2 \gamma[1](-\mathrm{q}[1,3]+(\mathrm{a}[3]+\mathrm{a}[4]-\mathrm{b}[4] \mathrm{q}[3,4]+\mathrm{q}[1,3] \gamma[1]+\mathrm{q}[2,3]$

$\gamma[2]) /(b[3]+b[4]+\gamma[1]+\gamma[2]))^{2}$

$\mathrm{ps}[2]=1 / 2 \mathrm{p}[2] \mathrm{y}[2]$

$1 / 2 \gamma[2](-\mathrm{q}[2,3]+(\mathrm{a}[3]+\mathrm{a}[4]-\mathrm{b}[4] \mathrm{q}[3,4]+\mathrm{q}[1,3] \gamma[1]+\mathrm{q}[2,3]$

$\gamma[2]) /(b[3]+b[4]+\gamma[1]+\gamma[2]))^{2}$

\section{Consumers' surplus}

$\operatorname{cs}[3]=1 / 2 \times[3](a[3] / b[3]-p[3]) / /$ FullSimplify

$(a[3](b[4]+\gamma[1]+\gamma[2])-b[3](a[4]-b[4] \mathrm{q}[3,4]+q[1,3] \gamma[1]+q[2,3] \gamma[2]))^{2} /(2 b[3]$

$\left.(b[3]+b[4]+\gamma[1]+\gamma[2])^{2}\right)$

$\operatorname{cs}[4]=1 / 2 \times[4](a[4] / b[4]-p[4]) / /$ FullSimplify 
$(\mathrm{a}[4](\mathrm{b}[3]+\gamma[1]+\gamma[2])-\mathrm{b}[4](\mathrm{a}[3]+\mathrm{q}[1,3] \gamma[1]+\mathrm{q}[2,3] \gamma[2]+\mathrm{q}[3,4](\mathrm{b}[3]+\gamma[1]+\gamma[2])))^{2} /(2$ $\left.b[4](b[3]+b[4]+\gamma[1]+\gamma[2])^{2}\right)$

Social welfare, as a function of the regulated tolls $\left(q_{13}, q_{23}, q_{34}\right)$

$\mathrm{W}=\mathrm{ps}[1]+\mathrm{ps}[2]+\mathrm{cs}[3]+\mathrm{cs}[4] / /$ FullSimplify;

The toll revenues obtained

$f[1,3]=q[1,3]$ y[1]

$\mathrm{q}[1,3] \gamma[1](-\mathrm{q}[1,3]+(\mathrm{a}[3]+\mathrm{a}[4]-\mathrm{b}[4] \mathrm{q}[3,4]+\mathrm{q}[1,3] \gamma[1]+\mathrm{q}[2,3]$

$\gamma[2]) /(b[3]+b[4]+\gamma[1]+\gamma[2]))$

$\mathrm{f}[2,3]=\mathrm{q}[2,3] \mathrm{y}[2]$

$\mathrm{q}[2,3] \gamma[2](-\mathrm{q}[2,3]+(\mathrm{a}[3]+\mathrm{a}[4]-\mathrm{b}[4] \mathrm{q}[3,4]+\mathrm{q}[1,3] \gamma[1]+\mathrm{q}[2,3]$

$\gamma[2]) /(b[3]+b[4]+\gamma[1]+\gamma[2]))$

$f[3,4]=q[3,4] \times[4]$

$\mathrm{q}[3,4](\mathrm{a}[4]-\mathrm{b}[4](\mathrm{q}[3,4]+(\mathrm{a}[3]+\mathrm{a}[4]-\mathrm{b}[4] \mathrm{q}[3,4]+\mathrm{q}[1,3] \gamma[1]+\mathrm{q}[2,3]$

$\gamma[2]) /(b[3]+b[4]+\gamma[1]+\gamma[2])))$ 
The revenue constraint $(Z$ is the reqiured global revenue to recover the pipeline operators' investment)

$\mathrm{g}=\mathrm{Z}-\mathrm{f}[1,3]-\mathrm{f}[2,3]-\mathrm{f}[3,4] / /$ FullSimplify;

The regulated tolls on the three pipelines are obtained by solving the following Ramsey pricing problem:

$$
\max _{\left(q_{13}, q_{23}, q_{34}\right)} W\left[q_{13}, q_{23}, q_{34}\right]
$$

subject to

$g\left[q_{13}, q_{23}, q_{34}\right] \leq 0$.

The Lagrangian

$\mathcal{L}=\mathrm{W}-\lambda \mathrm{g}$;

The first-order conditions

foc $[1,3]=D[\mathcal{L}, \mathrm{q}[1,3]]==0 / /$ FullSimplify;

foc $[2,3]=D[\mathcal{L}, \mathrm{q}[2,3]]==0 / /$ FullSimplify;

foc $[3,4]=D[\mathcal{L}, \mathrm{q}[3,4]]==0 / /$ FullSimplify;

solution=Solve $[\{$ foc $[1,3]$, foc $[2,3]$, foc $[3,4], \mathrm{g}==0\},\{\mathrm{q}[1,3], \mathrm{q}[2,3], \mathrm{q}[3,4], \lambda\}] /$ FullSimplify

$\left\{\left\{\mathrm{q}[1,3] \rightarrow\left(\mathrm{a}[3]\left((\mathrm{a}[4] \mathrm{b}[3]-\mathrm{a}[3] \mathrm{b}[4])\left(-2 \mathrm{a}[3] \mathrm{a}[4] \mathrm{b}[3] \mathrm{b}[4]+\mathrm{a}[4]^{2} \mathrm{~b}[3]\right.\right.\right.\right.\right.$

$\left.(b[3]+\gamma[1]+\gamma[2])+a[3]^{2} b[4](b[4]+\gamma[1]+\gamma[2])\right)-\backslash[S q r t]\left((a[4] b[3]-a[3] b[4])^{2}(-2 a[3] a[4]\right.$ 
$\left.b[3] b[4]+a[4]^{2} b[3](b[3]+\gamma[1]+\gamma[2])+a[3]^{2} b[4](b[4]+\gamma[1]+\gamma[2])\right)(-2 a[3] a[4] b[3]$ $b[4]+a[4]^{2} b[3](b[3]+\gamma[1]+\gamma[2])+b[4]\left(a[3]^{2}(b[4]+\gamma[1]+\gamma[2])-4 Z b[3]\right.$ $(b[3]+b[4]+\gamma[1]+\gamma[2])))))) /\left(2 b[3](a[4] b[3]-a[3] b[4])\left(-2 a[3] a[4] b[3] b[4]+a[4]^{2} b[3]\right.\right.$ $\left.\left.(b[3]+\gamma[1]+\gamma[2])+a[3]^{2} b[4](b[4]+\gamma[1]+\gamma[2])\right)\right), q[2,3] \rightarrow(a[3]((a[4] b[3]-a[3] b[4])(-2$ $\left.a[3] a[4] b[3] b[4]+a[4]^{2} b[3](b[3]+\gamma[1]+\gamma[2])+a[3]^{2} b[4](b[4]+\gamma[1]+\gamma[2])\right)-$ $\backslash[\operatorname{Sqrt}]\left((a[4] b[3]-a[3] b[4])^{2}\left(-2 a[3] a[4] b[3] b[4]+a[4]^{2} b[3](b[3]+\gamma[1]+\gamma[2])+a[3]^{2}\right.\right.$ $\mathrm{b}[4](b[4]+\gamma[1]+\gamma[2]))\left(-2 a[3] a[4] b[3] b[4]+a[4]^{2} b[3](b[3]+\gamma[1]+\gamma[2])+b[4]\left(a[3]^{2}\right.\right.$ $(b[4]+\gamma[1]+\gamma[2])-4 \mathrm{Z} b[3](b[3]+b[4]+\gamma[1]+\gamma[2])))))) /(2 \mathrm{~b}[3](a[4] b[3]-a[3] b[4])(-2$ $\left.\left.a[3] a[4] b[3] b[4]+a[4]^{2} b[3](b[3]+\gamma[1]+\gamma[2])+a[3]^{2} b[4](b[4]+\gamma[1]+\gamma[2])\right)\right), \lambda \rightarrow((a[4]$ $b[3]-a[3] b[4])\left(-2 a[3] a[4] b[3] b[4]+a[4]^{2} b[3](b[3]+\gamma[1]+\gamma[2])+b[4]\left(a[3]^{2}\right.\right.$ $(b[4]+\gamma[1]+\gamma[2])-4 Z$ b[3] $(b[3]+b[4]+\gamma[1]+\gamma[2])))+\backslash[\operatorname{Sqrt}]\left((a[4] b[3]-a[3] b[4])^{2}(-2 a[3]\right.$ $\left.a[4] b[3] b[4]+a[4]^{2} b[3](b[3]+\gamma[1]+\gamma[2])+a[3]^{2} b[4](b[4]+\gamma[1]+\gamma[2])\right)(-2 a[3] a[4]$ $b[3] b[4]+a[4]^{2} b[3](b[3]+\gamma[1]+\gamma[2])+b[4]\left(a[3]^{2}(b[4]+\gamma[1]+\gamma[2])-4 \mathrm{Z} \mathrm{b}[3]\right.$ $(b[3]+b[4]+\gamma[1]+\gamma[2]))))) /\left(2(a[4] b[3]-a[3] b[4])\left(-2 a[3] a[4] b[3] b[4]+a[4]^{2} b[3]\right.\right.$ $(b[3]+\gamma[1]+\gamma[2])+b[4]\left(a[3]^{2}(b[4]+\gamma[1]+\gamma[2])-4 Z\right.$ b $[3]$ $(b[3]+b[4]+\gamma[1]+\gamma[2])))), q[3,4] \rightarrow\left((a[4] b[3]-a[3] b[4])\left(-2 a[3] a[4] b[3] b[4]+a[4]^{2} b[3]\right.\right.$ $\left.(b[3]+\gamma[1]+\gamma[2])+a[3]^{2} b[4](b[4]+\gamma[1]+\gamma[2])\right)--[\operatorname{Sqrt}]\left((a[4] b[3]-a[3] b[4])^{2}(-2 a[3] a[4]\right.$ $\left.b[3] b[4]+a[4]^{2} b[3](b[3]+\gamma[1]+\gamma[2])+a[3]^{2} b[4](b[4]+\gamma[1]+\gamma[2])\right)(-2 a[3] a[4] b[3]$ $b[4]+a[4]^{2} b[3](b[3]+\gamma[1]+\gamma[2])+b[4]\left(a[3]^{2}(b[4]+\gamma[1]+\gamma[2])-4 Z b[3]\right.$ $(b[3]+b[4]+\gamma[1]+\gamma[2]))))) /\left(2 b[3] b[4]\left(-2 a[3] a[4] b[3] b[4]+a[4]^{2} b[3]\right.\right.$ $\left.\left.\left.(\mathrm{b}[3]+\gamma[1]+\gamma[2])+\mathrm{a}[3]^{2} \mathrm{~b}[4](\mathrm{b}[4]+\gamma[1]+\gamma[2])\right)\right)\right\},\{\mathrm{q}[1,3] \rightarrow(\mathrm{a}[3]((\mathrm{a}[4] \mathrm{b}[3]-\mathrm{a}[3] \mathrm{b}[4])(-2$ $a[3] a[4] b[3] b[4]+a[4]^{2} b[3](b[3]+\gamma[1]+\gamma[2])+a[3]^{2} b[4]$ $(b[4]+\gamma[1]+\gamma[2]))+\left\lfloor[\operatorname{Sqrt}]\left((a[4] b[3]-a[3] b[4])^{2}\left(-2 a[3] a[4] b[3] b[4]+a[4]^{2} b[3]\right.\right.\right.$ 
$\left.(b[3]+\gamma[1]+\gamma[2])+a[3]^{2} b[4](b[4]+\gamma[1]+\gamma[2])\right)\left(-2 a[3] a[4] b[3] b[4]+a[4]^{2} b[3]\right.$

$\left.\left.\left.\left.(b[3]+\gamma[1]+\gamma[2])+b[4]\left(a[3]^{2}(b[4]+\gamma[1]+\gamma[2])-4 \mathrm{Z} b[3](b[3]+b[4]+\gamma[1]+\gamma[2])\right)\right)\right)\right)\right) /(2$ $b[3](a[4] b[3]-a[3] b[4])\left(-2 a[3] a[4] b[3] b[4]+a[4]^{2} b[3](b[3]+\gamma[1]+\gamma[2])+a[3]^{2} b[4]\right.$ $(b[4]+\gamma[1]+\gamma[2]))), q[2,3] \rightarrow\left(a[3]\left((a[4] b[3]-a[3] b[4])\left(-2 a[3] a[4] b[3] b[4]+a[4]^{2} b[3]\right.\right.\right.$ $\left.(b[3]+\gamma[1]+\gamma[2])+a[3]^{2} b[4](b[4]+\gamma[1]+\gamma[2])\right)+\left\lfloor\left[\operatorname{Sqrtt}\left((a[4] b[3]-a[3] b[4])^{2}(-2 a[3]\right.\right.\right.$ $\left.a[4] b[3] b[4]+a[4]^{2} b[3](b[3]+\gamma[1]+\gamma[2])+a[3]^{2} b[4](b[4]+\gamma[1]+\gamma[2])\right)(-2 a[3] a[4]$ $b[3] b[4]+a[4]^{2} b[3](b[3]+\gamma[1]+\gamma[2])+b[4]\left(a[3]^{2}(b[4]+\gamma[1]+\gamma[2])-4 Z b[3]\right.$ $(b[3]+b[4]+\gamma[1]+\gamma[2]))))) /\left(2 b[3](a[4] b[3]-a[3] b[4])\left(-2 a[3] a[4] b[3] b[4]+a[4]^{2} b[3]\right.\right.$ $\left.\left.(b[3]+\gamma[1]+\gamma[2])+a[3]^{2} b[4](b[4]+\gamma[1]+\gamma[2])\right)\right), \lambda \rightarrow((a[4] b[3]-a[3] b[4])(-2 a[3] a[4]$ $b[3] b[4]+a[4]^{2} b[3](b[3]+\gamma[1]+\gamma[2])+b[4]\left(a[3]^{2}(b[4]+\gamma[1]+\gamma[2])-4 Z b[3]\right.$ $(b[3]+b[4]+\gamma[1]+\gamma[2])))--[S q r t]\left((a[4] b[3]-a[3] b[4])^{2}\left(-2 a[3] a[4] b[3] b[4]+a[4]^{2} b[3]\right.\right.$ $\left.(b[3]+\gamma[1]+\gamma[2])+a[3]^{2} b[4](b[4]+\gamma[1]+\gamma[2])\right)\left(-2 a[3] a[4] b[3] b[4]+a[4]^{2} b[3]\right.$ $(b[3]+\gamma[1]+\gamma[2])+b[4]\left(a[3]^{2}(b[4]+\gamma[1]+\gamma[2])-4 Z\right.$ b $\left.\left.\left.\left.[3](b[3]+b[4]+\gamma[1]+\gamma[2])\right)\right)\right)\right) /(2$ $(a[4] b[3]-a[3] b[4])\left(-2 a[3] a[4] b[3] b[4]+a[4]^{2} b[3](b[3]+\gamma[1]+\gamma[2])+b[4]\left(a[3]^{2}\right.\right.$ $(b[4]+\gamma[1]+\gamma[2])-4 Z \mathrm{Zb}[3](b[3]+b[4]+\gamma[1]+\gamma[2])))), q[3,4] \rightarrow((a[4] b[3]-a[3] b[4])(-2$ $a[3] a[4] b[3] b[4]+a[4]^{2} b[3](b[3]+\gamma[1]+\gamma[2])+a[3]^{2} b[4]$ $(b[4]+\gamma[1]+\gamma[2]))+\left\lfloor[S q r t]\left((a[4] b[3]-a[3] b[4])^{2}\left(-2 a[3] a[4] b[3] b[4]+a[4]^{2} b[3]\right.\right.\right.$ $\left.(b[3]+\gamma[1]+\gamma[2])+a[3]^{2} b[4](b[4]+\gamma[1]+\gamma[2])\right)\left(-2 a[3] a[4] b[3] b[4]+a[4]^{2} b[3]\right.$ $\left.\left.\left.(b[3]+\gamma[1]+\gamma[2])+b[4]\left(a[3]^{2}(b[4]+\gamma[1]+\gamma[2])-4 \mathrm{Zb}[3](b[3]+b[4]+\gamma[1]+\gamma[2])\right)\right)\right)\right) /(2$ $b[3] b[4]\left(-2 a[3] a[4] b[3] b[4]+a[4]^{2} b[3](b[3]+\gamma[1]+\gamma[2])+a[3]^{2} b[4]\right.$ $(b[4]+\gamma[1]+\gamma[2])))\}\}$ 
There are two sets of tolls that satisfy the first-order conditions. Only the set with $\lambda>0$ can be accepted as the solution of the regulator's problem. In both sets, $\mathrm{q}[1,3]=\mathrm{q}[2,3]$, as can be verified and this means that the toll on $\left[\mathrm{n}_{1}, \mathrm{n}_{3}\right]$ is equal to the toll on $\left[\mathrm{n}_{2}, \mathrm{n}_{3}\right]$.

$(\mathrm{q}[1,3]-\mathrm{q}[2,3]) /$. solution[[1]]//FullSimplify

0

$(\mathrm{q}[1,3]-\mathrm{q}[2,3]) /$ solution[[2]]//FullSimplify

0

Some numerical values for the parameters

$$
\begin{aligned}
& \text { parameters[1] }=\text { Table }[\{\gamma[1] \rightarrow \operatorname{Random}[], \gamma[2] \rightarrow \operatorname{Random}[], \mathrm{a}[3] \rightarrow \operatorname{Random}[], \mathrm{b}[3] \rightarrow \\
& \text { Random[],a[4] } \rightarrow \text { Random[],b[4] } \rightarrow \text { Random[] }\},\{i, 1,5\}] \\
& \{\{\gamma[1] \rightarrow 0.789612, \gamma[2] \rightarrow 0.572919, \mathrm{a}[3] \rightarrow 0.707357, \mathrm{~b}[3] \rightarrow 0.964127, \mathrm{a}[4] \rightarrow 0.653237, \mathrm{~b}[4] \rightarrow 0 \\
& .240858\},\{\gamma[1] \rightarrow 0.9701, \gamma[2] \rightarrow 0.105988, \mathrm{a}[3] \rightarrow 0.658387, \mathrm{~b}[3] \rightarrow 0.792353, \mathrm{a}[4] \rightarrow 0.644808, \mathrm{~b} \\
& [4] \rightarrow 0.686851\},\{\gamma[1] \rightarrow 0.169308, \gamma[2] \rightarrow 0.73597, \mathrm{a}[3] \rightarrow 0.945559, \mathrm{~b}[3] \rightarrow 0.937118, \mathrm{a}[4] \rightarrow 0.6 \\
& 82555, \mathrm{~b}[4] \rightarrow 0.268303\},\{\gamma[1] \rightarrow 0.302741, \gamma[2] \rightarrow 0.0419485, \mathrm{a}[3] \rightarrow 0.225247, \mathrm{~b}[3] \rightarrow 0.19707 \\
& 8, \mathrm{a}[4] \rightarrow 0.704779, \mathrm{~b}[4] \rightarrow 0.166122\},\{\gamma[1] \rightarrow 0.435634, \gamma[2] \rightarrow 0.624159, \mathrm{a}[3] \rightarrow 0.997422, \mathrm{~b}[3] \\
& \rightarrow 0.201996, \mathrm{a}[4] \rightarrow 0.782397, \mathrm{~b}[4] \rightarrow 0.383301\}\} \\
& \mathrm{m}[1]=\text { parameters }[1][[1]]
\end{aligned}
$$


$\{\gamma[1] \rightarrow 0.789612, \gamma[2] \rightarrow 0.572919, \mathrm{a}[3] \rightarrow 0.707357, \mathrm{~b}[3] \rightarrow 0.964127, \mathrm{a}[4] \rightarrow 0.653237, \mathrm{~b}[4] \rightarrow 0$. $240858\}$

$\mathrm{v}=$ solution $/ . \mathrm{m}[1] / . Z \rightarrow 0.05$

$\{\{\mathrm{q}[1,3] \rightarrow 0.0241672, \mathrm{q}[2,3] \rightarrow 0.0241672, \lambda \rightarrow 1.03526, \mathrm{q}[3,4] \rightarrow 0.06517\},\{\mathrm{q}[1,3] \rightarrow 0.709509$, $\mathrm{q}[2,3] \rightarrow 0.709509, \lambda \rightarrow-0.035263, \mathrm{q}[3,4] \rightarrow 1.91328\}\}$

There are two sets of tolls that satisfy the first-order conditions for the constrained welfare maximization. According to the Kuhn Tucker theore, the multiplier associated with the revenue requirement constraint must be positive, and this means that the second set of tolls (with $\lambda \rightarrow-0.035263<0$ ) must be rejected.

$\mathrm{pp}[1]=\mathrm{p}[1] / \mathrm{v}[[2]] / \mathrm{m}[1]$

0.0174557

$\mathrm{pp}[2]=\mathrm{p}[2] / . \mathrm{v}[[2]] / \mathrm{m}[1]$

0.0174557

$\mathrm{pp}[3]=\mathrm{p}[3] / \mathrm{v}[[2]] / \mathrm{m}[1]$

0.726965

$\mathrm{pp}[4]=\mathrm{p}[4] / . \mathrm{v}[[2]] / \mathrm{m}[1]$

2.64024

$\mathrm{pp}[4]==\mathrm{pp}[3]+(\mathrm{q}[3,4] / . \mathrm{v}[[2]])$

True

$y y[1]=y[1] / v[[2]] / . m[1]$ 
0.0137833

$\mathrm{yy}[2]=\mathrm{y}[2] / \mathrm{v}[[2]] / \mathrm{m}[1]$

0.0100007

$\mathrm{xx}[3]=\mathrm{x}[3] / \mathrm{v}[[2]] / \mathrm{m}[1]$

0.00647075

$\mathrm{xx}[4]=\mathrm{x}[4] / \mathrm{v}[[2]] / \mathrm{m}[1]$

0.0173132

$\mathrm{yy}[1]+\mathrm{yy}[2]==\mathrm{xx}[3]+\mathrm{xx}[4]$

True

Now we repeat the experiment using the third set of randomly generated values for the parameters.

$\mathrm{m}[3]=$ parameters[1][[3]]

$\{\gamma[1] \rightarrow 0.169308, \gamma[2] \rightarrow 0.73597, \mathrm{a}[3] \rightarrow 0.945559, \mathrm{~b}[3] \rightarrow 0.937118, \mathrm{a}[4] \rightarrow 0.682555, \mathrm{~b}[4] \rightarrow 0.2$ $68303\}$

$\mathrm{v}=$ solution $/ \mathrm{m}[3] / \mathrm{Z} \rightarrow 0.05$

$\{\{\mathrm{q}[1,3] \rightarrow 0.0364858, \mathrm{q}[2,3] \rightarrow 0.0364858, \lambda \rightarrow 1.03898, \mathrm{q}[3,4] \rightarrow 0.0555047\},\{\mathrm{q}[1,3] \rightarrow 0.9725$

$21, \mathrm{q}[2,3] \rightarrow 0.972521, \lambda \rightarrow-0.0389791, \mathrm{q}[3,4] \rightarrow 1.47947\}\}$

There are two sets of tolls that satisfy the first-order conditions for the constrained welfare maximization. According to the Kuhn Tucker theorem, the multiplier associated 
with the revenue requirement constraint must be positive, and this means that the second set set of tolls (with $\lambda \rightarrow-0.0389791<0$ ) must be rejected.

$\mathrm{pp}[1]=\mathrm{p}[1] / \mathrm{v}[[1]] / \mathrm{m}[3]$

0.74347

$\mathrm{pp}[2]=\mathrm{p}[2] / \mathrm{v}[[1]] / . \mathrm{m}[3]$

0.74347

$\mathrm{pp}[3]=\mathrm{p}[3] / \mathrm{v}[[1]] / \mathrm{m}[3]$

0.779956

$\mathrm{pp}[4]=\mathrm{p}[4] / . \mathrm{v}[[1]] / \mathrm{m}[3]$

0.835461

$\mathrm{pp}[4]==\mathrm{pp}[3]+(\mathrm{q}[3,4] / . \mathrm{v}[[1]])$

True

$\mathrm{yy}[1]=\mathrm{y}[1] / . \mathrm{v}[[1]] / \mathrm{m}[3]$

0.125875

$\mathrm{yy}[2]=y[2] / . \mathrm{v}[[1]] / \mathrm{m}[3]$

0.547172

$\mathrm{xx}[3]=\mathrm{x}[3] / . \mathrm{v}[[1]] / \mathrm{m}[3]$

0.214648

$\mathrm{xx}[4]=\mathrm{x}[4] / . \mathrm{v}[[1]] / \mathrm{m}[3]$

0.458399

$y y[1]+y y[2]==x x[3]+x x[4]$

True 